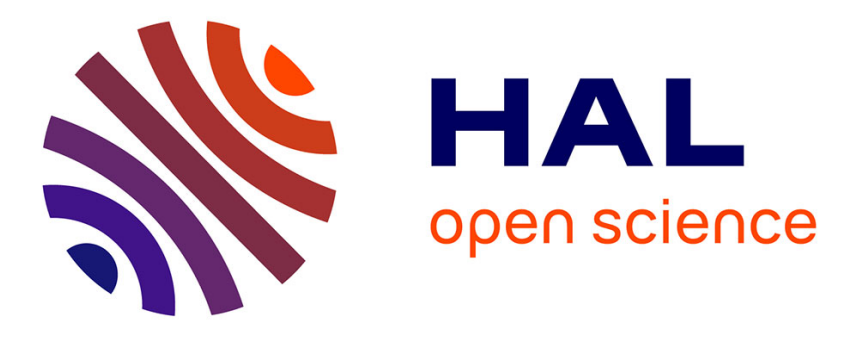

\title{
Highly Functionalized Ferrocenes
}

Emmanuel Lerayer, Léa Radal, Tuan Anh Nguyen, Nejib Dwadnia, Hélène

Cattey, Régine Amardeil, Nadine Pirio, Julien Roger, Jean-Cyrille Hierso

\section{To cite this version:}

Emmanuel Lerayer, Léa Radal, Tuan Anh Nguyen, Nejib Dwadnia, Hélène Cattey, et al.. Highly Functionalized Ferrocenes. European Journal of Inorganic Chemistry, 2020, 2020 (5), pp.419-445. 10.1002/ejic.201901183 . hal-03467773

\section{HAL Id: hal-03467773 https://hal.science/hal-03467773}

Submitted on 6 Dec 2021

HAL is a multi-disciplinary open access archive for the deposit and dissemination of scientific research documents, whether they are published or not. The documents may come from teaching and research institutions in France or abroad, or from public or private research centers.
L'archive ouverte pluridisciplinaire HAL, est destinée au dépôt et à la diffusion de documents scientifiques de niveau recherche, publiés ou non, émanant des établissements d'enseignement et de recherche français ou étrangers, des laboratoires publics ou privés. 


\title{
Highly Functionalized Ferrocenes
}

\author{
Emmanuel Lerayer, ${ }^{[\mathrm{a}]}$ Léa Radal, ${ }^{[\mathrm{a}]}$ Tuan Anh Nguyen, ${ }^{[\mathrm{a}]}$ Nejib Dwadnia, ${ }^{[\mathrm{a}]}$ Hélène Cattey, ${ }^{[\mathrm{a}]}$ Régine \\ Amardeil, ${ }^{[a]}$ Nadine Pirio, ${ }^{[a]}$ Julien Roger, ${ }^{[a]}$ and Jean-Cyrille Hierso ${ }^{\star[a, b]}$
}

This paper is dedicated to Prof. Roger Guilard for his contribution to the excellence of Coordination Chemistry in France

\begin{abstract}
Ferrocene is unique among organometallic compounds, and serves notably as a versatile platform towards the production of ligands useful to promote transition metals chemistry. A general limiting aspect of the synthesis of ferrocene derivatives is the efficient access to sophisticated highly functionalized polysubstituted ferrocenes, i. e. bearing four or more substituents replacing hydrogen atoms on the cyclopentadienyl rings. These ferrocene derivatives can bear various functional or/and structuring spectator substituents. Their preparation involves synthetic difficulties resulting from the need of multiple functionalizations coexisting altogether, and satisfying functional group compatibility and high selectivity issues. In the last decades, our group initially designed highly functionalized polyphosphines and hybrid ligands (1,1',3,3'tetrafunctionalized Fc) using dialkylated 1,1'-tert-butylferrocene as a scaffold, which opened the way to various new classes of hybrid compounds. Some of these original ferrocenes were used as ligands, promoting metal catalysed $\mathrm{C}-\mathrm{C}$ and $\mathrm{C}-\mathrm{X}$ bond formation $(\mathrm{X}=\mathrm{O}, \mathrm{S}$, $\mathrm{N}$, etc.). Thus, highly functionalized ferrocenes, which include notably $(\mathrm{P}, \mathrm{P}, \mathrm{P}, \mathrm{P})-,,(\mathrm{P}, \mathrm{P}, \mathrm{N}, \mathrm{N})-$, $\left(\mathrm{P}, \mathrm{P}, \mathrm{P}^{\prime}\right)-,(\mathrm{P}, \mathrm{P}, \mathrm{B})-$, $(\mathrm{P}, \mathrm{B})-$ and $(\mathrm{N}, \mathrm{B})-$ compounds were developed in which the heteroatoms coexist in a close proximity on a common ferrocene platform with a controlled conformation. The present review details the concepts attached to the synthesis of these highly functionalized ferrocene species, and illustrates their main features and applications related to organometallic chemistry directed towards organic synthesis by metal catalysis.
\end{abstract}

\section{Introduction, "Personal" Historical Perspective and Scope}

Air stable, thermodynamically robust, electroactive, soluble in many organic solvents, easily modifiable by convenient synthetic methods, the ferrocene ( $F \mathrm{c})$ backbone is unique among organometallic compounds, including among the metallocenes family. ${ }^{[1-3]}$ The outstanding structuring potential of ferrocene, as a multi-functionalizable platform, allows assembling donor (and acceptor) heteroatoms via $\mathrm{C}-\mathrm{H}$ bond replacement by a great variety of $\mathrm{C}-\mathrm{X}$ bonds (where $\mathrm{X}=\mathrm{B}, \mathrm{N}, \mathrm{O}, \mathrm{P}$, Si, Se, $\mathrm{As}, \mathrm{F}, \mathrm{Cl}, \mathrm{Br}$, $I$ and many others). The functionalization of cyclopentadienyl

[a] Dr. E. Lerayer, L. Radal, T. A. Nguyen, Dr. N. Dwadnia, Dr. H. Cattey, Dr. R. Amardeil, Prof. Dr. N. Pirio, Dr. J. Roger, Prof. Dr. J. C. Hierso

Institut de Chimie Moléculaire de l'Université de Bourgogne (ICMUB) UMR CNRS 6302

Université de Bourgogne Franche-Comté (UBFC)

9 avenue Alain Savary, 21078 Dijon, France

E-mail:hiersojc@u-bourgogne.fr

Homepage: http://www.icmub.com/en/members-en/hierso-jeancyrille.html

[b] Prof. Dr. J.-C. Hierso

Institut Universitaire de France (IUF)
(Cp) rings in ferrocene derivatives has been initially focused on the efficient and practical synthesis of mono- and difunctionalized compounds. From these species, ferrocenyl mono- and diphosphines - including the ubiquitous 1,1'bis(diphenylphosphino)ferrocene (dppf) - provided the impetus for the development of ferrocene-based ligand chemistry since the 1950's. Owing to their usefulness in homogeneous catalysis for fine chemistry, ferrocene derivatives were used for assisting metal-catalyzed $\mathrm{C}-\mathrm{C}$ bond and $\mathrm{C}-\mathrm{X}$ bond formation, including in challenging asymmetric approaches. ${ }^{[4-6]}$ Because the ferrocene backbone can valuably transfer its geometric and electronic features (including chirality and redox behavior) to the polyfunctionalized compounds which are synthesized from it, the development of its functionalization chemistry is very attractive.

In France, following the works on ferrocenes which were conducted by pioneers from the Universities of Dijon and Rennes including -non-exhaustively $-^{[7]} \mathrm{J}$. Tirouflet, R. Dabard, P. H. Dixneuf, D. Astruc ${ }^{[8-11]}$ the group of B. Gautheron initiated before $2000^{[12]}$ the polyphosphine studies developed by our group.

In the present account we focused on the synthesis and applications of highly functionalized ferrocenyl derivatives, mainly phosphine derivatives that we developed in our group for the last fifteen years (2003-2018). These polyfunctionalized synthetic targets are challenging, and as such their syntheses were rather scarcely addressed by the others groups which are mentioned in the reviews and book chapters above quoted. ${ }^{[1-6,8-}$

12] Two specificities of our work is that it generally deals not with optically active ferrocenes, and that the emphasis is put on the development of rather sophisticated species bearing at least four (or more) functionalizations out of the ten positions available on the two $\mathrm{Cp}$ rings of ferrocene. Along the years, an important objective has been the systematic study of the control of the ferrocene conformation by using additional bulky groups (alkyl groups such as tert-butyl or surrogates) and the physicochemical and reactivity consequences. These issues are discussed herein.

\section{Ferrocenyl phosphines}

Examination of the literature before 2004 reveals that only a few ferrocenyl polyphosphine ligands of higher rank than diphosphines are available for use as ligands in synthetic chemistry and homogeneous catalysis. ${ }^{[13,14]}$ Some seminal works of our group are detailed in a tutorial review on ferrocenyl polyphosphine multidentate effects. ${ }^{[15]}$ 


\subsection{Tetraphosphines}

\subsubsection{Synthesis by a direct functionalization of the ferrocene} backbone

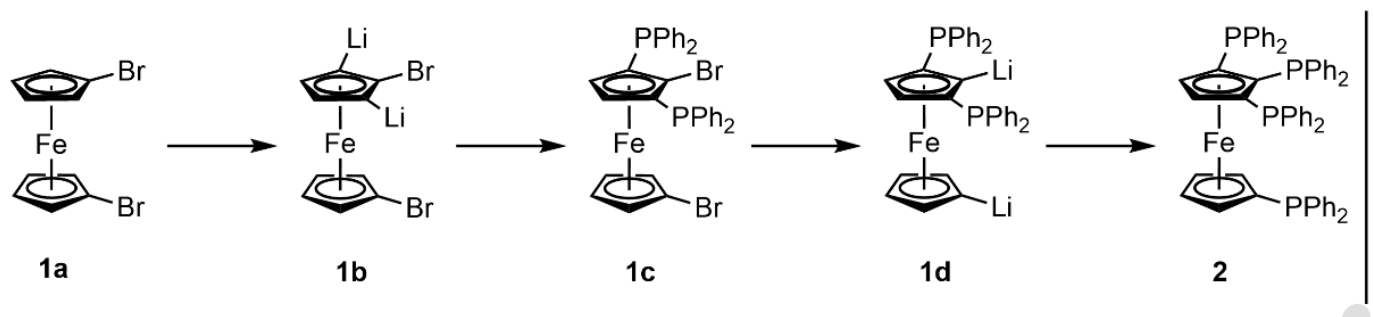

Figure 1. Synthesis of 1,1',2,3-tetraphosphine 2
The synthesis of ferrocenyl polyphosphines by direct functionalization of ferrocene backbone has been described by the Butler group ${ }^{[16]}$ for which a typical illustration is the synthesis of the polydentate ligand 1,1',2,3tetrakis(diphenylphosphino)ferrocene 2 (Figure 1). ${ }^{[1]}$ This tetraphosphine is obtained starting from the addition of 1,1'dibromoferrocene $\mathbf{1 a}$ to freshly prepared LDA. Compound $\mathbf{1 b}$ is formed and quenched with chlorodiphenylphosphine to get $\left[1,1^{\prime}\right.$ dibromo-2,5-bis(diphenylphosphino)]ferrocene 1c in 55\% (Figure 1). 1,1',2,3-tetrakis(diphenylphosphino)ferrocene 2 is obtained in $90 \%$ yield from 1 d reacted with $\mathrm{CIPPh}_{2}$. We studied jointly with Butler group the coordination chemistry of $\mathbf{2}$ towards palladium and nickel. From $\mathrm{PdCl}_{2} \mathrm{~L}\left(\mathrm{~L}=\mathrm{COD},(\mathrm{RCN})_{2}\right)$ dinuclear species easily formed, while from nickel halides only mononuclear species were identified. The rotational flexibility of this tetraphosphine ligand was evidenced by comparing the XRD structures of 2 and dinuclear palladium complex $2-\left(\mathbf{P d C l}_{2}\right)_{2}$ (Figs. 1 and 2). The coordination chemistry of 2 clearly combines individual classical schemes of 1,2- and 1,1'-chelating ferrocenyl diphosphines. However, based on ferrocenyl tetraphosphines our group envisioned the development of a more cooperative polydentate ligand chemistry on the metal center, achieved by tri- or tetra-coordination at the same metal center.

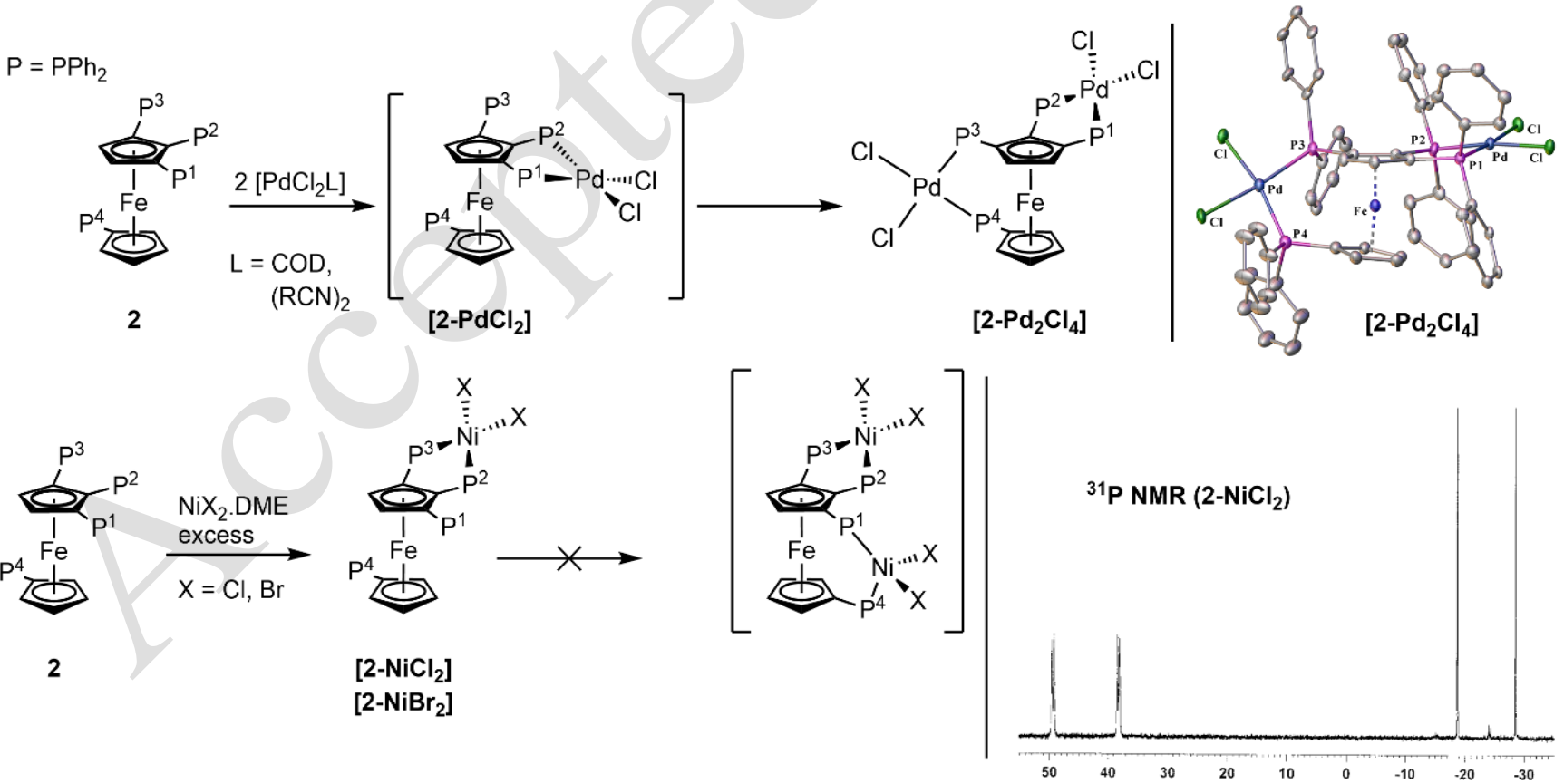

Figure 2. Complexation of 1,1',2,3-tetraphosphine 2 with palladium and nickel halide salts.

An important prerequisite for the coordination of three or more donors at the same metal center, ${ }^{[15]}$ is the adequate geometrical/sterical control of the ferrocene ligand conformation. We thus explored the coordination chemistry of hindered alkylated tetraphosphines originally designed by Broussier and Gautheron (Figure 3). ${ }^{[18-20]}$

2.1.2. Synthesis by the assembly of adequately substituted cyclopentadienyl rings 
The assembly with $\mathrm{Fe}^{\text {II }} \mathrm{Cl}_{2}$ of cyclopentadienyl lithium $\mathbf{A}$, which is obtained via a multistep synthesis involving two sequential lithiation/phosphination reactions of 1,2,3-trimethylcyclopenta1,3-diene, provides the methylated 1,1',2,2'-tetraphosphine 3 in $83 \%$ (Fig. 3). ${ }^{[19]}$ The tert-butylated cyclopentadienyl $\mathbf{B}$ is obtained from sequential lithiation/phosphination reactions of dimethylfulvene and was also employed with $\mathrm{Fe}^{\prime \prime} \mathrm{Cl}_{2}$ to form the 1,1',2,2'-tetraphosphine 4 in $70 \%$ (Figure 3). ${ }^{[20]}$ The diphosphino functionalization of $\mathrm{Cp}$ ring in $\mathbf{B}$ is highly selective, and directed by both the electronic and steric effects of tert-butyl group.

For the phosphines 3 and $\mathbf{4}$, both solution ${ }^{31} \mathrm{P}$ NMR and single crystal XRD analyses showed that the structure and conformation adopted by these compounds are very different. Tetraphosphine $\mathbf{3}$ can be viewed as a bis(diphosphine) for which all the phosphorous atoms in solution NMR are chemically and magnetically equivalent. Consistently, XRD structure analysis indicates a symmetrical structure distributing the phosphino groups as far as possible from each other. Conversely, the solution ${ }^{31} \mathrm{P}$ NMR of 4 revealed a rare AA'BB' phosphorus spin system in which two pairs of $P$-nuclei (central 1,1'-P and peripheral $2,2^{\prime}-P$ ) are magnetically inequivalent with strong mutual spin-spin couplings. A large nuclear spin-spin coupling $\left(J_{\mathrm{PP}}=59 \mathrm{~Hz}\right.$, Fig. 3) related to the eclipsed mutual position of central phosphorus is conveyed by their lone pair sharing the same space in a proximity forced by the global conformation constraint. ${ }^{[21,22]}$ Such non covalently bonding ${ }^{31} \mathrm{P} \ldots{ }^{31} \mathrm{P}$ nuclear spin ${ }^{\mathrm{TS}} J_{\mathrm{PP}}$ interactions occur through-space, ${ }^{[23]}$ and since our work, have been widely recognized as a fairly common phenomenon in highly constrained dissymmetric diphosphines. ${ }^{[24-27]}$ This constrained proximity is also necessary to induce phosphorus cooperative behavior. This favors the stabilization of robust complexes, and consequently promotes low loading metal catalysis for high turnover numbers (TONs). Accordingly, tetraphosphine $\mathbf{4}$ promotes palladium catalyzed Suzuki cross-coupling and Heck vinylation reaction with TONs up to $1000000 .^{[28]}$
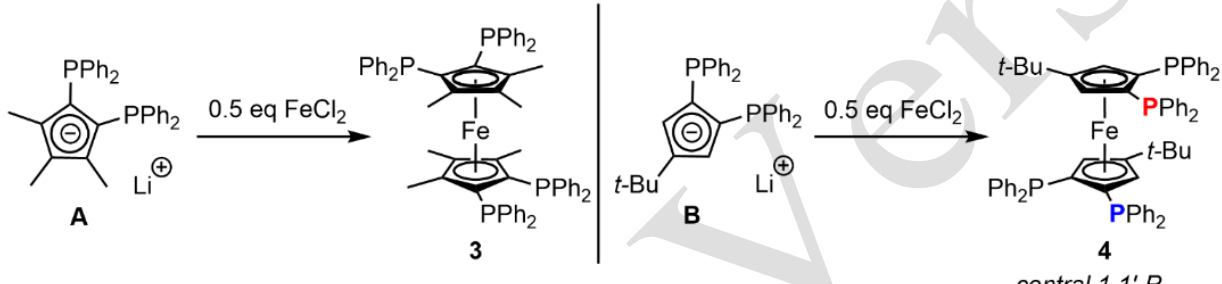

central $1,1^{\prime}-P$

$J_{\mathrm{pP}}=59 \mathrm{~Hz}$

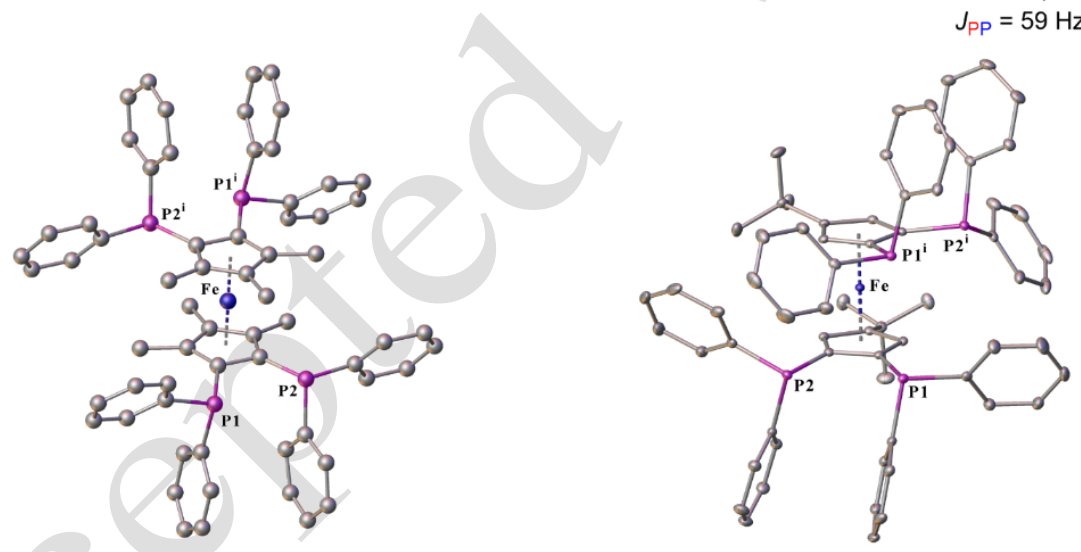

Figure 3. Synthesis of symmetrical tetraphosphines $\mathbf{3}$ [symmetry transformation: (i) 1-x, 1-y, 1-z] and $\mathbf{4}$ [symmetry transformation: (i) -x, y, 3/2-z] 


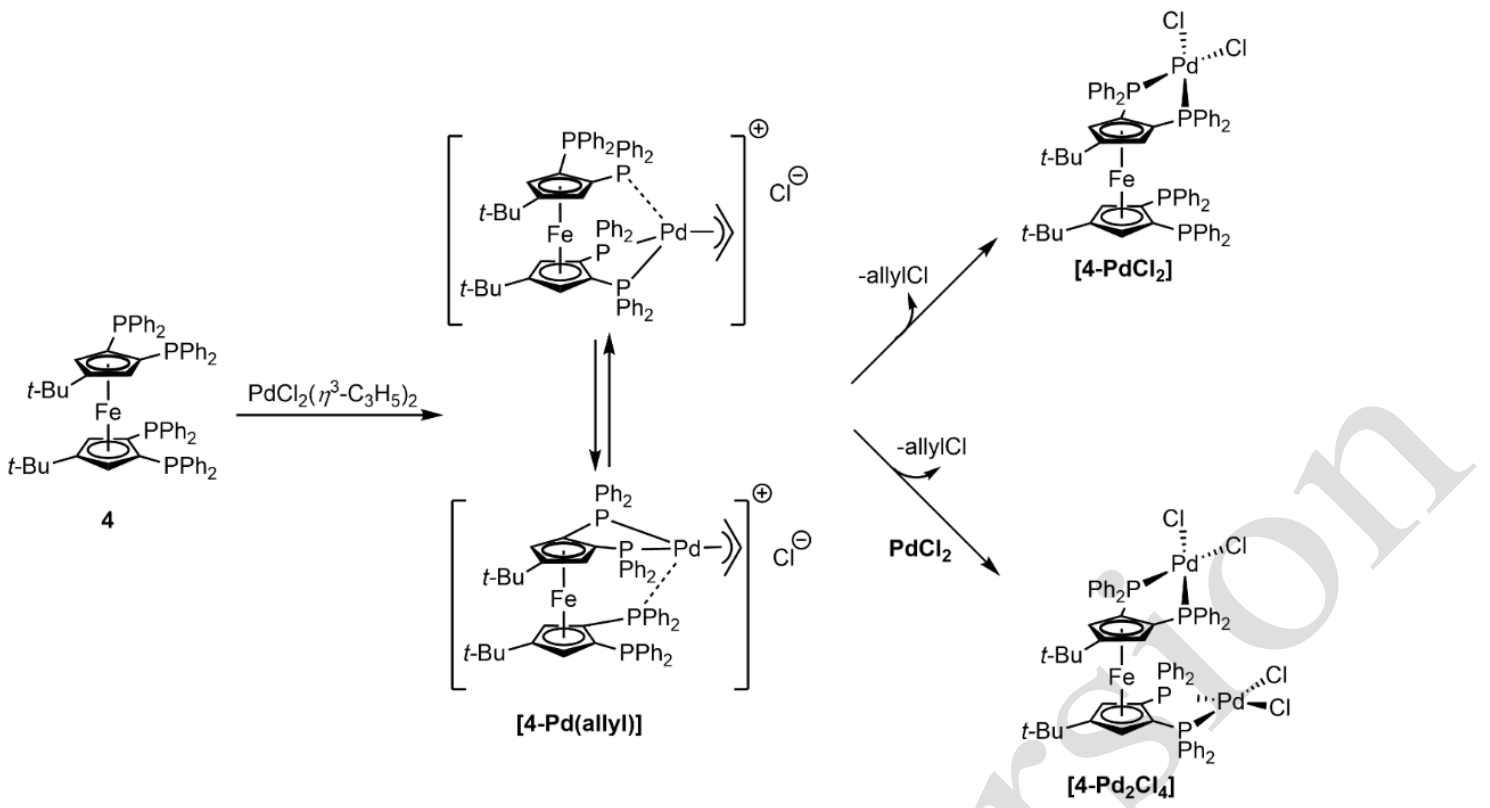

Figure 4. Dynamic three-coordinate complexation of tetraphosphine $\mathbf{4}$ with palladium.

The coordination chemistry of tetraphosphines 3 with group 6 $(\mathrm{Cr}, \mathrm{Mo}, \mathrm{W})$ and $7(\mathrm{Mn})$ metals $^{[29]}$ and of 4 with copper ${ }^{[30]}$ and gold $^{[31]}$ was thoroughly studied. However, the interactions between tetraphosphine 4 and group 10 metals $(\mathrm{Ni}, \mathrm{Pd}, \mathrm{Pt})^{[21]}$ remains the most striking. A dynamic evolution from initially formed labile [4-Pd(allyl)] species (Figure 4) towards the welldefined, stable, and non-fluxional complexes [4-PdCl$\left.{ }_{2}\right]$ and [4$\left(\mathrm{PdCl}_{2}\right)_{2}$ ] was observed. ${ }^{[28]}$ The dynamics of such unique interactions in polydentate ligands between the palladium metal center and the four phosphorus atoms has been studied, ${ }^{[32]}$ and exploited in $\mathrm{C}-\mathrm{C}$ cross coupling at low-palladium catalyst loading. The catalytic system combining the ferrocenyl tetraphosphine 4 and $[\mathrm{PdCl}(\text { allyl })]_{2}$ promotes the cross-coupling of aryl halides with aryl boronic acids (Suzuki reaction) and the vinylation of aryl halides with alkenes (Heck reaction) in the presence of 1.0 to $0.01 \%$ metal, while more reactive aryl bromides were reacted with aryl boronic acids or alkenes in the presence of 0.01 to $0.0001 \%$ catalyst (corresponding to catalysts TONs up to $\left.10^{4}-10^{6}\right) .{ }^{[28]}$

In relation with these cross-coupling reactions, kinetic studies based on electrochemical measurements were operated from the catalytically competent mononuclear complexes [4--PdCl${ }_{2}$ ] and its analogue [4- $\left.\mathrm{PdBr}_{2}\right]$. We originally measured the rate of $\mathrm{Ph}-\mathrm{I}$ oxidative addition (O. A.) on electrochemically generated $\left[4-\mathbf{P d}^{0}\right]^{[33]}$ In comparison with the systems combining $\left[\mathrm{Pd}^{0} / \mathrm{nPPh}_{3}\right](\mathrm{n}=2-4)$ reported by Jutand and Amatore groups
(Fig. 5, eq. 1), we find a half-reaction time of $t_{1 / 2}=130 \pm 10 \mathrm{~ms}$ (Figure 5, eq. 2). ${ }^{[3,35]}$ The measurements established thus that [4- $\mathbf{P d}^{0}$ ] combines an excellent reactivity towards oxidative addition -since the classical pre-catalyst $\left[\mathrm{Pd}^{0}\left(\mathrm{PPh}_{3}\right)_{4}\right]$ has $t_{1 / 2}=$ $30 \mathrm{~s}, 200$ fold slower- with a strongly enhanced stability compared to the low-coordinated reactive species " $\mathrm{Pd}^{0}\left(\mathrm{PPh}_{3}\right)_{2}$ " for which $t_{1 / 2}=80 \mathrm{~ms}$ (i.e. 1.5 times faster and thus highly unstable $\mathrm{Pd}^{0}$ ). We further investigated the addition of aryl bromide and alkyl chloride substrates that are the true substrates used in couplings achieved by $\left[\mathbf{4}-\mathbf{P d}^{\mathbf{0}}\right]$ catalyst. ${ }^{[36]}$ Kinetic constants for the oxidative addition of haloarenes to $\mathrm{Pd}^{0}$ intermediates generated by electrochemical reduction of [4$\mathrm{PdCl}_{2}$ ] and [4- $\mathrm{PdBr}_{2}$ ] was found to be: $\mathrm{k}_{\text {app }}(\mathrm{Ph}-\mathrm{Br})=0.48$ (in $\left.\mathrm{mol}^{-1} \mathrm{~L} \mathrm{~s}^{-1}\right)>\mathrm{k}_{\text {app }}\left(\mathrm{ClCH}_{2}-\mathrm{Cl}\right)=0.25 \gg \mathrm{k}_{\mathrm{app}}\left(p-\mathrm{MeC}_{6} \mathrm{H}_{4}-\mathrm{Br}\right)=0.08$ $\approx \mathrm{k}_{\text {app }}\left(0-\mathrm{MeC}_{6} \mathrm{H}_{4}-\mathrm{Br}\right)=0.07 \gg \mathrm{k}_{\text {app }}(\mathrm{Ph}-\mathrm{Cl})\left(\right.$ Fig. 5 , eq. 3-7). ${ }^{[36]}$

Kinetic measurements clarified the fact that the presence of supplementary phosphorus atoms (three and four) in polyphosphines of the type of $\mathbf{4}$ stabilizes $\mathrm{Pd}^{0}$ molecular complexes, and consequently slows down the O.A. of aryl halides to $\mathrm{Pd}^{0}$ by at least two orders of magnitude compared to diphosphine coordination. Conversely, these polydentate ligands efficiently inhibit the decoordination of palladium and deleterious formation of palladium black colloids. This work also evidenced the perfect stereoselectivity of the oxidative addition reactions which is induced by the tetraphosphine ligand $4^{[37]}$ 


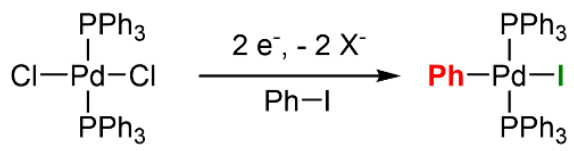

eq. (6)

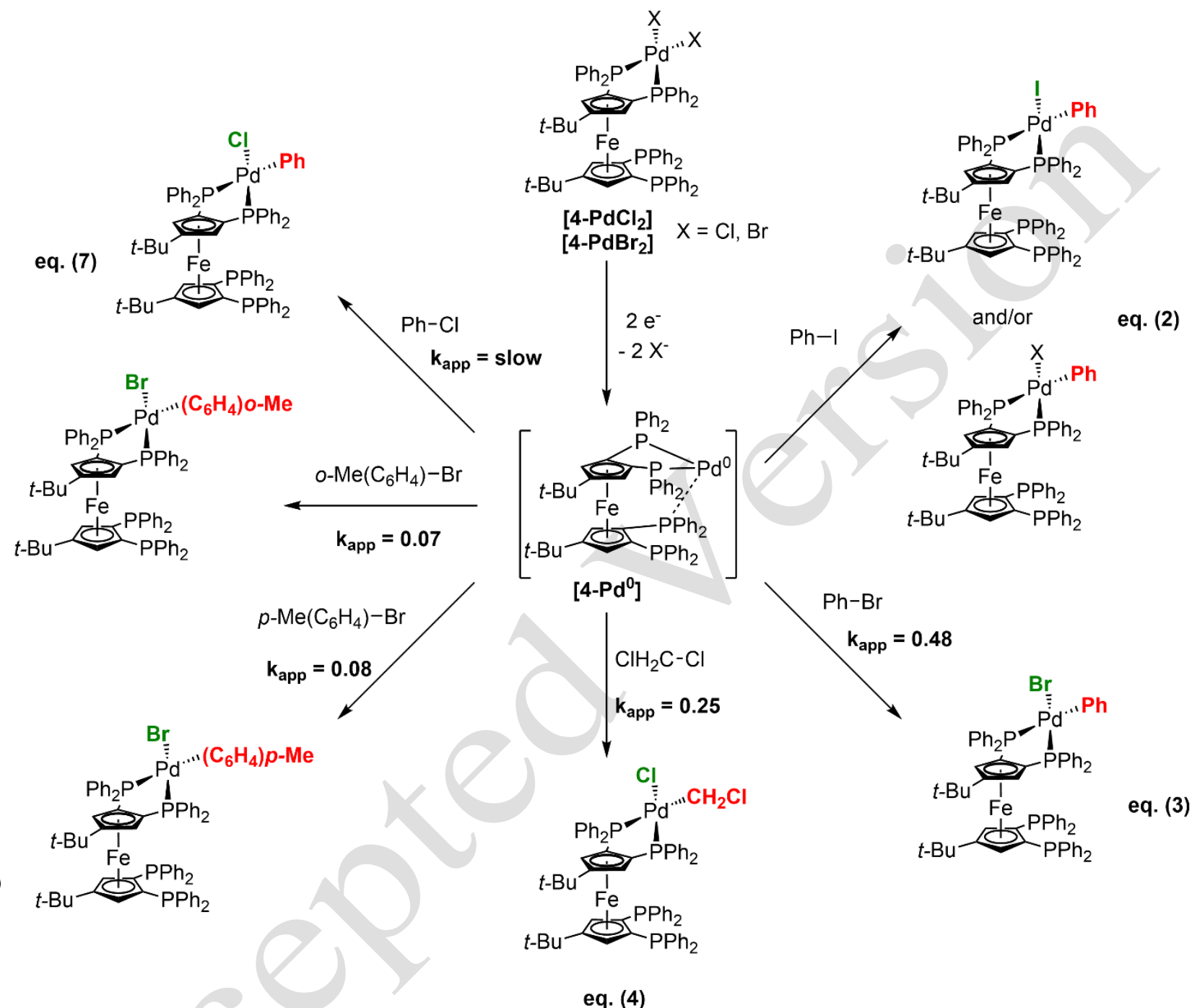

Figure 5. Kinetic Constants $k_{\text {app }}$ (in mol ${ }^{-1}$ L. $s^{-1}$ ) for O.A. of phenyl bromide and methyl-substituted derivatives to a tetraphosphine-stabilized $\operatorname{Pd}(0)$ complex

The proximity of phosphorus atoms in $\mathbf{4}$ was also originally exploited in zirconium coordination chemistry. ${ }^{[38]} A$ unique mixed ferrocenyl diphosphonium-diphosphine dication $\mathbf{5}$, associated with two $\left[\mathrm{ZrCl}_{5} \cdot \mathrm{thf}^{-}\right.$anions was obtained as a rare didentate ionic metalloligand. A perfectly selective bis-protonation reaction induced by $\mathrm{ZrCl}_{4}$ in THF was observed (Figure 6). This reactivity was not obtained from organic acids like triflic acid, from which the expected tetraphosphonium salt is obtained. The use of a non-metallocene zirconium chloride adduct in THF as a selective protonation (or "auto-protonation") agent for a polyphosphine ligand involve both carbon-oxygen bond cleavage and carbonhydrogen activation of THF at ambient temperature in a short period of time (Figure 6, bottom). 

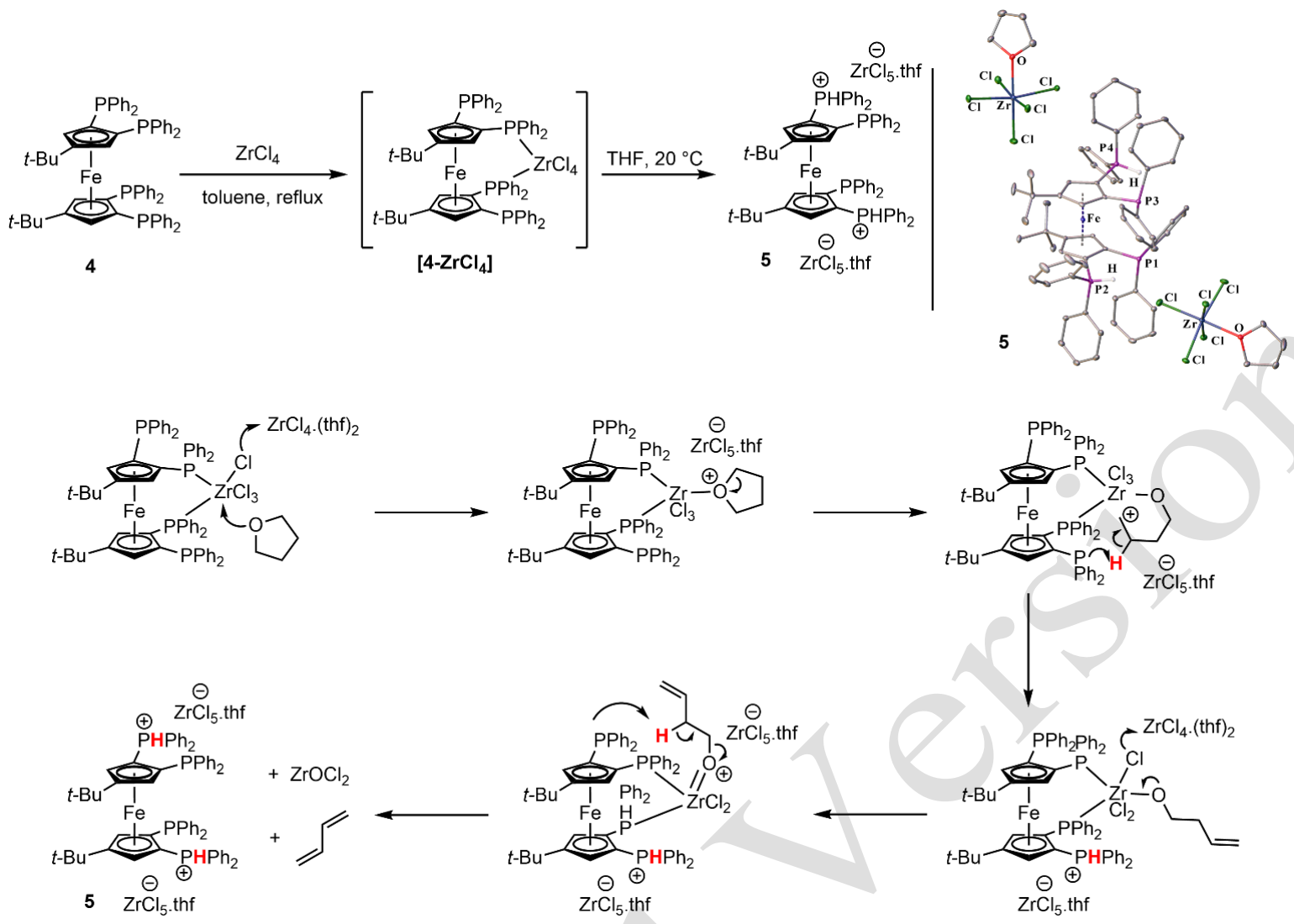

Figure 6. Synthesis and molecular structure of $\mathbf{5}$. Proposal for concerted selective formation of complex $\mathbf{5}$ from tetraphosphine 4.

The assembly of adequately substituted cyclopentadienyl rings (C-E, Figure 7) allowed a large extension of the family of tetraphosphine ligand $\mathbf{4}$ with the conservation of the specific cisoid conformation, in which, for instance, acetal functionalized tetraphosphines 6 and its aldehyde derivative 7 displayed in ${ }^{31} \mathrm{P}$ NMR an AA'BB' spin system. This conformation of ferrocenyl phosphines was controlled by the introduction of gem-methyl groups which play the role attributed to tert-butyl substituents in 4 and ensure the mutual proximity of the phosphorus atoms in 6 and 7. Accordingly, the existence of a strong through-space spin-spin coupling ( ${ }^{T S} J_{\mathrm{PP}}=64.3 \mathrm{~Hz}$ and $61.0 \mathrm{~Hz}$, respectively) between internal heteroannular $A^{\prime}$ pairs of $P$-atoms is due to the overlapping of their lone pairs. Such spin couplings attest for the ligand conformation in solution. ${ }^{[39]}$ Tetraphosphine 7 was modified to give the functionalized polyphosphines 8-11 (Figure 8). The carbonyl derivative 7 can be grafted directly on preformed Merrifield-type resins. Styrenyl moieties $(\mathbf{9}, \mathbf{1 0})$ allow for processing tetraphosphine immobilization by copolymerization with styrene, and alkyltriethoxysilane (11 obtained from 8) allow sol-gel mediated anchoring of the ligands on inorganic supports like silica.

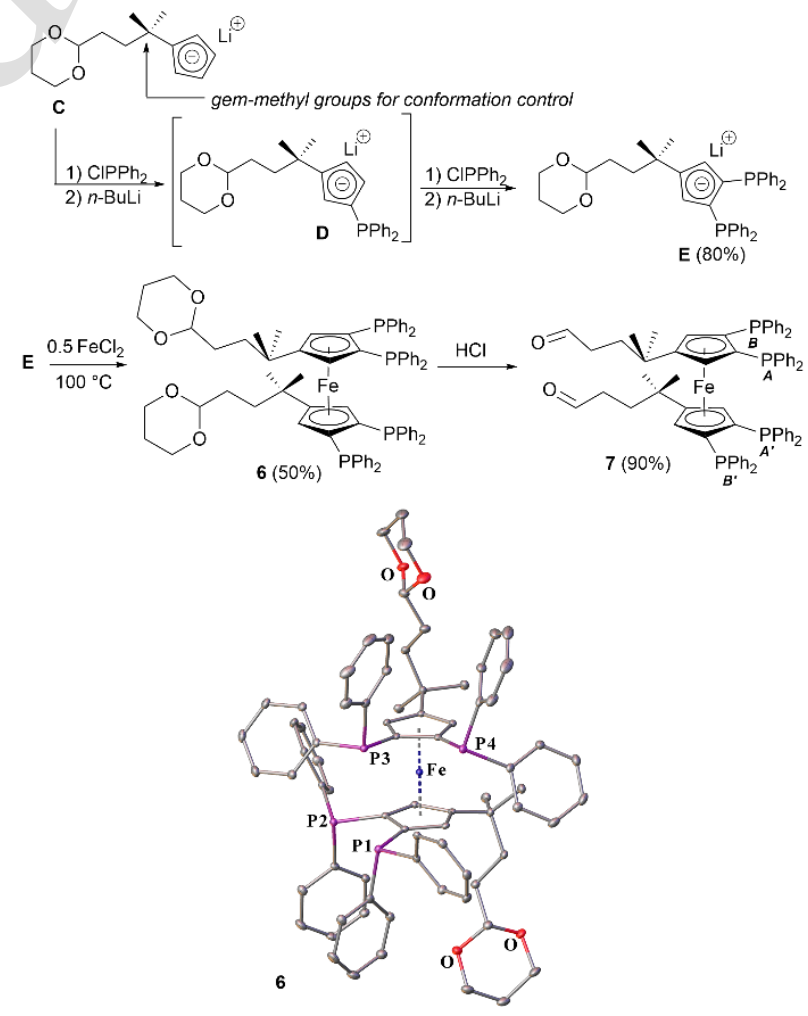

Figure 7. Synthesis and molecular structure of protected tetraphosphine 6 and dialdehyde 7 .

The monofunctionalized analogues 12-14 and the vinyl difunctionalized tetraphosphines 15 (Fig. 8) were also 
synthesized following the method of assembling adequately substituted $\mathrm{Cp}$ rings. ${ }^{[39]}$ One aim was to increase the flexibility of the anchoring upon immobilization (12-14, being not crosslinking species) or to generate a short cross-linker tetraphosphine (15). These functionalized ligands have been incorporated into polystyrene to give either soluble or insoluble polymers, and on inorganic supports such as silica. We reported the catalytic performance in $\mathrm{C}-\mathrm{C}$ bond formation (Suzuki and Sonogashira reactions, and difficult $\mathrm{C}-\mathrm{H}$ functionalization of heteroaromatics with demanding chloroarenes) at $0.05-0.5$ mol\% low palladium loading of the immobilized polyphosphine ligands. ${ }^{[0]}$ They showed excellent performance and good potential for recycling up to six successive runs limited because of accumulative loss of material during filtration. When used with chloroarenes the resulting cumulative turnover numbers of the heterogeneous catalytic systems were found to be satisfactory relative to their homogeneous counterparts tetraphosphine (TONs $=270-1700)$. Nevertheless, the TONs over $10^{4}$ obtained in coupling bromoarenes under homogeneous conditions was not reached by the supported ligands. ${ }^{[40]}$

Another conceptual interest of the back-modified tetraphosphine ligands was illustrated with the first ${ }^{31} \mathrm{P}$ NMR ABCD spin systems reported for tetraphosphine 12 (Fig. 8). The simulation of its second order spectrum (Figure 9) evidenced four different but proximate chemical shifts $\left(\delta_{A}=-33.9, \delta_{B}=-\right.$ 29.9, $\delta_{C}=-30.3, \delta_{D}=-34.0$, with $J_{A B}=73.3 \mathrm{~Hz}, J_{B C}=61.6 \mathrm{~Hz}$ and $\mathrm{J}_{\mathrm{CD}}=74.2 \mathrm{~Hz}$, all other coupling constants involved in the ABCD spin system being null. These ${ }^{3} J_{A B},{ }^{3} J_{C D}$ and ${ }^{T S} J_{B C}$, are fully consistent with the values obtained for ${ }^{T S} J_{A A}$ and ${ }^{3} J_{A B}={ }^{3} J_{A^{\prime} B^{\prime}}$ in the symmetrical ferrocenyl phosphine analogues $\mathbf{3}$ and $\mathbf{4}$.

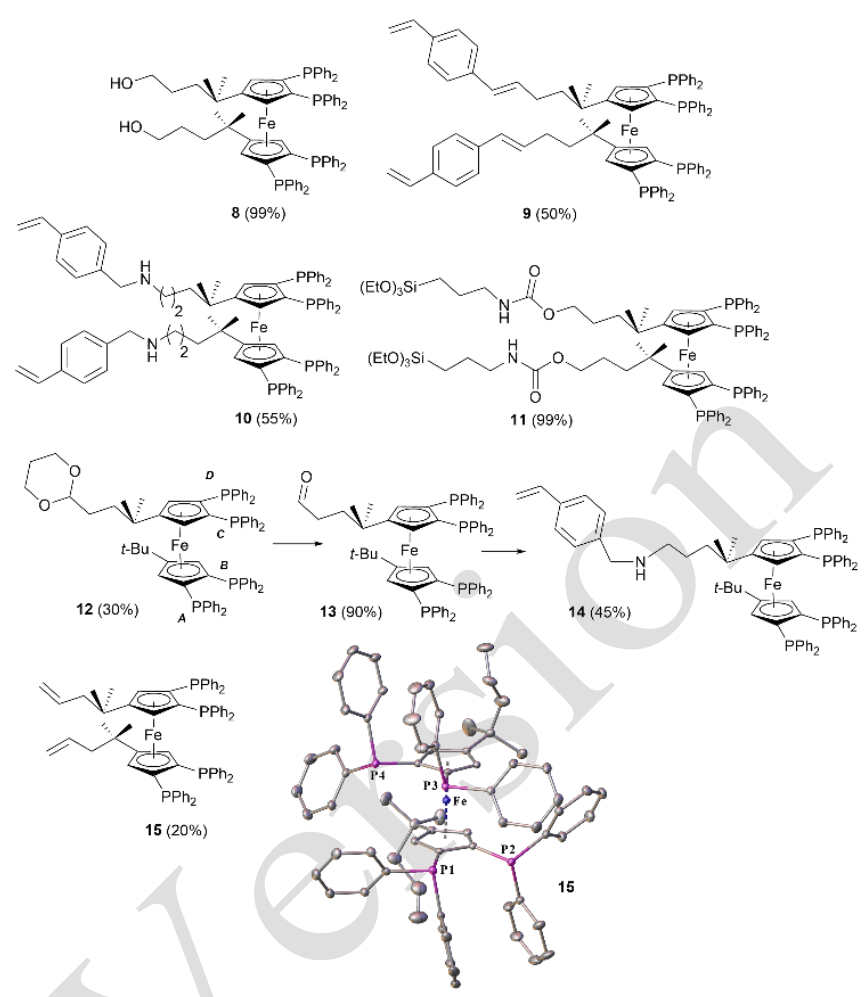

Figure 8. Tail-functionalized tetraphosphines 8-15 "ready for immobilization" on various supports.
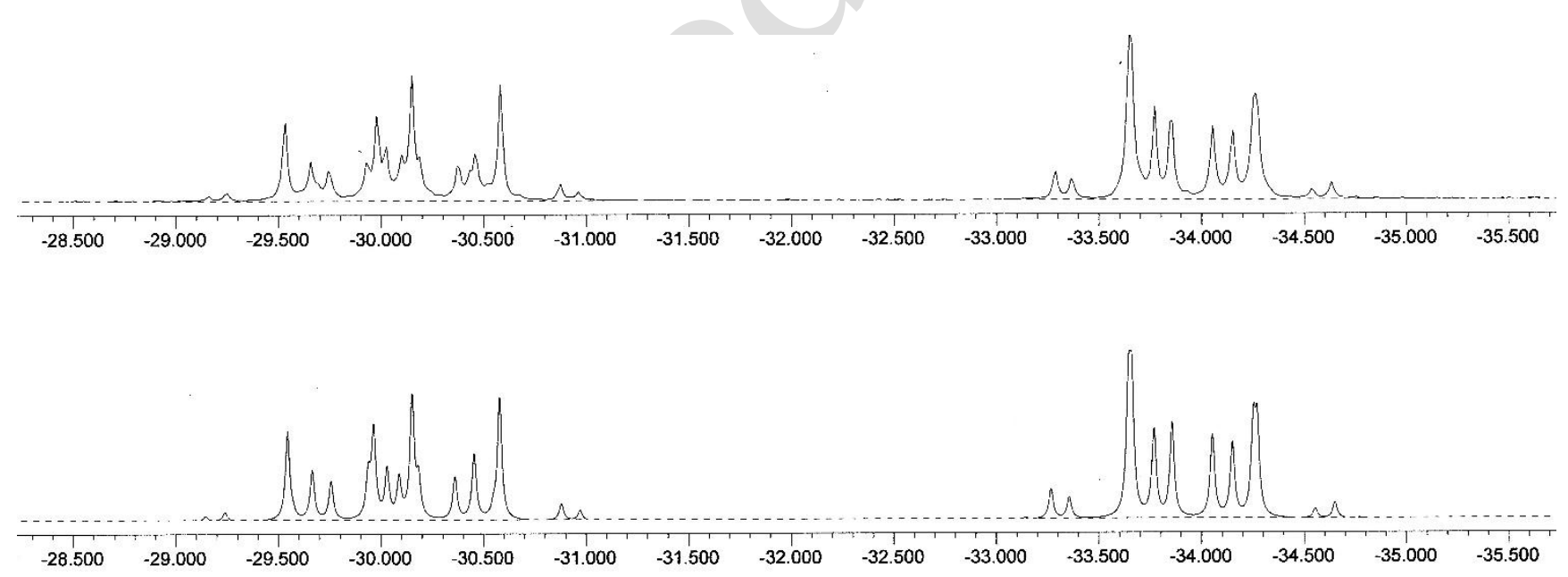

Figure 9. Unique ABCD ${ }^{31}$ P NMR spin system for tetraphosphine 12: experimental (top) and simulated spectra (bottom)

The controlled conformation and cooperative behavior in complexes formed from tert-butylated-tetraphosphines allowed relevant advances in both conceptual understanding of ${ }^{31} \mathrm{P}$ nuclear spin-spin coupling chemical physics, ${ }^{[25]}$ and palladium or palladium/copper catalysis. ${ }^{[30,41]}$ The coordination chemistry of bis(diphosphine) such as ligand 16 (Figure 10), ${ }^{[42]}$ obtained in $73 \%$ from $\mathbf{F}$, was also found to be useful. Indeed, binuclear palladium complexes derived from $\mathbf{1 6}$ where palladium centers are coordinated in a bis- $\mathrm{k}^{2}$ mode (XRD in Fig 10) have been identified as competent intermediates in $\mathrm{C}-\mathrm{S}$ bond formation.
The complex $\left[16-\mathrm{Pd}_{2}(\mathrm{CHCl})_{2} \mathrm{Cl}_{2}\right]$ displays a binuclear coordination, resembling the 1,1'-P-coordination of dppf and its derivatives. This coordination mode, which involves heteroannular (bridging) coordination with a large bite angle, is related to the high reactivity of such complexes found in the reductive elimination of heteroaromatic thioethers. 


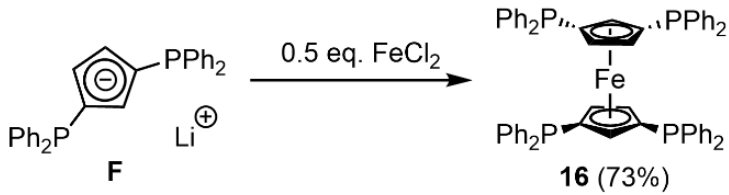

$16+\left[\mathrm{Pd}^{\prime \prime}\left(\text { allyl) } \mathrm{Cl}_{2}\right]_{2} \frac{+2 \mathrm{CHCl}_{3}}{-2 \text { (allylCl) }} \mathrm{Cl}_{2} \mathrm{HC}^{\circ}{ }^{\circ} \mathrm{C}\right.$

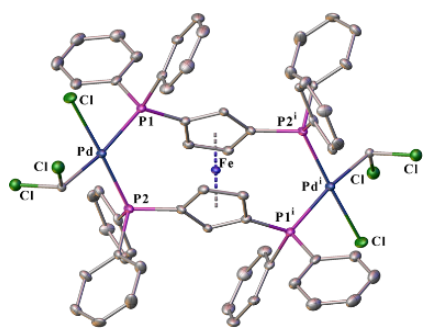

Figure 10. Synthesis and molecular structure of chloroform O.A. palladium complex of 16 [symmetry transformation: (i) $1-x, 1-y,-z]$.

Selective thioetherification of a large range of functionalized arene thiols was achieved with chloroheteroaromatic partners at the highest TONs up to 500 with Pd catalyst content down to 0.2 mol\%. ${ }^{[42]}$ A variety of reactive functions was tolerated with the coupling of thiophenols to six and five-membered 2chloroheteroarenes, functionalized pyridine and pyrazine, quinoline, pyrimidine, furane, thiazole, and 3-bromoheteroarenes (pyridine and furane). Electron-rich congested thiophenols, as well as fluorinated thiophenols, were also suitable partners. The couplings of unprotected amino-2-chloropyridines with thiophenol, as well as the successful employment of synthetically valuable chlorothiophenols, were described with the same catalyst system. DFT studies conducted in cooperation with M. Saeys group attributed the high performance of this binuclear palladium catalyst to the reduced stability of thiolatecontaining resting states. ${ }^{[42]}$

Some dissymmetric ferrocenyl phosphines have been synthesized by post-functionalization of preformed ferrocene derivatives, especially using directing groups on ferrocene like amine, acetal, sulfoxide, amide, oxazoline, etc. ${ }^{[4,43]}$ However, to obtain rare 1,2- plus 1',3'-substituted ferrocenes, the assembling of two different functionalized $\mathrm{Cp}$ salts in a two-step protocol is necessary, and allows some very original dissymmetric tetraphosphine formation like for instance $\mathbf{1 7}$ that was obtained in $45 \%$ yield (Figure 11). ${ }^{[43]}$ This synthetic way inspired the synthesis of many new ferrocenyl triphosphines obtained in good yields and exploited for various catalytic cross-couplings with palladium.

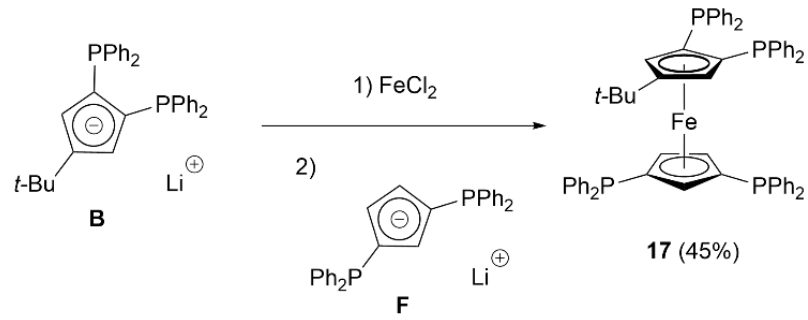

Figure 11. Synthesis of the dissymmetric 1,2,1',3'-tetrakis(diphenylphosphino) ferrocene 17.

\subsection{Triphosphines}

The assembly of different functionalized cyclopentadienyl rings at $\mathrm{FeCl}_{2}$ provides a robust method to access various ferrocenyl triphosphines with different electronic and steric properties at the donor atoms. It allows also the introduction of a variety of other structuring substituents on ferrocene backbone.

This synthetic method, however, preferentially leads to the formation of symmetric products, and as a consequence, limits the yields of dissymmetric (triphosphine) targets. Yet, in some cases satisfactory yields are reachable -the course of this selectivity remains an unpredictable experimental issue. Thus, the reaction of $\mathrm{Cp}$ ring $\mathbf{A}$ with iron dichloride, followed by the addition of $\mathbf{G}$ lead to the formation of $\mathbf{1 8}$ in $63 \%$ yield (Figure 12). ${ }^{[19]}$ The coordination of 18 to $\mathrm{Cr}(\mathrm{CO}){ }_{4} \mathrm{NBD}$ gave complex [18- $\left.\mathrm{Cr}(\mathrm{CO})_{4}\right]$ in $86 \%$ (Figure 13). ${ }^{[19]}$

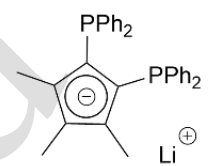

A

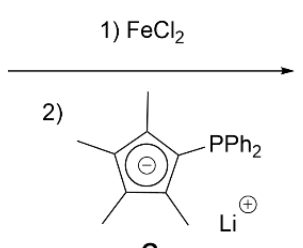

G

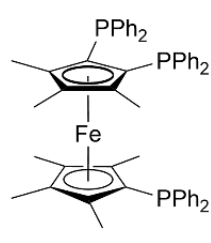

$18(63 \%)$
Figure 12. Synthesis of ferrocenyl triphosphine $\mathbf{1 8}$

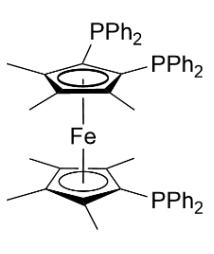

18
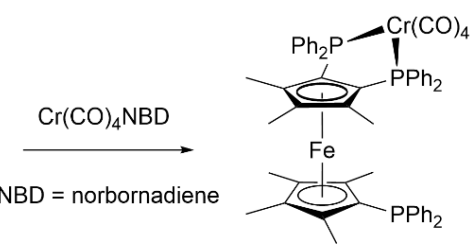

$\left[18-\mathrm{Cr}(\mathrm{CO})_{4}\right]$
Figure 13. Coordination of 18 with $\mathrm{Cr}(\mathrm{CO}){ }_{4} \mathrm{NBD}$

The assembly synthetic route (Fig. 12) was successfully extended to a wide variety of ferrocenyl triphosphines (Figure 14). By reacting the precursor $\mathrm{Cp} \mathbf{B}$ with various rings $(\mathrm{Cp} \mathbf{H}-\mathbf{R})$ the formation of ferrocenyl triphosphines 19-29 was achieved. ${ }^{[43,44,46,47]}$ Except for 19 and 20, which have excellent yield $(84 \%$ and $70 \%)$, and for 25 obtained with a satisfactory $55 \%$ yields, the other synthesis suffered from the selectivity limitation evoked above. Both the competitive formation of symmetric compounds and eventually tedious purification processes are responsible for these yields (3-35\%). However, even with low yield, the access to these new class of ferrocenyl triphosphines is hardly achieved by post-functionalization of ferrocene. 


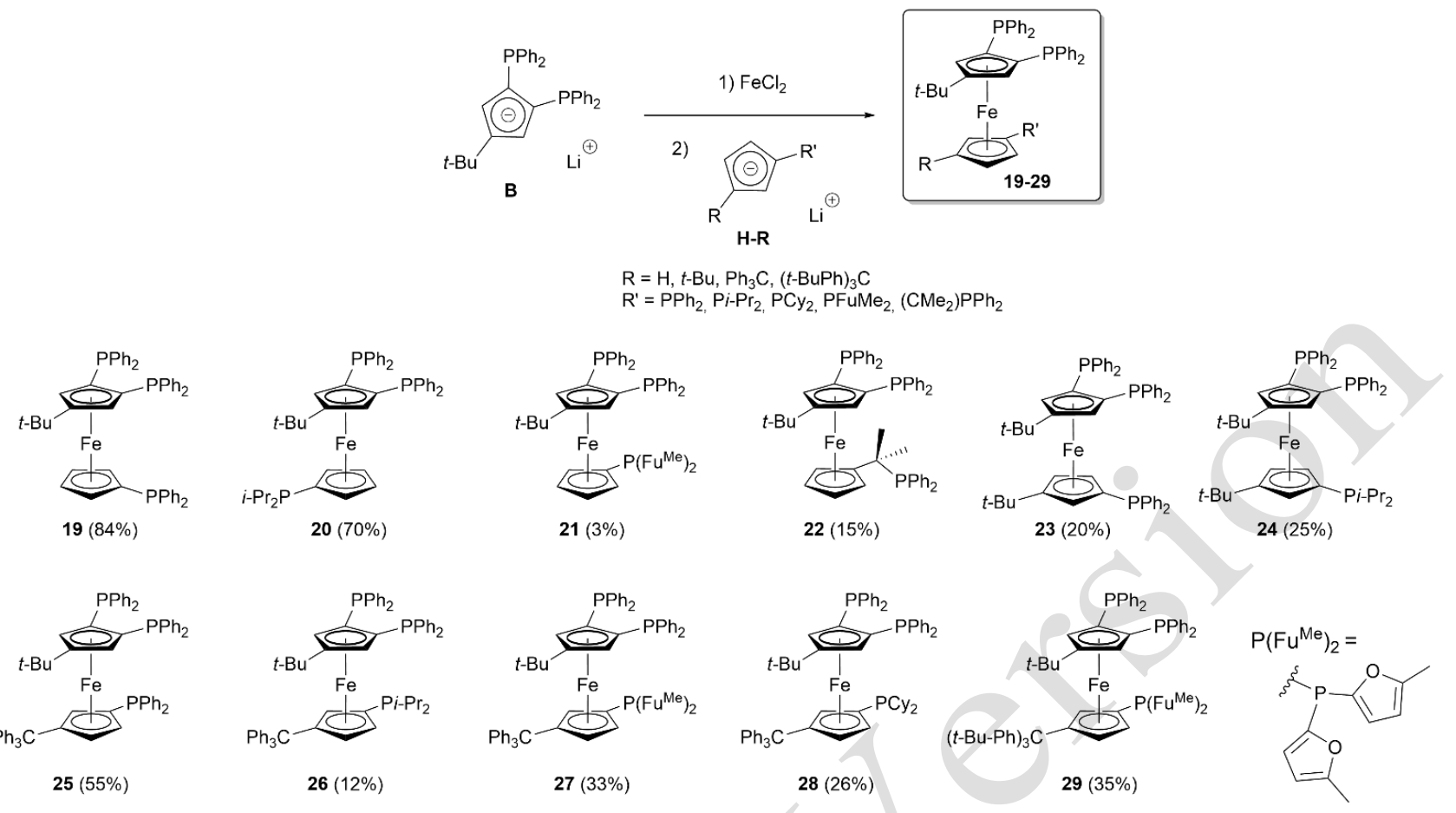

Figure 14. Synthesis of ferrocenyl triphosphines $19-29$ by two $\mathrm{Cp}$ rings assembly at $\mathrm{FeCl}_{2}$.

Depending on the conformation adopted in solution, these triphosphines can reveal close proximity between heteroannular phosphorous atoms as observed from strong ${ }^{31} \mathrm{P}$ NMR spin-spin coupling operating through-space via lone pair overlap ( $\left.{ }^{\mathrm{TS}} \mathrm{JPP}_{\mathrm{PP}}\right)$ as observed for the ferrocenyl tetraphosphine 4 (Fig. 3).

Thus, ${ }^{31} \mathrm{P}$ NMR delivers information about the solvated conformation of these ferrocenes. For instance, while 20-22 did not show ${ }^{\mathrm{TS}} J_{\mathrm{PP}}$ coupling, compound 19 displayed a ${ }^{\mathrm{TS}} \mathrm{JPP}_{\mathrm{PP}}$ coupling between the two vicinal phosphorus atoms and the heteroannular one (Figure 15, top). Consistently, this spin-spin coupling is strongly influenced by the solvent nature with a $J_{\mathrm{PP}}$ constant of $2.8 \mathrm{~Hz}$ in $\mathrm{CDCl}_{3}$, and $5.0 \mathrm{~Hz}$ in $\mathrm{C}_{6} \mathrm{D}_{6}$. ${ }^{[43]}$

Whereas the different phosphorus donors in compound 20 showed no TS spin-spin coupling, a rarely exemplified throughspace coupling ${ }^{\mathrm{TS}} J_{\mathrm{CP}}=5.5 \mathrm{~Hz}$ was observed between the heteroannular phosphorous atom and the three methyl carbon atoms of $t$-Bu substituent (Fig. 15, top). A spatial proximity has been confirmed in the solid state by $X R D$, with a short $C \cdots P$ distance of $3.64 \AA .^{[43,48]}$

For these triphosphines the presence of a substituent on the monophosphinated $\mathrm{Cp}$ ring induces a loss of symmetry. Thereby, the two vicinal phosphorous atoms become anisochronous and their spin coupling is directly observable on the NMR spectrum. The ${ }^{31} \mathrm{P}$ NMR spectra results in various $A B$ spin systems as observed in compound 23 and $24\left({ }^{3} J_{\mathrm{PP}}=98\right.$ and $87 \mathrm{~Hz}$, respectively, Fig. 15). These two compounds do not present through-space coupling with the third heteroannular phosphorous atom. The analogues in which a ring substitution with a triphenylmethyl group is present (trityl, 25-29) however display such ${ }^{31} \mathrm{P}-{ }^{31} \mathrm{P}$ spin-spin couplings. This TS coupling can occur with only one of the vicinal phosphorous atom as for $\mathbf{2 6}$ ( ${ }^{\mathrm{TS}} \mathrm{JPP}_{\mathrm{PP}}=6 \mathrm{~Hz}$ in $\mathrm{CDCl}_{3}$, Fig. 15, bottom), or with both phosphorus donors as for $\mathbf{2 5}$ and 27-29. The coupling constants can be either different $\left({ }^{\mathrm{TS}} \mathrm{JPP}_{\mathrm{PP}}=22\right.$ and $6 \mathrm{~Hz}$ for $\mathbf{2 8}$ ), or similar (between
11 to $23 \mathrm{~Hz}$ for 25, 27 and 29) (Fig. 15, bottom), which gives an indication of the spatial proximity of the phosphorus atoms in solution and their mutual positioning. ${ }^{[46]}$

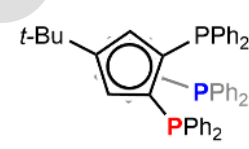

19<smiles>CC(C)(C)c1cc(P)c(P(#P)c2ccccc2)cc1P</smiles>

20

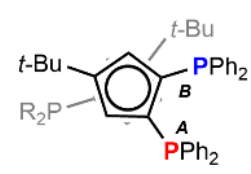

23-24

$$
{ }^{\mathrm{TS}} J_{\mathrm{PP}}=2.8 \mathrm{~Hz} \quad \mathrm{TS}_{J_{\mathrm{CP}}}=5.5 \mathrm{~Hz} \quad \text { AB system }{ }^{3} J_{\mathrm{AB}}=87-98 \mathrm{~Hz}
$$

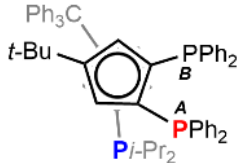

26<smiles>Cc1cc(Br)cc(P(C)c2ccccc2)c1P(C)c1ccccc1</smiles>

25, 27-29
TS $_{J_{P P}}=6 \mathrm{~Hz}$ $\mathrm{AB}$ system ${ }^{3} J_{\mathrm{AB}}=59 \mathrm{~Hz}$

Ts $_{\text {JPP }} 6$ to $23 \mathrm{~Hz}$ $\mathrm{AB}$ system ${ }^{3} \mathrm{~J}_{\mathrm{AB}}=41-72 \mathrm{~Hz}$

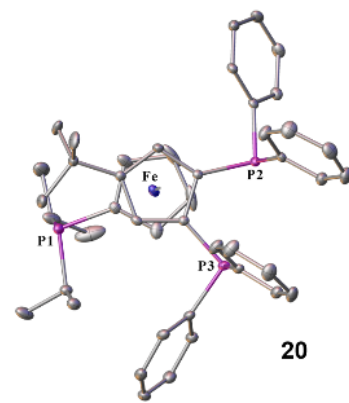

Figure 15. Average conformation of ferrocenyl triphosphines in $\mathrm{CDCl}_{3}$ solution (view from above), according the existence and values of $J_{\mathrm{PP}}$ couplings.

Several of these triphosphines 19-29 have been studied in catalysis, in cooperation with $\mathrm{H}$. Doucet group, and some 
achieved remarkable performances in palladium-catalyzed cross-coupling reactions. The ferrocenyl triphosphines 19 and 20 with one non-alkylated $\mathrm{Cp}$ ring presented an excellent activity as ligands in $\mathrm{Pd} / \mathrm{Cu}$-catalyzed Sonogashira cross-coupling reactions. Compound $\mathbf{2 0}$ showed high robustness and activity giving TONs up to 250000 for coupling phenylacetylene with bromoacetophenone (Figure 16, left)..$^{15,41,47,49,50]}$ The mixed ferrocenyl aryl/alkyl triphosphine $\mathbf{2 0}$ is thermally stable and insensitive to air or moisture, and its robustness allows aryl alkynylation at $10^{-1}$ to $10^{-4} \mathrm{~mol} \%$ catalyst loadings, copper-free coupling using phenylacetylene is also accessible in good yield. Unconstrained triphosphine $\mathbf{1 9}$ has been used in the $\mathrm{C}-\mathrm{H}$ bond activation of heteroarenes with TONs up to 9000 for coupling (Fig. 16, middle). ${ }^{[51]}$ The coupling of some sterically hindered bromoarenes to alkylated furans and thiophenes gave good to excellent yields using $0.1 \mathrm{~mol} \%$ catalyst. Very high yields for coupling thiophene and 1,3-thiazole derivatives with activated bromides were achieved using only 0.1 to 0.01 mol\% catalyst. ${ }^{[51]}$ Compound 20 has presented a noticeable selectivity in $\mathrm{C}-\mathrm{N}$ palladium-catalyzed bond formation for coupling of aniline derivatives to challenging difunctionalized dichloroarenes (Fig. 16 , right). ${ }^{[52,53]}$

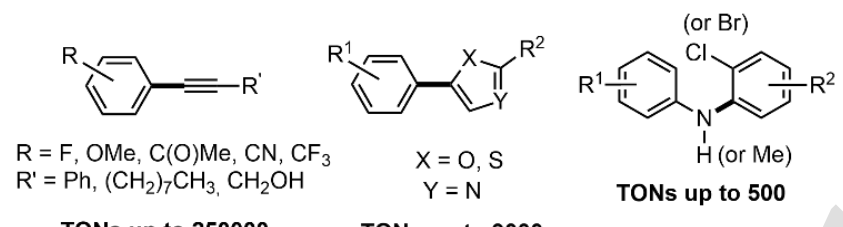

TONs up to $250000 \quad$ TONs up to 9000

Figure 16. Sonogashira coupling, heteroarene $\mathrm{C}-\mathrm{H}$ activation $\mathrm{C}-\mathrm{N}$ bond formation promoted by non-congested ferrocenyl triphosphines.

Ferrocenyl triphosphines built from one unconstrained monofunctionalized $\mathrm{Cp}$ ring are useful ligands in the previous catalytic reactions, but they were found generally inactive in more challenging $\mathrm{C}-\mathrm{H}$ functionalization reactions. However, the analogous five-functionalized triphosphines 23-25 -with a more constraint conformation- were found active in the use of demanding haloarenes such as aryl chlorides and congested aryl bromides. The ligands 23-25 associated with $\mathrm{Pd}$ have shown a very good activity for arylation of highly functionalized heteroaromatics with TONs up to 1800 (Figure 17)..$^{[44,54,55]}$ Thus, ligand $\mathbf{2 5}$ was mainly used for bromoarene substrates, but by using triphosphine 23, electron-rich, electron-poor and multifunctionalized furans, thiophenes, pyrroles or thiazoles were arylated by various chloroarenes at 0.1-0.5 mol\% catalyst loadings.

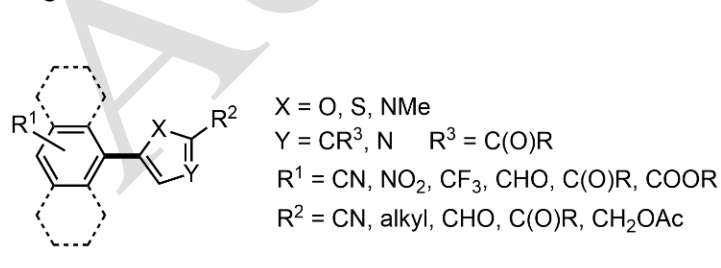

TONs up to 1800

Figure 17. Arylation of heteroarenes by direct $\mathrm{C}-\mathrm{H}$ activation promoted by constrained ferrocenyl triphosphines 23-25.

Triphosphine ligand 24 associated with palladium promotes the coupling of hindered substrates such as 2-bromobiphenyl, 9bromoanthracene and 2,6-dimethylbromobenzene to the same wide variety of heteroaromatics. These coupling reactions can generally again be performed by using catalyst low-loading ranging in 0.1-0.5 mol\% Pd/ligand. Overall, Pd/triphosphine 2325 catalytic systems generally tolerate useful functions such as formyl, nitriles, nitro, keto, and ester groups in para-, meta- or ortho-positions of aromatics. ${ }^{[55]}$

In addition to relevant performances in $\mathrm{C}-\mathrm{H}$ bond functionalization, the triphosphine $\mathbf{2 4}$ also achieved unprecedented activity in palladium-catalyzed $\mathrm{C}-\mathrm{O}$ bond formation via etherification of functionalized phenols with 2chloroheteroarenes. ${ }^{[45]}$ The air-stable palladium/triphosphine 24 system is efficient for the selective synthesis of heteroaryl aryl ether by using $0.2 \mathrm{~mol} \%$ or less of catalyst. Thus, para-, metaand ortho-substituted phenols with electron-donating or electronwithdrawing groups (including unprotected aminophenol) couple with a wide scope of heteroaryl 2-chlorides, including pyridines, pyrimidines and thiazoles bearing cyano, methoxy, and fluoro unprotected groups. This catalytic system was used in ten to fifty fold lesser amount of palladium and ligand than the previously reported systems, resulting in TONs up to 500 (Figure 18). ${ }^{[45]}$

DFT calculations conducted in M. Saeys group demonstrated that the conformation control in ferrocenyl triphosphine $\mathbf{2 4}$ open up new pathways for $\mathrm{C}-\mathrm{O}$ reductive elimination, which do involve the third phosphine group (Figure 19). The rate for one of these new pathways was calculated to be about $10^{3}$ times faster than for reductive elimination from a complex with a similar ferrocenyl ligand, but without phosphino group on the second cyclopentadienyl ring. The coordination of the third phosphino group to the $\mathrm{Pd}(\mathrm{II})$ center stabilizes the transition state in this new pathway, thereby enhancing the reductive elimination rate. ${ }^{[45]}$

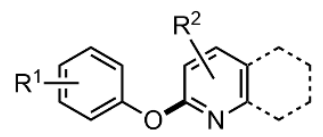

TON up to 495

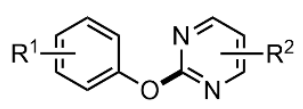

TON up to 495

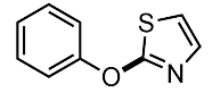

TON $=305$

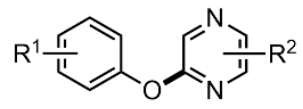

TON up to 495
Figure 18. Palladium catalyzed etherification of functionalized phenols with chloroheteroarenes promoted by constrained ferrocenyl triphosphines $\mathbf{2 4}$.

Reductive elimination (R.E.) is known to be the decisive step in aryl ether formation, and the bulkiness of air-sensitive electronrich monophosphines has been reported to promote this reaction. We provided the first study of polydentate ligand influence in this reaction. As shown in Figure 19, relevant pathways involve isomerization between homoannular coordination (1,2-bonded, iso.1 and iso.4, Fig. 19) and heteroannular (1,1'-bonded iso.2 and iso.3, Fig. 19), reachable with a low barrier $(E=2$ and 9 $\left.\mathrm{kJ} . \mathrm{mol}^{-1}\right)$. In iso.3, the free phosphorous from top $\mathrm{Cp}$ ring comes closer to the $\mathrm{Pd}(\mathrm{II})$ center forming a pseudo pentacoordinated palladium intermediate with a lower barrier $\left(E=83 \mathrm{~kJ} \mathrm{~mol}^{-1}\right.$ RE.TS3, Fig. 19, bottom). Faster reductive elimination may occur and the resulting $\mathrm{Pd}(0)$ complex formed is stabilized by a three-P donors coordination $\left(-108 \mathrm{~kJ}^{-\mathrm{mol}^{-1}} \mathbf{P}\right.$, Fig. 19, bottom) ${ }^{[45]}$ 


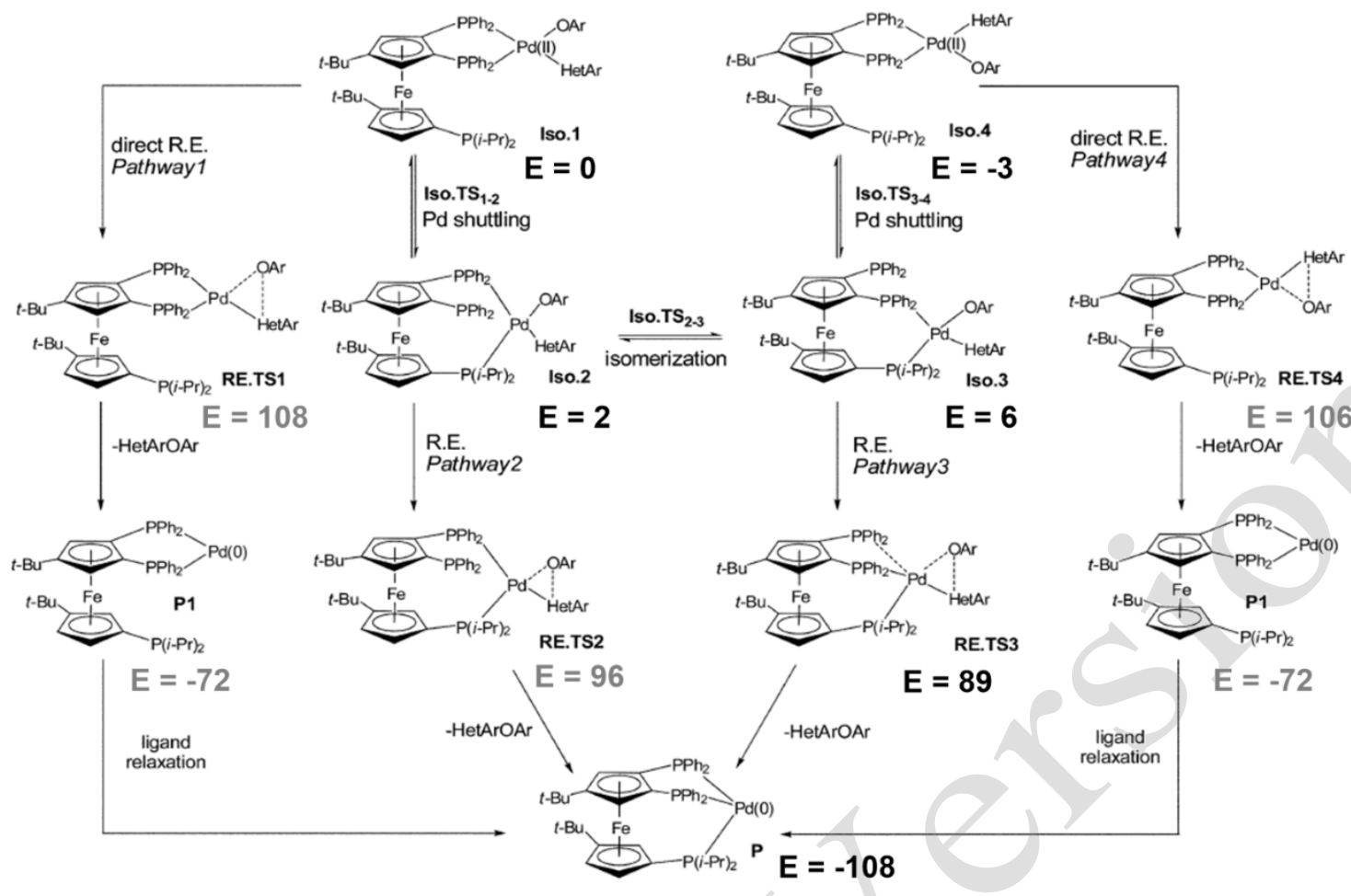

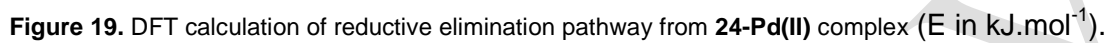

Because of their efficiency in $\mathrm{Pd}$-catalyzed $\mathrm{C}-\mathrm{C}$ and $\mathrm{C}-\mathrm{O}$ bond formation, ferrocenyl triphosphines were extended to specimens "ready for immobilization", as we achieved for a number of ferrocenyl tetraphosphines (Fig. 8). The triphosphines 30-35 (Figure 20) were obtained by the assembly of substituted cyclopentadienyl lithium at $\mathrm{FeCl}_{2}$, using the same kind of precursors as E (Fig. 7), together with (phosphino)cyclopentadienyl lithium salts. ${ }^{[39,40]}$

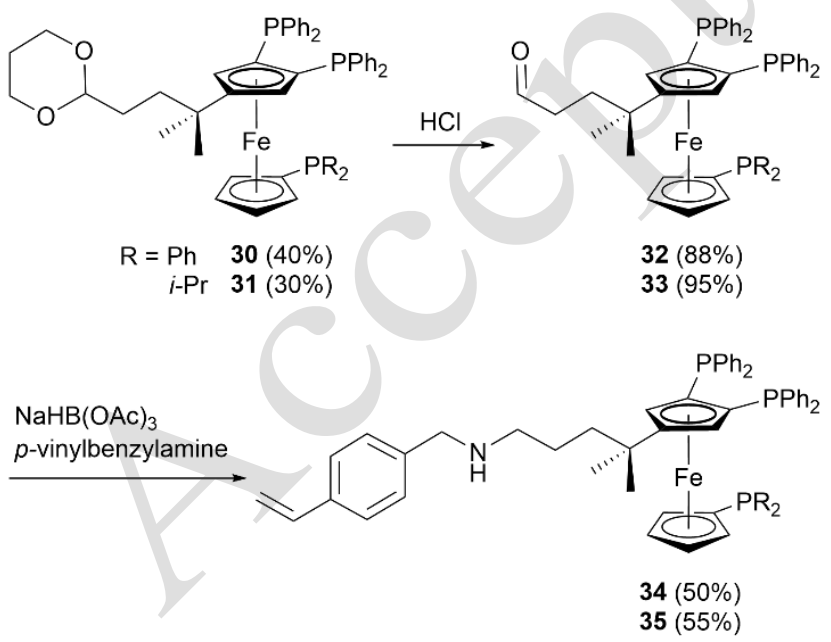

Figure 20. Tail-functionalized triphosphines 30-35 "ready for immobilization" on various supports.

In cooperation with $\mathrm{P}$. Toy group, the functionalized triphosphine $\mathbf{3 5}$ was immobilized by radical-induced copolymerization with styrene (60 equiv) and divinyl benzene (7 equiv) to give an insoluble resin with a $1.05 \%$ phosphorus content. ${ }^{[40]}$ This heterogenization strategy was applicable to the entire class of triphosphine ligands (and tetraphosphines), and which contain the 1,2-bis(diphenylphosphino)-4-tert-

butylcyclopentadienyl fragment. The resulting polystyrene supported ligand 35-PS has been engaged in palladiumcatalyzed cross-coupling by direct $\mathrm{C}-\mathrm{H}$ functionalization, and in copper-free Sonogashira coupling of bromobenzene with phenylacetylene (Figure 21). ${ }^{[40]}$ In general, the resulting cumulative turnover numbers, TONs ranging $270-1700$, of the catalysts were satisfactory relative to their homogeneous counterparts when used with chloroarenes, and showed good potential for recycling. The unsupported analogues yielded TONs over $10^{4}$ with bromides under homogeneous conditions, which was not reached by the supported ligands to date. Indeed, efficient recycling of the catalysts after six runs cannot be established because of accumulative loss of material during filtration. Overall, we described an efficient strategy for assembling a new class of branched tetra- and triphosphine ligands with a unique rigid conformation of ferrocene providing a high local density of phosphorus atoms for an extended coordination to the metal center. This study provided proof-ofconcepts of supported catalytic materials built from modular polyphosphines to generate polydentate heterogeneous catalysts both active for $\mathrm{C}-\mathrm{C}$ cross-coupling reactions and even very challenging $\mathrm{C}-\mathrm{H}$ functionalization from chloroarenes.

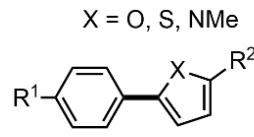

TONs up to 136

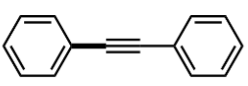

cumulative TON 554 after 3 runs

Figure 21. Polystyrene supported 35-PS in palladium catalyzed arylation of heteroarene and Sonogashira coupling.

While highly functionalized ferrocenyl polyphosphines present unique properties, their synthesis mode also encouraged us to develop simpler, more easily accessible ferrocenyl diphosphines. Still the search for conformation control and pertinent ring 
additional modifications ultimately led to the development of different classes of tetrasubstituted ferrocenyl diphosphines.

\subsection{Diphosphines - 1,1'-diphosphine alkylated symmetric specimens}

The direct functionalization of the ferrocene backbone most generally enables the synthesis of two big families of diphosphines, which can be distinguished as either 1,1'homoannular and 1,2-heteroannular diphosphines, depending on the place of the phosphorus atoms substitution on the $\mathrm{Cp}$ rings.

The commonly developed 1,1'-homoannular ferrocenyl diphosphines bear two identical phosphino groups on each ring (dppf is the typical example). Compound $\mathbf{3 6}$ was the first specimen of highly functionalized symmetric ferrocenyl diphosphines which was synthesized in Dijon laboratories in the 1990s. ${ }^{[56]}$ This ferrocene derivative was obtained in moderate yield $(46 \%)$ by reacting the tetramethylated (diphenyl)phosphino Cp ring $\mathbf{G}$ with $\mathrm{FeCl}_{2}$ (Figure 22). ${ }^{[57]}$

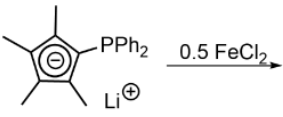

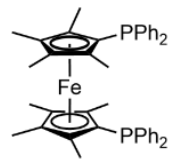

$36(46 \%)$
Figure 22. Synthesis of diphosphine 36 .

The phosphine oxide derived from $\mathbf{3 6}$ has shown good activity as phase-transfer catalyst in nucleophilic substitution reactions of alkyl halides with potassium iodide or thiocyanate. ${ }^{[58]}$ The complexation of 36 with groups 6 and 7 transition metals $\mathrm{Cr}$, Mo, $\mathrm{W}$, and $\mathrm{Mn}$ displayed a variety of monoligate and bridging or chelating biligate coordination (Figure 23). ${ }^{[58]}$

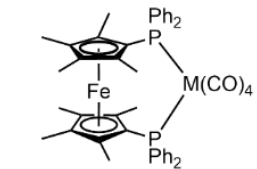

[36- $\left.\mathrm{MCO}_{4}\right] \mathrm{M}=\mathrm{Cr}, \mathrm{Mo}, \mathrm{W}$

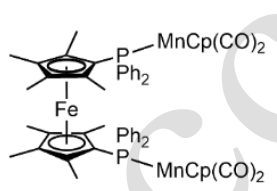

[36- $\left.\mathrm{Mn}_{2} \mathrm{Cp}_{2}(\mathrm{CO})_{4}\right]$

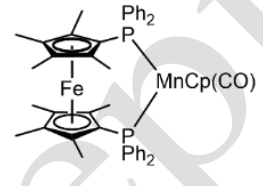

[36-MnCp(CO)]

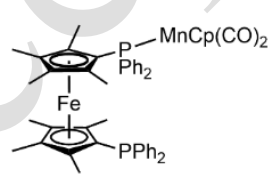

[36- $\mathrm{MnCp}(\mathrm{CO})_{2}$ ]
Figure 23. Different coordination modes of diphosphine 36

However, the synthesis of the precursor $\mathrm{Cp}$ ring $\mathbf{G}$, was found tedious and therefore dialkylated ferrocenyl diphosphines were developed by our group following this pioneering work.

To produce 1,1'-heteroannular diphosphines with dialkylated ferrocene backbone two synthetic pathways are accessible, which are distinguished as "converging" and "diverging" pathway (Figure 24). The converging way is illustrated by the assembly synthesis of 36 , while the diverging way is based on the postfunctionalization of a preexisting dialkyl ferrocene. The presence in 1,3-position of two substituents on each $\mathrm{Cp}$ ring induces the formation of two diastereoisomers, a chiral compound in racemic mixture (rac) and the achiral meso stereoisomer (Figure 24).
1) Converging pathway

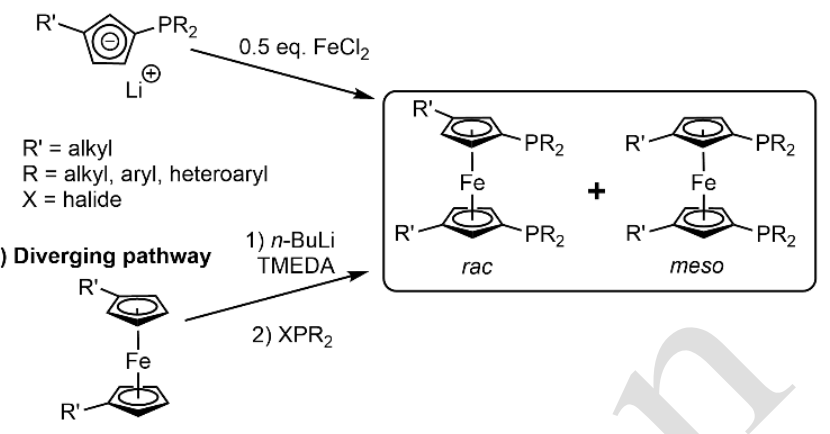

Figure 24. Synthetic access to alkylated 1,1'-heteroannular ferrocenyl diphosphines.

Bis(phosphino)ferrocenes 37-39, bearing bulky groups such as tert-butyl and $-\mathrm{OSi}(i-\mathrm{Pr})_{3}$ on the $\mathrm{Cp}$ rings were obtained using a converging method (Figure 25). The assembling of $C p$ salts $\mathbf{L}$, $\mathbf{M}$, and $\mathbf{S}$ provided the expected mixture of rac and meso diastereoisomers. ${ }^{[31,44,57]}$ Diastereomers $\mathbf{3 7}$ and $\mathbf{3 7}$ ' were separated by column chromatography, while 38 and 39 could not be easily separated from achiral $38^{\prime}$ and $39^{\prime}$, respectively.

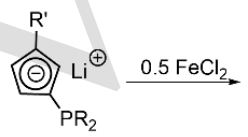

L, M, S

$\mathrm{R}^{\prime}=t-\mathrm{Bu}, \mathrm{R}=\mathrm{Ph}(\mathrm{L})$

$\mathrm{R}^{\prime}=t-\mathrm{Bu}, \mathrm{R}=i-\operatorname{Pr}(\mathrm{M})$

$\mathrm{R}^{\prime}=i-\mathrm{Pr}_{3} \mathrm{SiO}, \mathrm{R}=\mathrm{Ph}(\mathbf{S})$

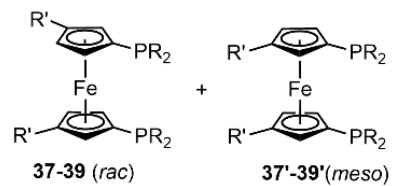

$\mathrm{R}^{\prime}=t-\mathrm{Bu}, \mathrm{R}=\mathrm{Ph}, 37(9 \%)$ and $\mathbf{3} 7^{\prime}(14 \%)$

$\mathrm{R}^{\prime}=t-\mathrm{Bu}, \mathrm{R}=i-\mathrm{Pr}, \mathbf{3 8}(6 \%)$ and $\mathbf{3 8}^{\prime}(36 \%)^{*}$

$\mathrm{R}^{\prime}=i-\mathrm{Pr}_{3} \mathrm{SiO}, \mathrm{R}=\mathrm{Ph}, 39(27 \%)$ and $39^{\prime}(27 \%)^{*}$
* the two isomers were obtained as a mixture, yields are calculated based on ${ }^{31} \mathrm{P}$ NMR

Figure 25. Synthesis of ferrocenyl diphosphine 37-39 by cyclopentadienyl $(\mathrm{Cp})$ rings assembling method. Pure rac isomers synthesis (see below) and XRD allowed the identification of stereoisomers. ${ }^{[31,44,57]}$

Ferrocenyl diphosphines 40'-42' bearing a (triphenyl)methyl group (trityl) on $\mathrm{Cp}$ rings were also synthesized by the converging way. ${ }^{[46]}$ The trityl group on $\mathrm{Cp}$ rings decreases the global nucleophilicity of the ring and generates a significant steric hindrance. For an unclear reason, probably related to the hindrance of trityl groups, compounds $40^{\prime}$ and $41^{\prime}$ were obtained as a single meso diastereoisomer, while the mixture $\mathbf{4 2}$ and $\mathbf{4 2}^{\prime}$ was not resolved (Figure 26).
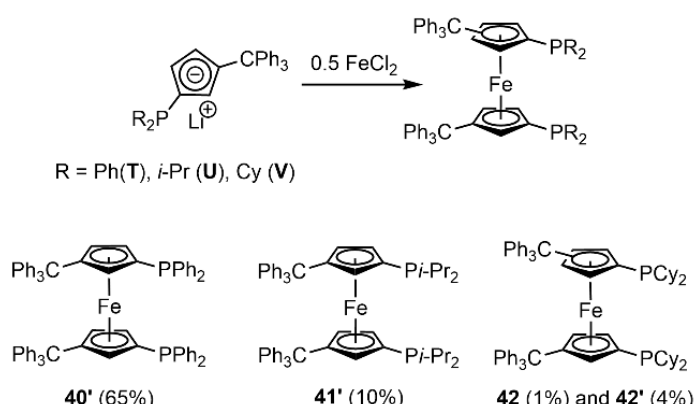

the two isomers were obtained as a mixture, yields are calculated based on ${ }^{31} \mathrm{P}$ NMR Figure 26. Ditrityl substituted ferrocenyl diphosphines. ${ }^{[46]}$

The complexation of $40^{\prime}$ with $\left[\mathrm{PdCl}-\left(\eta_{3}-\mathrm{C}_{3} \mathrm{H}_{5}\right)\right]_{2}$ produced [40'$\mathrm{Pd}($ allyl)Cl] in quantitative yield (Figure 27$) \cdot{ }^{[46]}$ The ${ }^{31} \mathrm{P}$ variable- 
temperature NMR (VT-NMR) experiment of [40'-Pd(allyl)Cl] in $\mathrm{CD}_{2} \mathrm{Cl}_{2}$ showed at $298 \mathrm{~K}\left(25^{\circ} \mathrm{C}\right)$ two overlapping singlets located at 21.1 and $21.5 \mathrm{ppm}$. Upon heating at $318 \mathrm{~K}\left(45^{\circ} \mathrm{C}\right)$, these two singlets coalesce into a singlet at $21.3 \mathrm{ppm}$ attributed to the rapid dynamic exchange between the anisochronous phosphorus. Upon cooling to $278 \mathrm{~K}\left(-20^{\circ} \mathrm{C}\right)$, the exchange phenomenon slowed down, resulting in an $A B$ spin system centered at $21.2 \mathrm{ppm}$ with a $J_{\mathrm{AB}}=46 \mathrm{~Hz}$. This dynamic behavior remind the fluxionality also observed in the tetraphosphine ferrocenes (Fig. 5), showing the relationship between these ferrocenyl phosphine metal/allyl derivatives.
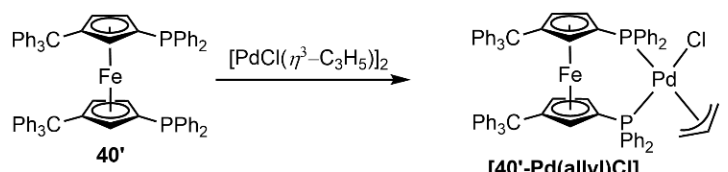

[40'-Pd(allyl)Cl]

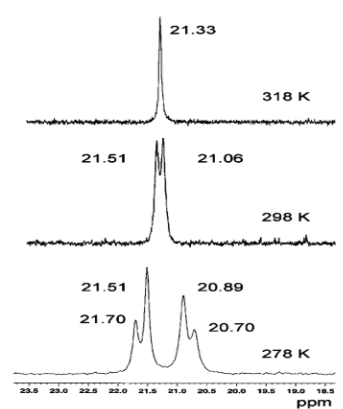

Figure 27. Complexation of $40^{\prime}$ with palladium and ${ }^{31} \mathrm{P}$ VT-NMR $\left(\mathrm{CD}_{2} \mathrm{Cl}_{2}\right)$ experiments.

The ferrocenes $40^{\prime}-42$ ' were tested in the palladium-catalyzed arylation of aromatic heterocycles via $\mathrm{C}-\mathrm{H}$ bond activation (Figure 28).$^{[44,46]}$ The palladium complex of the diphosphine $40^{\prime}$ was successfully used in the direct $\mathrm{C}-\mathrm{H}$ activation of electronrich heteroaromatics for coupling to demanding aryl bromides, whether electron rich and/or sterically congested. Products such as 2-butyl-5-(4-methoxyphenyl)furan, 2-butyl-5-o-tolylfuran, and thiophene analogues were obtained in yields higher than $90 \% .{ }^{[32]}$ We further demonstrated the higher performance of the electronrich diphosphines $\mathbf{4 1}$ ' and $\mathbf{4 2 / 4 2}$ ' (in diasteromeric mixture) in the arylation of substituted furans with functionalized electrondeficient aryl chlorides, such as 4-chlorobenzonitrile, 4chloronitrobenzene, 4-chloropropiophenone, and 4(trifluoromethyl)chlorobenzene. The performances illustrate the utility of air-stable, moisture-insensitive alkylated electron-rich diphosphines in this specific arylation reaction. We assumed by comparison with other ferrocenyl di- and triphosphines that these ligands promote oxidative addition, because of electronrich alkylated-P donors and that the large bite angle that is associated to 1,1'-phosphorus-chelating coordination may facilitate reductive elimination at palladium.

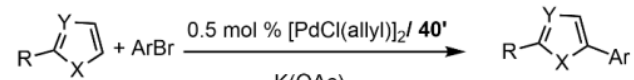

$$
\begin{aligned}
& \mathrm{X}=\mathrm{O}, \mathrm{S}, \mathrm{Y}=\mathrm{CH}, \mathrm{N} \quad \mathrm{K}(\mathrm{OAC}) \quad \mathrm{R}=n-\mathrm{Bu}, i-\mathrm{Pr} \\
& n-\mathrm{Bu}\left\langle\mathrm{O}+\mathrm{ArCl} \frac{1 \mathrm{~mol}^{2} \mathrm{POAc}_{2} / \mathbf{4 1} \text { or } \mathbf{4 2 / 4 2}}{\mathrm{K}(\mathrm{OAC})} n-\mathrm{Bu}\right.
\end{aligned}
$$

Figure 28. Pd-catalyzed $\mathrm{C}-\mathrm{H}$ arylation of heteroaromatics with bromo and chloroarenes using diphosphine ligands 40', 41', 42/42
We were pleased to recently achieve the diasterereoselective synthesis of a new series of dialkylated ferrocenyl diphosphines bearing aryl, alkyl and hetero- or polycyclic substituents on the phosphorus atom (Figure 29). ${ }^{[59]}$ The diverging synthetic route was beneficially employed and was unexpectedly selective. Apparently, the steric effect of the substituents present on the ferrocene platform has a significant influence on the stereoselectivity during the lithiation (with a presumed joint structuring role of tert-butyl and TMEDA) and phosphination steps. The tert-butylated ferrocenyl diphosphines $\mathbf{3 7}, \mathbf{3 8}$ and $\mathbf{4 4}$ 47 were synthesized as pure rac stereoisomer in good to excellent yields (42-88\%, Fig. 29) from the alkylated precursor 43a.

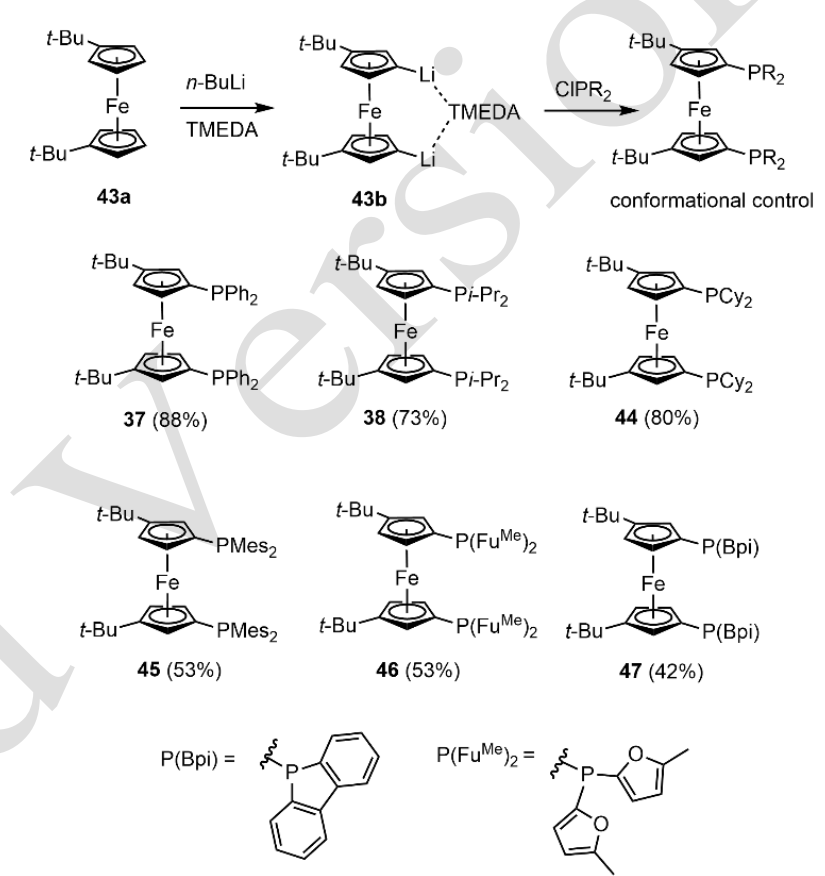

Figure 29. Diastereoselective synthesis of ferrocenyl diphosphines $\mathbf{3 7}, \mathbf{3 8}$ and 44-47 by sequential lithiation/phosphination of dialkylated ferrocene.

For compounds $\mathbf{3 7}$ and $\mathbf{3 8}$ the converging synthetic pathway gave the mixture of rac + meso diastereoisomers in moderate to low yield (23-42\%, Fig. 25), but these phosphines are obtained as pure rac diastereoisomers in much higher yield of $88 \%$ and $73 \%$, respectively, from a lithiation/phosphination sequence (Fig. 29). Compounds $\mathbf{4 4 - 4 7}$ are obtained in satisfactory yield despite the low stability of some of the corresponding phosphination agents under the reaction conditions. Thus, the postfunctionalization of the tert-butylated ferrocene platform constitutes a powerful strategy for the diastereoselective synthesis of symmetrically substituted 1,1'-diphosphines. Accordingly, the analogous compounds holding $i-\operatorname{Pr}$ groups, 50 and 51, and trimethylsilyl (TMS), 52 and 53, have also been synthesized from ferrocene post-functionalization (Figure 30). ${ }^{[59,60]}$ Compounds $\mathbf{5 0}$ and $\mathbf{5 1}$ were synthesized from precursor $\mathbf{4 8 a}$ in two steps, and $\mathbf{5 2}$ and $\mathbf{5 3}$ obtained in a one-pot protocol from $49 a$, without isolating the intermediate $49 \mathrm{~b}(35 \%$ and $33 \%$ overall yields, respectively). The introduction of less congested $i$-Pr group on the ferrocene platform decreases the diastereoselectivity of the reaction leading to the formation of a diasteroisomeric mixture of $\mathbf{5 1}$ and $\mathbf{5 1}$ ', confirming the unique role of tert-butyl groups. 
The bis(phosphino)ferrocenes 37,38 and their analogs $44-47$ and 50-53 were all tested in the substitutive nucleophilic fluorination of 2-chloroquinoline and chloropyridine derivatives using mild palladium-catalyzed conditions.

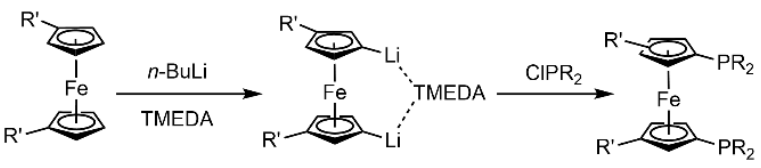
$\begin{array}{ll}\mathrm{R}^{\prime}=j-\operatorname{Pr}(\mathbf{4 8 a}) & \mathrm{R}^{\prime}=j-\operatorname{Pr}(\mathbf{4 8 b}), 68 \% \\ \mathrm{R}^{\prime}=\operatorname{TMS}(\mathbf{4 9 a}) & \mathrm{R}^{\prime}=\operatorname{TMS}(\mathbf{4 9 b})\end{array}$

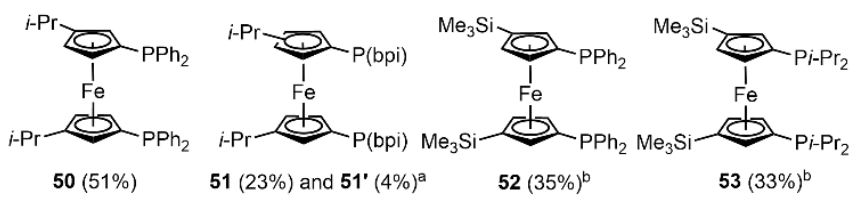

a the two isomers were obtained as a mixture, yields are calculated based on ${ }^{31} \mathrm{P}$ NMR b overall yields

Figure 30. Alkylated diphosphines 50-53 holding $i$-Pr and TMS groups.

Among these diphosphines, $\mathbf{3 7}$ (Fig. 29) is the most effective for assisting transhalogenation by using $\mathrm{AgF}$ as nucleophilic $\mathrm{F}^{-}$ source. However, to our surprise the complete removal of palladium in the reaction much reduces detrimental side reactions such as dehalogenation and homocoupling, and also avoids the facile fluorination of the phosphorus atoms $\left(\delta^{31} \mathrm{P}\right.$ 45.12, and $\delta^{19} \mathrm{~F}-73.29 \mathrm{ppm}$, with ${ }^{1} J_{\mathrm{P}, \mathrm{F}}=1020 \mathrm{~Hz}$ ). Finally using palladium-free conditions with bis(phosphino)ferrocenes clearly assured, in our hands, a better reproducibility of fluorination. This nucleophilic transhalogenation albeit of limited scope avoided strictly anhydrous conditions and the use of highly specialized fluorination reagents. ${ }^{[59]}$

The complexation of some of these 1,1'-diphosphines with gold(I) halide were studied, in view of further extension to goldcatalyzed reactions related to dinuclear species and the promotion of a better control in generating $\mathrm{Au}$...A Au aurophilic interactions. tert-Butylated diphosphines meso $37^{\prime}$ and rac 46 (Fig. 25 and 29) were reacted with two equivalents of $\left[\mathrm{AuCl}(\mathrm{SMe})_{2}\right]$ quantitatively yielding dinuclear gold (I) species $\left[37^{\prime}-\mathrm{Au}_{2} \mathrm{Cl}_{2}\right.$ ] and $\left[46-\mathrm{Au}_{2} \mathrm{Cl}_{2}\right.$ ], respectively (Figure 31 ). ${ }^{[31]}$ Based on XRD structure in the solid state and ${ }^{31} \mathrm{P}$ NMR in solution at $-80^{\circ} \mathrm{C}$ complex $\left[37^{\prime}-\mathbf{A u}_{2} \mathbf{C l}_{2}\right.$ ] formed the expected dinuclear complex with an intramolecular aurophilic interaction $A u \cdots A u^{\prime}$ showing a $d_{A u \cdots A u^{\prime}}=3.0781(6) \AA . . A n$ aurophilic interaction was also observed in $\left[46-\mathbf{A u}_{2} \mathbf{C l}_{2}\right]$ with a distance $\mathrm{Au} \cdots \mathrm{Au}^{\prime}$ slightly longer $\mathrm{d}_{\mathrm{Au} \cdots \mathrm{Au} u^{\prime}}=3.2349(6) \AA$ (Fig. 31). ${ }^{\left[{ }^{[1]}\right.}$ Compared to dppf, the introduction of tert-butyl groups induces a smart steric control of the metallocene backbone in bis(phosphino)ferrocene ligands which favors intramolecular aurophilic interactions between $[\mathrm{AuCl}]$ fragments in dinuclear gold(I) complexes.

The complexation of the diastereomeric mixture of 39/39' with two equivalents of $\left[\mathrm{AuClSMe}_{2}\right]$ provided in $1: 1$ ratio the corresponding complexes [39- $\mathbf{A u}_{2} \mathrm{Cl}_{2}$ ] and [39'- $\mathbf{A u}_{2} \mathrm{Cl}_{2}$ ]. The complex [39- $\mathbf{A u}_{2} \mathrm{Cl}_{2}$ ], from rac 39 , crystallized independently, and could be isolated pure in $40 \%$ yield. The XRD analysis shows that it belongs to the C2-symmetry point group. The orientation of the phosphino groups displays a large torsion angle that precludes short contact distances and induces gold centers separation above $6.0 \AA$ (Fig. 31). Unlike tert-butyl groups, lesser steric control exerted by $-\mathrm{OSi}(i-\mathrm{Pr})_{3}$ groups was attributed to the oxygen atom, seen as a spacer, which presumably add a rotational degree of freedom to the ferrocene platform. Current studies of these dinuclear gold complexes aim at their use in catalytic reactions including $\mathrm{C}-\mathrm{C}$ bond formation by cross-coupling and enynes cycloaddition.

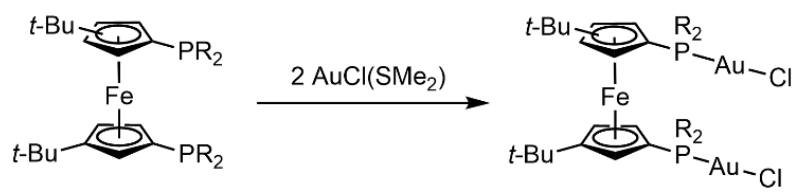

$37^{\prime}, 46,\left(39+39^{\prime}\right)$

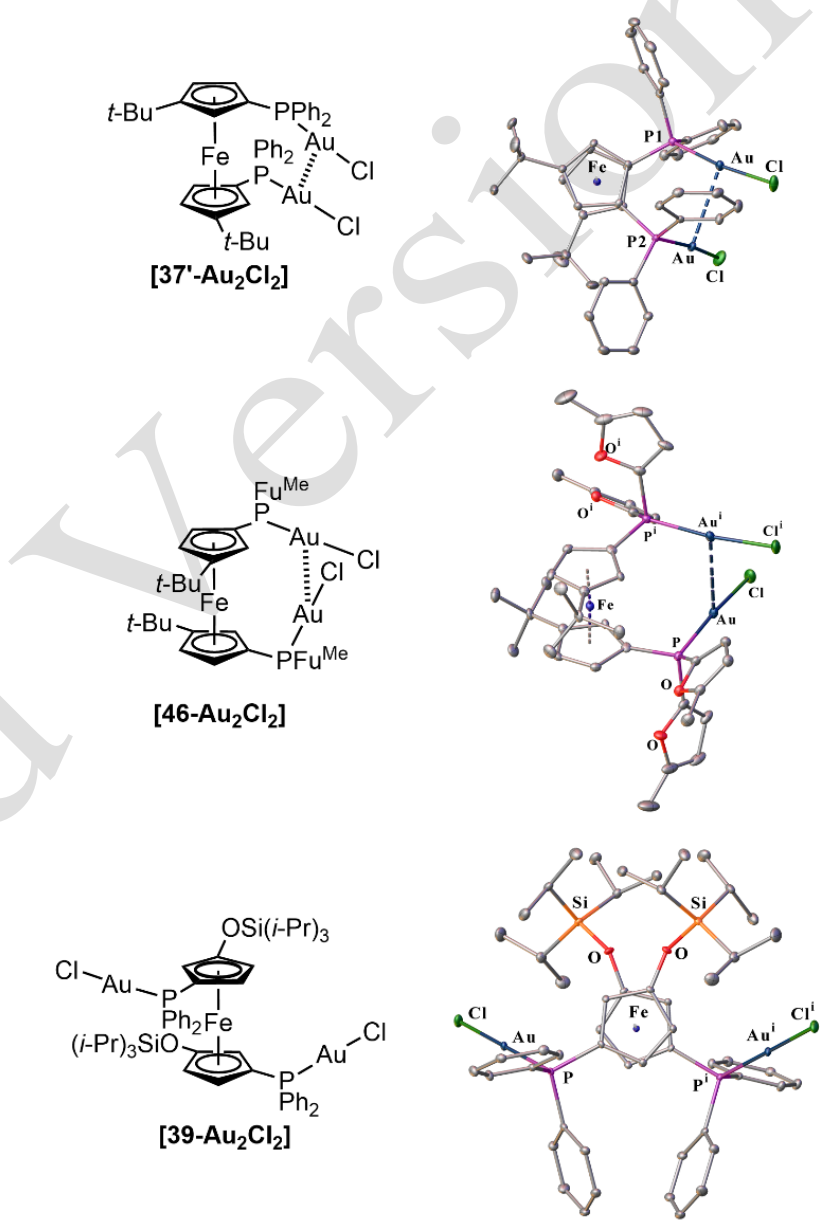

Figure 31. Dinuclear gold(I) chloride bis(phosphino)ferrocene complexes illustrating aurophilic and non-aurophilic situations (ORTEP views, right) [symmetry transformations: (i) $-\mathrm{x},+\mathrm{y}, 3 / 2-\mathrm{z}\left(\left[\mathbf{4 6}-\mathrm{Au}_{2} \mathrm{Cl}_{2}\right]\right)$ and $1-\mathrm{x},+\mathrm{y}, 1 / 2-\mathrm{z}$ $\left.\left(\left[39-\mathrm{Au}_{2} \mathrm{Cl}_{2}\right]\right)\right]$.

\subsection{Diphosphines - 1,1'-dissymetrically substituted specimens}

For producing dissymmetric 1,1'-diphosphino substituted ferrocene derivatives the direct phosphination of the ferrocenyl backbone can be employed via opening of ferrocenophane $54 \mathrm{~b}$ (Figure 32). Our group reported the synthesis of unconstrained dissymmetric ferrocenyl diphosphine 55, which bears both the electron-rich $-\mathrm{PPh}_{2}$ and electron-poor $-\mathrm{P}\left(\mathrm{Fu}^{\mathrm{Me}}\right)_{2}$ groups. ${ }^{[61]}$ Compound $\mathbf{5 5}$ was obtained in a modest $25 \%$ yield from $\mathbf{5 4 c}$ (Fig. 32) because its hydrolysis product mostly formed (40\%). Upon complexation to transition metals such compounds are expected to display some hemilabile behavior with possible 
beneficial effects in catalytic reactions. Thus, the complex [55$\mathrm{PdCl}_{2}$ ], obtained from the reaction of 55 and $\mathrm{PdCl}_{2}(\mathrm{PhCN})_{2}$, was engaged in palladium catalyzed allylic amination. ${ }^{[61]}$ In the presence of a low concentration of this complex as catalyst, used at $0.01 \mathrm{~mol} \%$, the coupling of aniline to allyl acetate occurs at a TOF (turnover frequency) of ca $5000 \mathrm{~h}^{-1}$. Allyl amines were produced in good to high yields (75 to 99\%) and excellent linear/branched selectivity (94/6\%) when applicable, with for instance hex-2-en-1-yl acetate reacted with piperidine and morpholine. The addition of the less nucleophilic morpholine to allyl acetate was achieved with a TOF of $3330 \mathrm{~h}^{-1}$. The amination of the sterically demanding geranyl acetate, a monoterpene derivative of interest in the flavor industry demonstrated the scope of this methodology, which provided noticeable advantages in terms of sustainable chemistry with high selectivity, and low metal content reactions. ${ }^{\left[{ }^{[1]}\right.}$
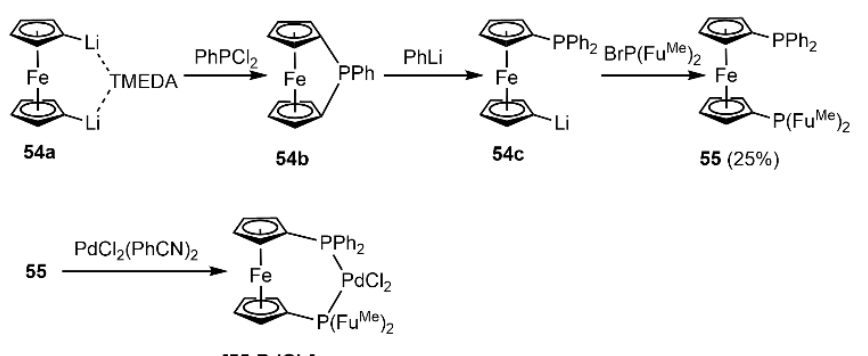

$\left[55-\mathrm{PdCl}_{2}\right]$

Figure 32. Hybrid diphosphine 55 and its complexation to $\mathrm{PdCl}_{2}$.

A similar sequential functionalization starting from alkylated 43a (Fig. 29) led to the formation of the hemilabile constrained ferrocenyl diphosphine 58 (Figure 33), which incorporates both $\mathrm{PPh}_{2}$ and $-{\mathrm{P} i-\mathrm{Pr}_{2}}_{\text {groups. }}{ }^{[62]}$ Sequential ferrocene lithiation/bromination allowed the formation of brominated precursor 56 that is followed by two sequential distinct phosphinations. At larger scale $(30 \mathrm{mmol}$ instead of $1 \mathrm{mmol})$ both the monobromination and hydrolysis side products of $43 a$ were difficult to separate from $\mathbf{5 6}$ by standard chromatography methods. We developed with D. Lucas and C. Devillers group an innovative oxidative purification based on controlled electrolysis. The distinct redox potential of these three ferrocene derivatives allowed the selective oxidation of the two undesired side products, and the aqueous phase extraction of the formed ferrocenium species. This led to isolate $\mathbf{5 6}$ as a pivotal precursor for further functionalization in high purity at multigram scale (> $20 \mathrm{~g}) .{ }^{[62,63]}$

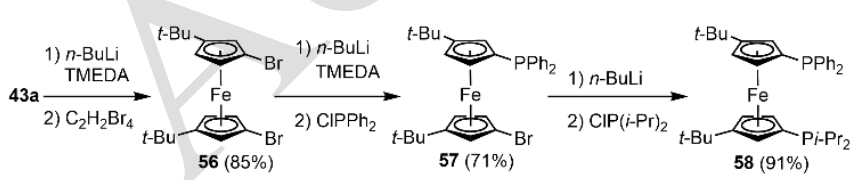

Figure 33. Synthetic pathway of hemilabile ferrocenyl diphosphine $\mathbf{5 8}$.

\subsection{Diphosphines -1,2-diphosphines alkylated specimens}

By converging assembly of pre-synthesized 1,2-phosphinated $\mathrm{Cp}$ rings, the alkylated ferrocenes 59-61 could be prepared albeit in contrasted yields (Fig. 34). Compounds 59 and 60 were early on reported to be obtained in yields around $70 \%,{ }^{[19,57]}$ while in our hands decomposition and/or oligomerization of in situ formed formyl precursor gave a limited $20 \%$ yield of 61 (Figure 34). ${ }^{[31]}$ However, the reactivity of the aldehyde group on the bottom $\mathrm{Cp}$ ring gives opportunity for further developing derivatives based on ferrocenyl 1,2-diphosphine structures.

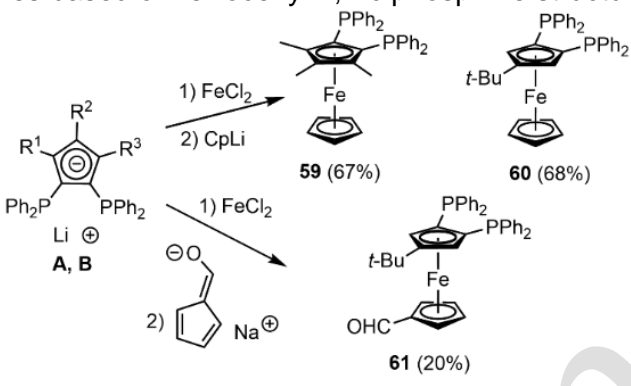

Figure 34. Synthesis of homoannular ferrocenyl diphosphines 59-61.

The coordination of 1,2-diphosphine 59 with metal carbonyl complexes $\mathrm{M}(\mathrm{CO})_{4} \mathrm{~L}_{2}(\mathrm{M}=\mathrm{Cr}, \mathrm{W}$ and $\mathrm{L}=$ norbornadiene or piperidine) gave the corresponding group 6 transition metal complexes in excellent yield [59-W(CO) $\left.)_{4}\right]$ and $\left[59-\mathrm{Cr}(\mathrm{CO})_{4}\right]$ (Figure 35). ${ }^{[19]}$

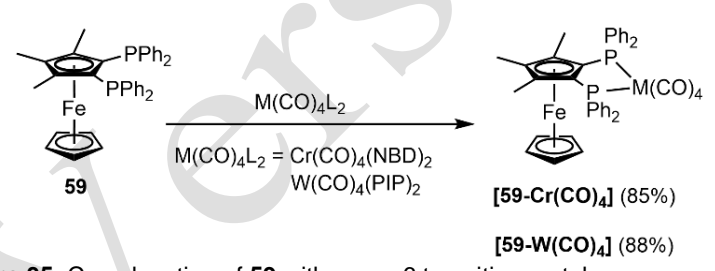

Figure 35. Complexation of $\mathbf{5 9}$ with group 6 transition metals.

The coordination chemistry of 1,2-diphosphine $\mathbf{6 0}$ with palladium and rhodium was studied (Figure 36). Palladium complex [60$\mathrm{PdCl}_{2}$ ] was obtained by the reaction of 60 with $(\mathrm{PhCN})_{2} \mathrm{PdCl}_{2}$ and its catalytic reactivity was investigated in palladiumcatalyzed olefin methoxycarbonylation and Heck C-C coupling. ${ }^{[65]}$

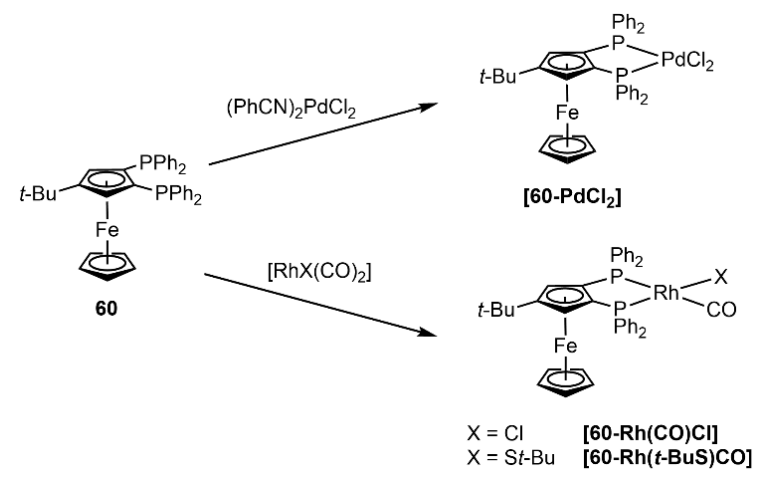

Figure 36. Complexation of 60 with rhodium and palladium

A variety of coordination schemes were obtained in the complexation of 60 with rhodium. The S-bridged dinuclear complex $\left[\mathrm{Rh}(t-\mathrm{BuS})(\mathrm{CO})_{2}\right]_{2}$ reacted with the ferrocenyl diphosphine 60 did not conserve the usual dinuclear framework and provided a mononuclear compound [60-Rh(t-BuS)CO]. The complex $[\mathbf{6 0}-\mathbf{R h}(\mathbf{C O}) \mathbf{C l}]$ was formed from the reaction of $\mathbf{6 0}$ with $\left[\mathrm{RhCl}(\mathrm{CO})_{2}\right]_{2}$ under $\mathrm{CO}$ atmosphere. In the absence of $\mathrm{CO}$ partial pressure, the reaction between 60 and the Rh precursor lead to the additional formation of cationic rhodium complex in cis and trans isomers mixture 62a and 62b (Figure 37). These cationic species were isolated from $[60-\mathbf{R h}(\mathbf{C O}) \mathbf{C l}]$ by precipitation, with $\left[\mathrm{RhCl}_{2}(\mathrm{CO})_{2}\right]^{-}$as counter ion. Complexes 62c and $\mathbf{6 2 d}$ were also obtained with chloride counter ions, by the 
addition of an excess of ferrocenyl diphosphine 60 to the rhodium precursor $\left[\mathrm{RhCl}(\mathrm{CO})_{2}\right]_{2}{ }^{[65]}$

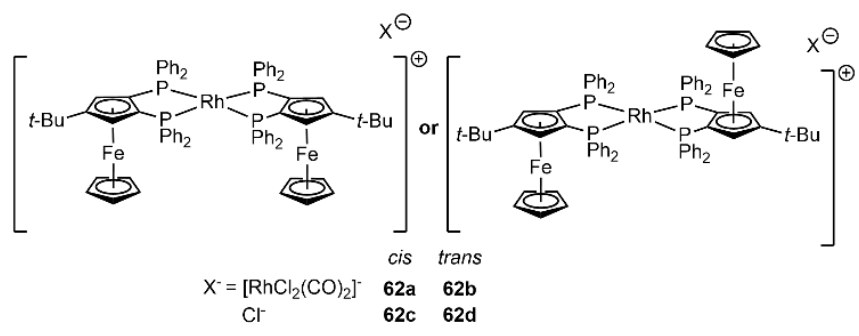

Figure 37. Cationic rhodium complexes $62 a-d$

Rhodium complexes [60-RhCl(CO)] and [60-Rh(t-BuS)CO] were employed in the catalytic hydroformylation of oct-1-ene, with a yield of aldehydes up to $96 \%$. ${ }^{[6]}$

\section{Ferrocenyl Amines and ( $P, N)$-Hybrids}

Based on the impetus provided by dialkylated tetraphosphines with a controlled conformation at the ferrocene platform, we developed the synthesis of polydentate aminomethyl ferrocenes and amino-phosphino ferrocenes also bearing tert-butyl groups on each $\mathrm{Cp}$. We first explored a converging way by cyclopentadienyl assembly, but the stereoselectivity control and the mixture of diastereomers formed needed too long separation procedure and limited the yield. We consequently explored a diverging way to obtain these ferrocenes with a high diastereoselectivity. ${ }^{[66]}$ This approach was initiated with the formation of aminomethyl and iminomethyl ferrocene derivatives.

\section{1. tert-Butylated aminomethyl ferrocenes and iminomethyl ferrocenes ligands}

The targeted tert-butylated aminomethyl ferrocene $\mathrm{N}$-ligands were distinguished as secondary and tertiary amine derivatives (Figure 38).
Secondary aminomethyl ferrocene<smiles>CCCCNCc1ccc(C(C)(C)C)cc1CNCCCC</smiles>

Tertiary aminomethyl ferrocenes<smiles>CCNCc1ccc(CNCC)c(POC(C)(C)C)c1</smiles><smiles>CC(C)(C)c1ccc(CN2CCCC2)c(CN2CCCC2)c1</smiles><smiles>CC(C)(C)c1ccc(CN2CCCCC2)c(CN2CCCCC2)c1</smiles><smiles>CC(C)(C)Oc1cc(C(C)(C)C)ccc1CN(Cc1ccccc1)Cc1ccccc1</smiles>

Iminomethyl ferrocene

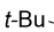<smiles>[131In]</smiles>
$\mathrm{Fe}$

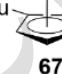

Figure 38. tert-Butylated amino and iminomethyl ferrocenes.

The secondary and tertiary aminomethyl ferrocenes $\mathbf{6 2 - 6 6}$ bear alkyl groups on each nitrogen atom. Compounds 62, 63 and 66 includes acyclic alkyl groups of different steric size at nitrogen with ethyl, butyl and benzyl groups, and diamines 64 and 65 , hold cycloalkyl groups. The iminomethylferrocene 67 bears a long-chain butyl group. These ferrocene derivatives were synthetized by reductive amination from the diformylferrocene 68, obtained in two steps from 43a with a full diastereoselectivity confirmed by XRD (Figure 39). After lithiation and formylation of 43a, the resulting compound 68 was reacted with primary or secondary amines and reduced using $\mathrm{NaHB}(\mathrm{OAc})_{3}$, which allowed the selective formation of diamines 63-66 in very good to high yields $(74-96 \%) .{ }^{[66]}$ As for the synthesis of diphosphinoferrocenes presented before, this functionalization way offers a high diastereoselectivity with the exclusive formation of rac stereoisomers.

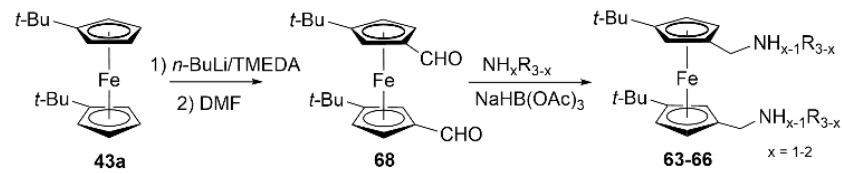

Figure 39. Synthesis of tert-butylated aminomethyl ferrocene derivatives. 
The synthesis of secondary aminomethylferrocene $\mathbf{6 2}$ is similar to 63-66 however, with the use of 3/1 ratio of amine/aldehyde (Figure 40). $\mathrm{LiAlH}_{4}$ was used for reducing the iminomethyl ferrocene 67 , leading to the secondary amine 62 with a high yield of $95 \%$. ${ }^{[66]}$

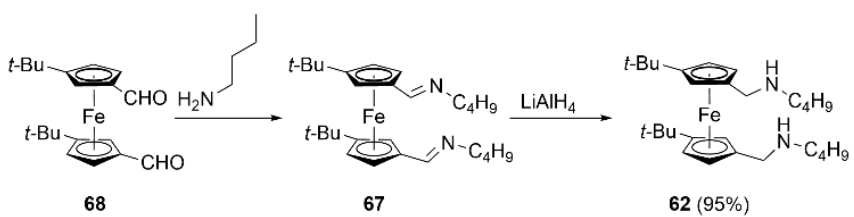

Figure 40. Synthesis of a tert-butylated secondary aminomethyl via an iminomethyl ferrocene.

A direct consequence of the introduction of $t$-Bu groups on the ferrocene platform was obtained by the coordination chemistry of 63 to $\left[\mathrm{PdCl}_{2}(\mathrm{PhCN})_{2}\right]$ (Figure 41). ${ }^{[66]}$ The spontaneous formation of a zwitterionic cyclopalladate 69 from $\mathrm{C}-\mathrm{H}$ activation and nitrogen attack to form ammonium was observed that does not occur with analogue non-tert-butylated diaminoferrocenes. Zwitterionic cyclopalladate formation from an (aminomethyl)ferrocene derivative, arising from intramolecular $\mathrm{Cp}$-proton transfer to the proximate free amino group by simple $\mathrm{C}-\mathrm{H}$ activation reaction in the presence of palladium dichloride was unprecedented. This reactivity was attributed both to electronic effects and steric control of tert-butyl groups. The flexibility of nitrogen arm at the bottom $\mathrm{Cp}$ rings probably also allows this cyclopalladate easy formation.

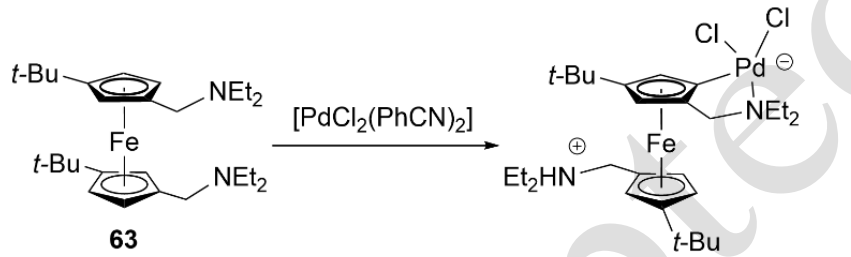

69

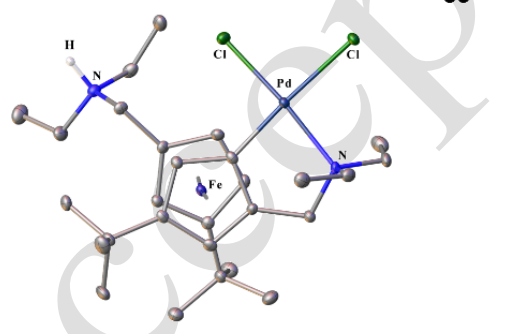

Figure 41. Intramolecular cyclopalladation of the diamine 63.

From these tert-butylated aminomethyl ferrocenes, the synthesis of tert-butylated amino phosphino ferrocenes ligands by a postfunctionalization strategy could be efficiently achieved.

\section{2. tert-Butylated (N)-amino-(P)-phosphino ferrocene ligands}

The synthesis of tert-butylated diamino diphosphino ferrocene ligands was attractive because of the possibility of coordination of both phosphorus and nitrogen atoms with transition metals. Therefore, the « soft » group (phosphine) and the « hard » group (amine) could be used as hemilabile system in catalytic reactions. ${ }^{[67]}$ The various acyclic $(\mathbf{7 0 - 7 3})$ and cyclic $(74)$ amino groups we originally introduced, were complemented with a panel of phosphino groups bearing either electron-donating or electron-withdrawing groups of various steric hindrance (Figure 42, 71-74).

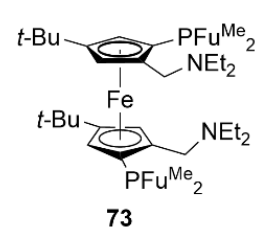

73<smiles>CN(CCc1ccccc1)c1ccccc1C(C)(C)C</smiles>
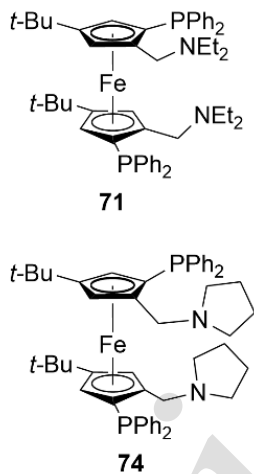

74

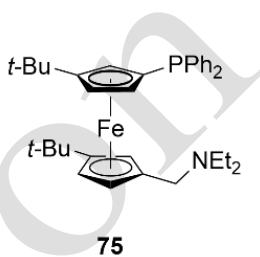

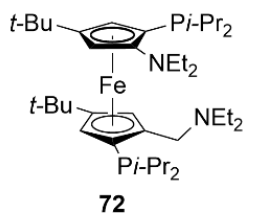

Figure 42. tert-butylated $N$-amino- $P$-phosphino ferrocenes.

Initially, the assembly of adequately substituted $\mathrm{Cp}$ salts was investigated for the formation of alkylated ferrocene $(P, N)$ ligands (Figure 43). ${ }^{[6]}$ Dimethylaminomethylation of (diphenylphosphino)-3-tert-butylcyclopentadienyllithium $\mathbf{L}$ was achieved in a $86 \%$ yield using an iminium salt. The synthesis of the ferrocenes 70/70' was achieved as a 2:1 mixture of rac and meso stereoisomers (39\% overall yields, that crystallized separately and were characterized by XRD and NMR, Fig. 43). ${ }^{[6]}$ In this converging pathway the cyclopentadienyl phosphination precedes its amination. In the diverging way the amination of ferrocene allows directing ortho-lithiation followed by site selective phosphination of the platform, giving for 63 and 64 rac diastereomer with generally satisfactory yields (71-74, Fig. 43). The ${ }^{15} \mathrm{~N}$ NMR measurement of ligands $\mathbf{7 0 - 7 4}$ indicates no significant interaction in solution between phosphorus and nitrogen atoms despite the relative proximity of these nuclei. tertButylated $\mathrm{N}$-amino- $P$-phosphino ferrocene 75 (Fig. 42) has been synthesized by the introduction of the phosphino group in a first step, followed by 1 '-formylation and reductive amination to obtain the hybrid compound 75 in $70 \%$ yield. ${ }^{[62]}$

The complexation of ligands $\mathbf{7 1 , 7 2}$ and $\mathbf{7 4}$ with palladium and gold was reported. The palladium complexation with bis(benzonitrile)palladium(II) chloride unexpectedly showed clearly distinct coordination modes depending on the palladium/ligand ratio and the ligand used. ${ }^{[62,68]}$ With 71 , when one equivalent of $\mathrm{Pd}(\mathrm{II})$ was added, the flexibility of the ferrocene platform allows a 1,1'-(P,P)-heteroannular coordination by the chelating diphosphine ([71-PdCl$\left.{ }_{2}\right]$, Figure 44). Conversely, the use of two equivalents of palladium systematically led to the quantitative formation of a dinuclear palladium compound with bis-1,2-(P,N)-homoannular coordination: [71- $\left.\mathrm{Pd}_{2} \mathrm{Cl}_{4}\right], \quad\left[72-\mathrm{Pd}_{2} \mathrm{Cl}_{4}\right]$ and $\left[74-\mathrm{Pd}_{2} \mathrm{Cl}_{4}\right]$. Conversely, similar attempts to form the mononuclear palladium species from $\mathbf{7 2}$ and $\mathbf{7 4}$ led to mixture of complexes.

Complexation of $\mathbf{7 1}, \quad \mathbf{7 2}$ and $\mathbf{7 4}$ using chloro(dimethylsulfide)gold(I) led to the formation of dinuclear gold complexes [71- $\left.\mathrm{Au}_{2} \mathrm{Cl}_{2}\right],\left[72-\mathrm{Au}_{2} \mathrm{Cl}_{2}\right]$ and [74-- $\mathrm{Au}_{2} \mathrm{Cl}_{2}$ ] (Figure 45). ${ }^{[63]}$ These were all characterized by a single ${ }^{31} \mathrm{P}$ NMR signal, which indicated a symmetric coordination mode involving phosphorus. FT-IR analyses of these complexes revealed the expected absorption bands between $321 \mathrm{~cm}^{-1}$ and $333 \mathrm{~cm}^{-1}$ and 
the XRD structure of [72- $\mathrm{Au}_{2} \mathrm{Cl}_{2}$ ] confirmed a dinuclear gold(I) chloride linear coordination involving exclusively $-\mathrm{P}(i-\mathrm{Pr})_{2}$ groups For the ligand $\mathbf{7 1}$, one equivalent of gold precursor was used in an attempt to obtain a mononuclear complex, but this reaction only led to a 1:1 mixture of the dinuclear complex together with the uncoordinated diaminodiphosphino ferrocene. ${ }^{[69]}$

Converging pathway

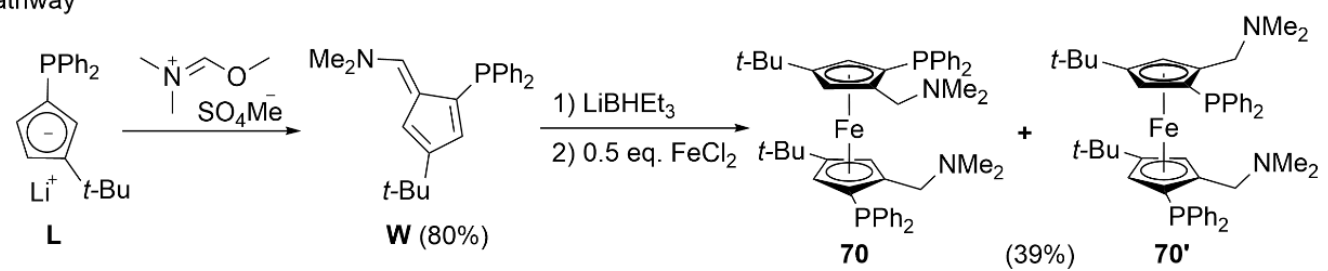

Diverging pathway
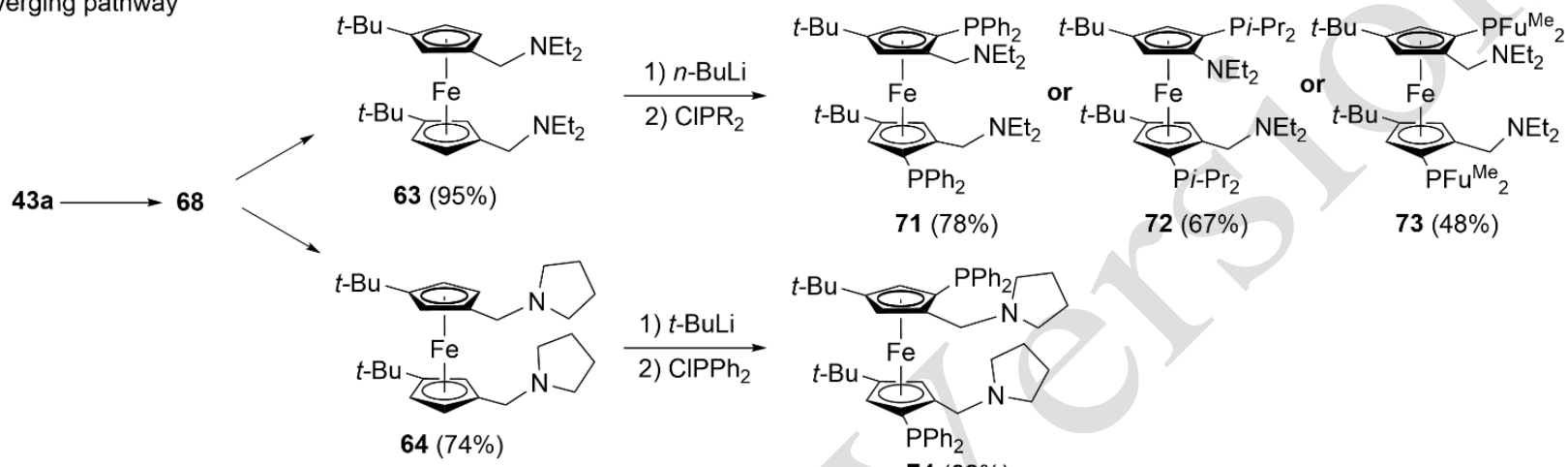

Figure 43. Converging and diverging routes towards hexafunctionalized ferrocene tetradentate $(P, P, N, N)$-ligands.

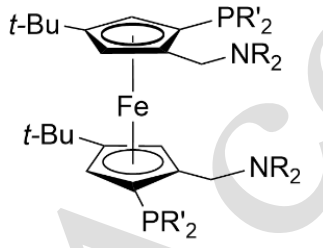

71, 72, 74

$\mathrm{R}=\mathrm{Et},-\mathrm{CH}_{2}\left(\mathrm{CH}_{2}\right)_{2} \mathrm{CH}_{2}$

$\mathrm{R}^{\prime}=\mathrm{Ph}, i-\mathrm{Pr}$

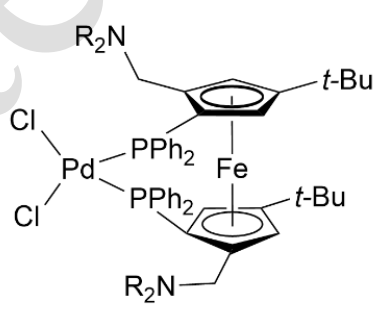

[71-PdCl $]$ (93\%)

$\left[74-\mathrm{PdCl}_{2}\right](97 \%)$

$\left[\mathrm{PdCl}_{2}(\mathrm{PhCN})_{2}\right]$

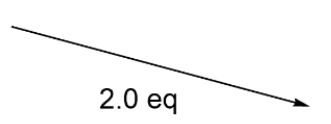

$\left[71-\mathrm{Pd}_{2} \mathrm{Cl}_{4}\right](95 \%)$

$\left[72-\mathrm{Pd}_{2} \mathrm{Cl}_{4}\right](97 \%)$

$\left[74-\mathrm{Pd}_{2} \mathrm{Cl}_{4}\right](95 \%)$
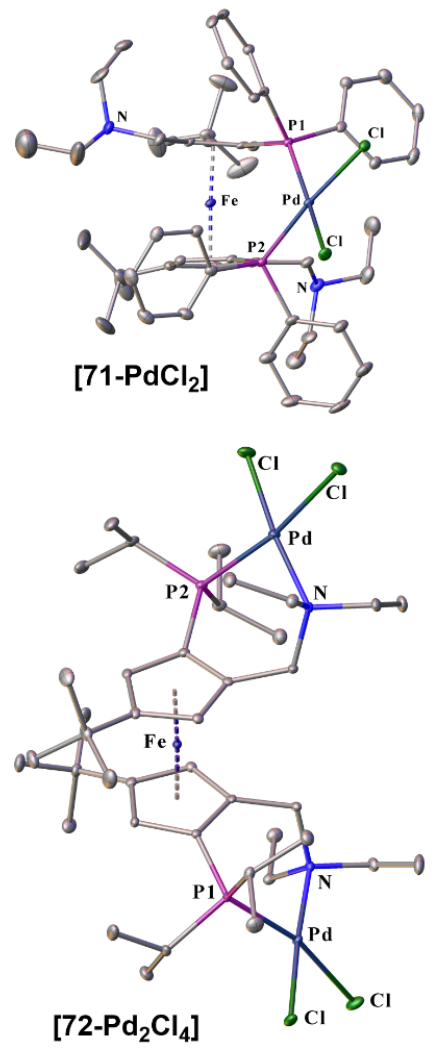

Figure 44. Mononuclear and dinuclear coordination modes of hexafunctionalized ferrocene tetradentate $(P, P, N, N)$-ligands to palladium. ${ }^{[62,68]}$ 


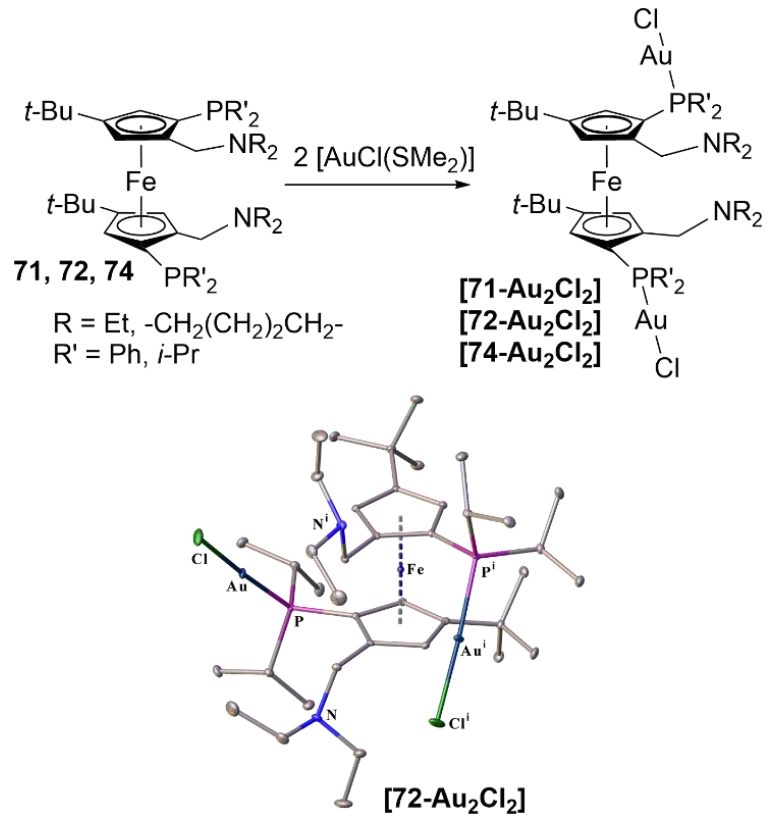

Figure 45. Dinuclear coordination mode of hexafunctionalized ferrocene tetradentate $(\mathrm{P}, \mathrm{P}, \mathrm{N}, \mathrm{N})$-ligands to gold [symmetry transformation: (i) $1-\mathrm{x},+\mathrm{y}$ $\left.1 / 2-z\left(\left[72-\mathrm{Au}_{2} \mathrm{Cl}_{2}\right]\right)\right]$.

The dinuclear gold $(I)$ complexes obtained from tetradentate $(N, N)$-diamino- $(P, P)$-disphosphino ferrocene hybrid ligands $\mathbf{7 1}$, $\mathbf{7 2}$ and $\mathbf{7 4}$ have been studied in the rare non-palladium Suzuki catalysis arylation of iodoarenes (Figure 46). Notably, gold(I) complexes have the same $d^{10}$ electronic configuration as $\operatorname{Pd}(0)$, $\mathrm{Ni}(0)$ and $\mathrm{Pt}(0)$, which can be typical catalysts for $\mathrm{C}-\mathrm{C}$ bond cross-coupling reactions. The ability of gold to undergo twoelectron redox elementary steps such as oxidative addition (O.A.) was recently demonstrated in some challenging $s p^{2}-\mathrm{C}-\mathrm{I}$ oxidative addition. ${ }^{[70]}$ Accordingly, the complex $\left[72-\mathrm{Au}_{2} \mathrm{Cl}_{2}\right]$ bearing electron-rich isopropyl groups on phosphorus was able to catalyze Suzuki coupling with a very good selectivity of heterocoupled product. Isolated molecularly-defined gold dinuclear complexes were used, but we also checked the absence of contaminant metal traces and especially palladium on the commercial $\mathrm{K}_{2} \mathrm{CO}_{3}$ used. No palladium was detected above the apparatus limit of $0.15 \mathrm{ppm}$. Therefore, $\left[\mathbf{7 2}-\mathrm{Au}_{2} \mathrm{Cl}_{2}\right]$ had a noticeable reactivity in the arylation of ortho-substituted iodoarenes bearing different substituents: electron-rich, electron poor and even towards hindered polyphenyl (Fig. 46). Based on the $(\mathrm{P}, \mathrm{N})$-ferrocene ligands, this catalytic system tolerated various valuable functional groups on iodoarenes, and contributed toward demonstrating the potential of gold complexes in elementary steps of cross-coupling reactions traditionally attributed to $\mathrm{d}^{10} \mathrm{metal}(0)$ complexes.

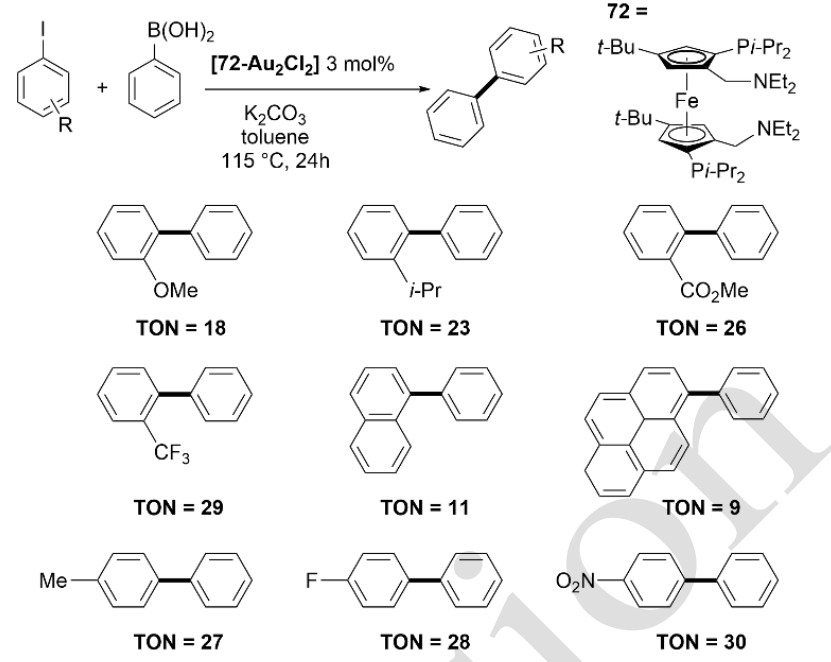

Figure 46. Gold-catalyzed Suzuki arylation of hindered iodoarenes.

\section{Ambiphilic Ferrocenes}

Molecules combining Lewis acids and Lewis bases on a same scaffold can lead to valuable cooperative reactivity. These ambiphilic molecules (also named frustrated Lewis pairs) have shown great interest in hydrogen splitting and metal-free hydrogenation reactions, or for the activation of $C 1$ small molecules $\left(\mathrm{CO}_{2}\right)$ as well as in coordination chemistry. ${ }^{[71,72]}$ Phosphines or amines are commonly associated to boranes or alanes. Various organic scaffolds have been used, but only few metallocene-bridged ambiphiles have been developed. Owing to its stability and flexibility, we used ferrocene as a linker for synthesizing diborane, phosphino-borane and amino-borane derivatives. Our expertise in the field of constrained polyphosphine ferrocenes and the development of these new ambiphilic ferrocenes inspired us for synthesizing new class of hybrid ferrocenes bearing both a Lewis base (phosphine) and a Brønsted acid or polar function (carboxylic acid). Hybrid ferrocenes of this type are viewed as potential hemilabile ligands exploitable in coordination chemistry and metal catalysis. ${ }^{[2,73,74]}$

\subsection{Ferrocenyl Boranes and (P, B)- and (N, B)-Hybrids}

In studies conducted in cooperation with G. Bouhadir and D. Bourissou, bis-Lewis acidic diborylferrocenes were synthesized via the assembling at metal salt of preformed $\mathrm{Cp}$ rings. ${ }^{[60]}$

Borylcyclopentadienyl lithium salts $\mathbf{X}-\mathbf{Y}$ were obtained from sequential lithiation/borylation of dimethylfulvene and then reacted with iron dichloride provides to form complexes $76-77$ in $61-93 \%$ (Figure 47). ${ }^{[60]}$ In contrast to the diverging synthesis of diphosphino ferrocenes described above (Figs. 23, 25 and 30), this synthesis was surprisingly fully diastereoselective and only led to the formation of the rac diastereoisomer. 

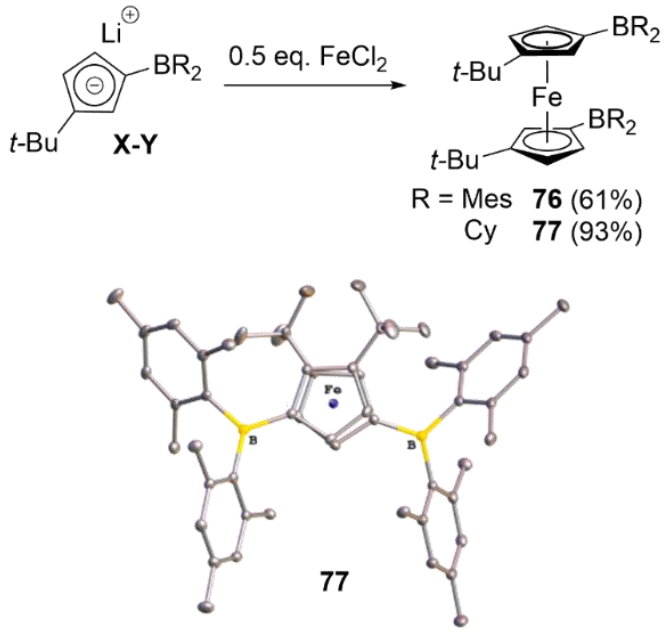

Figure 47. Diastereoselective synthesis of diborylferrocenes.

The origin of this unanticipated diastereoselectivity has been studied by DFT calculation. The potential energy surface was investigated so as to identify and compare the diastereoisomers and conformers. The origin of the stereoselectivity was attributed to steric repulsions which are minimized between the tert-butyl and the BMes ${ }_{2}$ groups in the eclipsed conformation of the racemic form. The boryl Cps rings $\mathbf{X}-\mathbf{Y}$ allow also the synthetic extension to other metallocenes as illustrated by the formation of cobaltocene 78 (Figure 48). DFT calculation showed, here also, that the energy formation of meso diastereoisomer is higher of ca $6 \mathrm{kcal} \mathrm{mol}^{-1}$ than the one found for the preferred eclipsed rac diastereoisomer.
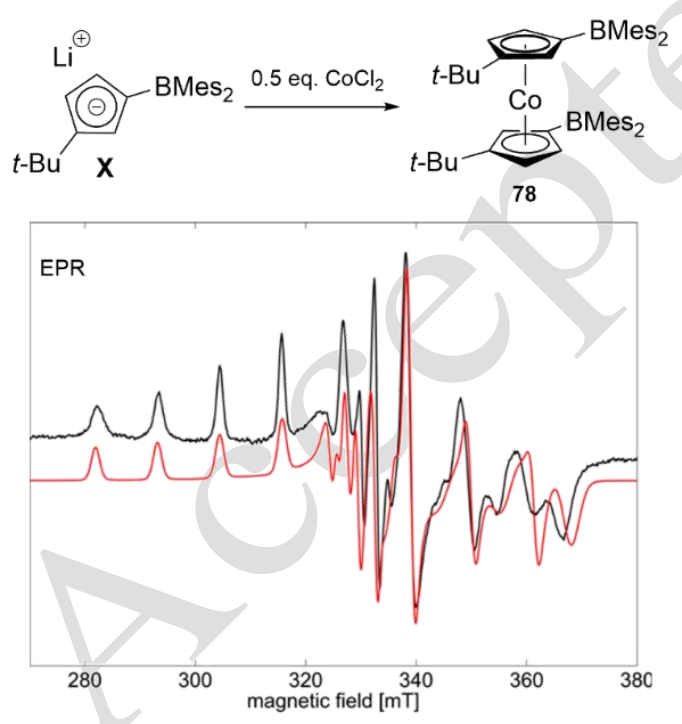

Figure 48. Synthesis of diborylcobaltocene 78 and EPR spectra (experimental in black, simulated in red).

The diastereoselectivity favoring the eclipsed rac diastereoisomer has been confirmed by the comparison of computed and simulated EPR spectra of the various isomers with the experimental EPR spectrum recorded. The electronic structure of cobaltocene $\mathbf{7 8}$ was analyzed by EPR. The spin density of this open-shell complex is mainly localized on the Co center, spin density is also found on the boron atoms indicating partial delocalization of the unpaired electron over the Lewis acid moieties. Consistently, the singly occupied molecular orbital is a combination of a Co-centered $3 d$ orbital with $\pi(B C)$ orbitals on each $\mathrm{CpBMes}_{2}$ rings. There is no significant direct $\mathrm{M} \cdots \mathrm{B}$ interaction in 76-78. ${ }^{[60]}$

To take advantage of the possible cooperativity between neighboring sites, we became interested in ambiphilic compounds featuring three or more functional groups directly bonded to the ferrocene platform. The boryl $\mathrm{Cp} \mathbf{X}$ was used for the synthesis of such an ambiphile, this by a mixed $\mathrm{Cp}$ assembling inspired by the synthesis of mixed triphosphines (see section 2.2). The assembling at iron dichloride of bis(diphenyl)phosphino Cp B and tert-butylated boryl $\mathrm{Cp} \mathbf{X}$ led to the formation of an unprecedented 1,2,1'-(P,P,B)bis(diphenyl)phosphinoborylferrocene, 79 , in $32 \%$ yield (Figure 49). ${ }^{[75]}$
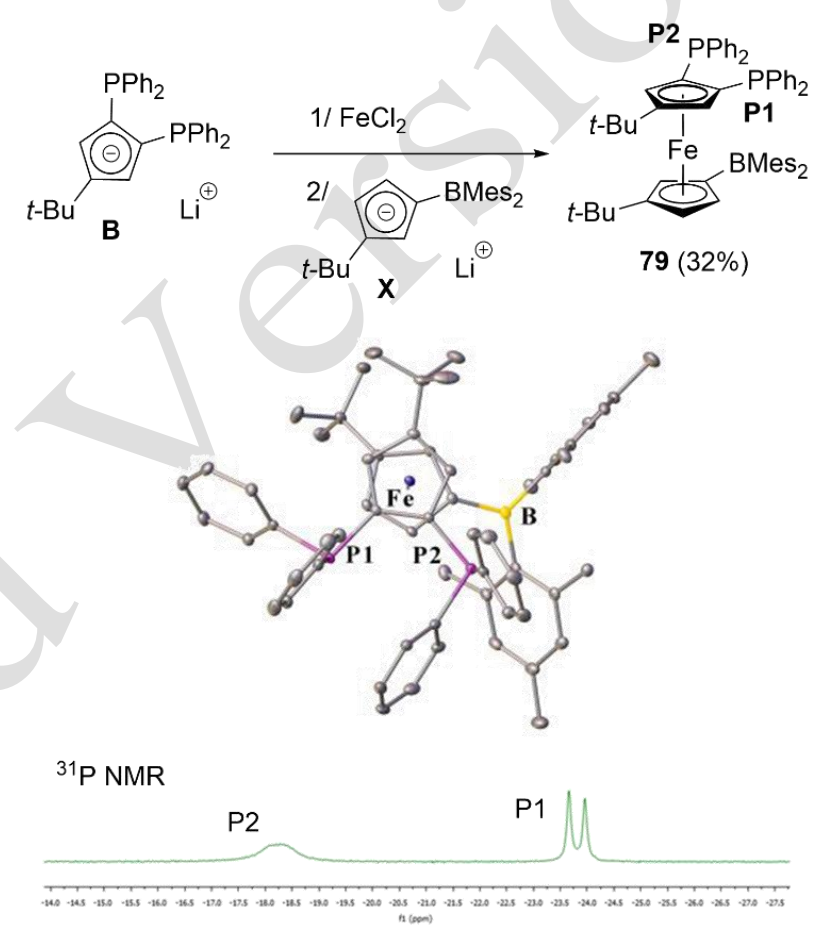

Figure 49. Synthesis and ${ }^{31} \mathrm{P} \mathrm{NMR}\left(243 \mathrm{MHz}, 300 \mathrm{~K}, \mathrm{CDCl}_{3}\right)$ and $\mathrm{XRD}$ of 1,2,1'-(P,P,B)-bis(diphenylphosphino)borylferrocene 79 .

Tritopic ligand $\mathbf{7 9}$ bears five bulky groups on the ferrocene backbone. The spatial distribution of the substituents, analyzed in the solid state by XRD, is optimized with the two cyclopentadienyl rings nearly eclipsed with a cisoid arrangement of the tert-butyl groups. The three heteroatoms are oriented in the same direction in this conformation, opposite to the tert-butyl groups and the phosphorus atoms are in very different environments with $\mathrm{P} 2$ proximate to boron $\left(\mathrm{d}_{\mathrm{P} 2 \ldots \mathrm{B}}=4.239(2) \AA\right)$. In comparison with related phosphino-boryl-ferrocenes with P...B distances ranging from $4.106(3)$ to 6.731 (3) $\AA$, see below, this distance is in the low range. ${ }^{[62,76-78]}$. The proximity of $\mathrm{P} 2$ and $B$, induces a steric congestion from which effects are also visible in ${ }^{31} \mathrm{P}$ NMR with an unusual very broad signal at $-18.2 \mathrm{ppm}$, while a net doublet is observed for the other P1 atom $(-23.8$ $\mathrm{ppm},{ }^{3} \mathrm{JPP}=60 \mathrm{~Hz}$ ). Hindered rotation around the Fc-B bond of 79 for P2 was shown to be responsible for this effect (inequivalent mesityl groups at $\mathrm{B}$ were evidenced by ${ }^{1} \mathrm{H}$ NMR). The strong $60 \mathrm{~Hz}$ magnitude of the $J_{\mathrm{P} 1 \mathrm{P} 2}$ coupling suggested some "through-space" (TS) spin coupling in line with the relatively short internuclear distance $\mathrm{d}_{\mathrm{P} 1 \ldots \mathrm{P} 2}=3.871(2) \AA . \mathrm{A}$ 
contribution of a $J$ "through-space" component was further supported by the solvent-dependence of the ${ }^{3} J_{\text {P1P2 }}$ coupling noticed when replacing chloroform with toluene (from 60 to 44 $\mathrm{Hz}$ ).

Coordination of the diphosphino boryl ferrocene 79 with platinum was easily achieved in quantitative yield (Figure 50). Despite its five sterically demanding substituents compound $\mathbf{7 9}$ preserves enough conformational flexibility to allow the chelating coordination of the two phosphorus atoms to platinum. The boron atom sensibly moved away from phosphorus P2 ( $\mathrm{d}_{\mathrm{P} 2 \ldots \mathrm{B}}=$ 5.294(7) ^), and accordingly the corresponding ${ }^{31} \mathrm{P}$ NMR signal get resolved in a well-defined singlet at 22.0 ppm (Fig. 50). No Lewis acid-metal Pt...B interaction was observed like in some other more constrained phosphinoborylferrocene platinum complexes. ${ }^{[79-81]}$

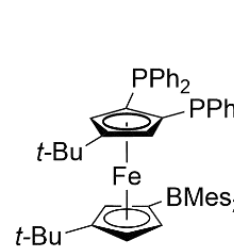

79

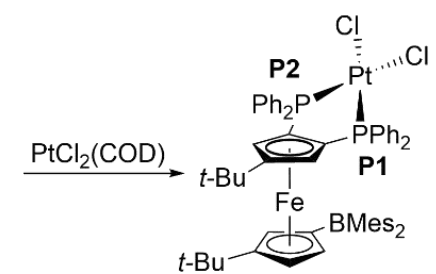

[79-PtCl $\left.{ }_{2}\right]$
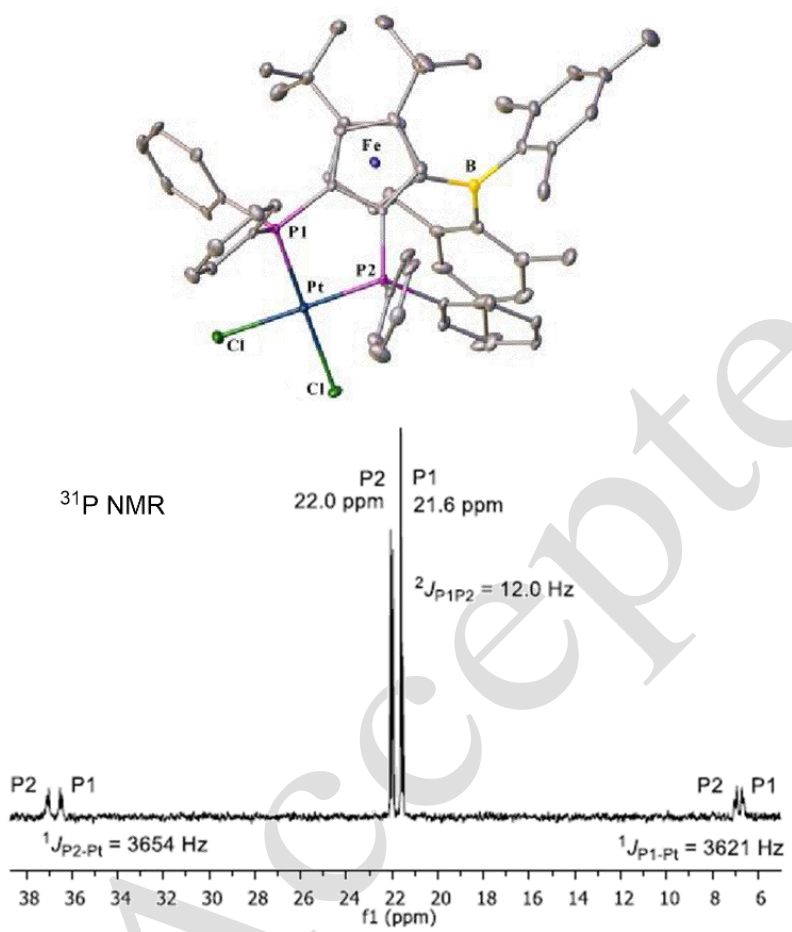

Figure 50. Coordination of the diphosphino boryl ferrocene 79 with platinum

Tetrafunctionalized dialkylated ( $\mathrm{P}, \mathrm{B})$ - or (N, B)-ambiphiles were prepared by sequential lithiation/electrophilic trapping from 1,1'-dibromo-3,3'-di-tert-butyl-ferrocene 56 (Figure 51). We found this synthetic pathway to be more efficient and selective than assembling from tert-butylated boryl cyclopentadienides, which is still also feasible. Monolithiation/phosphination of $\mathbf{5 6}$ leads to the formation of $\mathbf{8 0 - 8 2}$ in $43-76 \%$ yield. The targeted dialkylated boryl phosphino ferrocenes 83-87 were then obtained in $35-99 \%$ yield by lithiation/borylation of $\mathbf{8 0 - 8 2}$ (Fig. 51). ${ }^{[62,63]}$
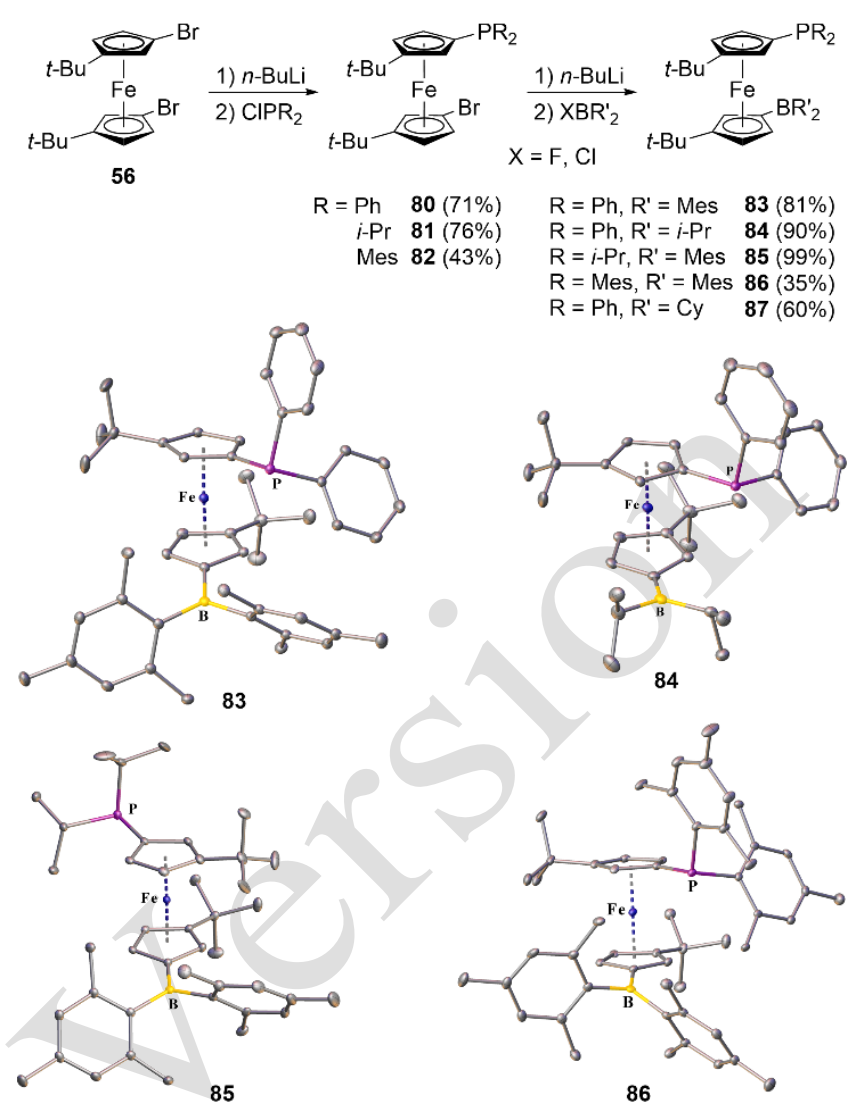

Figure 51. Synthesis of borylphosphinoferrocenes 83-87.

The diastereoselective stepwise modification of di-tertbutylated ferrocenes took also profit for this class of compounds of the separation of electroactive species from 56 after controlled electrolysis (see section 2.4). ${ }^{[58]}$ The bulky tert-butyl groups on ferrocene platform induced planar chirality of ambiphiles and enforced closer proximity of antagonist Lewis functions. The systematic structural analysis of compounds 83$\mathbf{8 6}$ in the solid state showed that ambiphiles $\mathbf{8 3}, \mathbf{8 4}$ and $\mathbf{8 6}$ were in a cisoid conformation of the heteroatoms, while compound 85 adopted a transoid arrangement. The introduction of bulky tertbutyl groups in general favored a closer proximity between the phosphine/borane pairs, however, this was not systematically the case, as seen for instance with $85\left(d_{\mathrm{P} 2 \ldots \mathrm{B}}=6.731(3) \AA\right)$. Therefore, the ferrocenyl platform in any case clearly conserved a certain degree of rotational flexibility. Yet, for all these ambiphiles, X-ray and NMR did not evidence any $\mathrm{P} \rightarrow \mathrm{B}$ pair closing.

By using reductive amination on the precursor $\mathbf{8 8}$ which was obtained in two steps of lithiation/formylation from dibromoferrocene $56 \quad(60 \%$ yield, Figure 52), the aminobromoferrocenes $89-90$ were isolated in $76-86 \%$ yield. Then aminoborylferrocenes 91-92 were synthesized by sequential lithiation/borylation of $89-90$ in $15-20 \%$ yield without further optimization of the reactions (Fig. 52). ${ }^{[62]}$

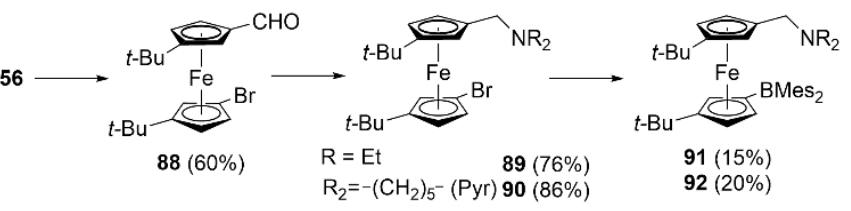

Figure 52. Synthesis of aminoborylferrocenes 91-92. 
Thus, we provided a robust method, fully diastereoselective, to produce highly functionalized sterically constrained 1,1'-planar chiral $(P, B)$-ferrocene ambiphiles. For these, in addition scale up in multigram amounts was reached by a purification mode taking advantage of ferrocene backbone redox properties through controlled electrolysis. The extension to a new class of $(\mathrm{N}, \mathrm{B})$-ferrocene ambiphiles as well as $(\mathrm{P}, \mathrm{P})$ - and $(\mathrm{P}, \mathrm{N})$-hybrids (potentially hemilabile compounds) ${ }^{[62]}$ illustrates the general interest of this synthetic chemistry. This constrained class of ligands has a potential which remains to be explored/exploited as frustrated Lewis Pairs (FLPs), and in intramolecular cooperative chemical reactivity or coordination chemistry.

\section{2. tert-Butylated phosphanyl carboxylic acids and derivatives}

Building on the successful development of highly functionalized phosphino-boryl ferrocenes 83-87, we further addressed the challenging preparation of ditopic polar hybrid ferrocene analogs such as tert-butylated phosphanyl carboxylic acids and their corresponding aldehydes. These hybrid ambiphilic species combines Brönsted-acidic and Lewis-basic functional moieties in their structure. Ferrocenophane opening method by $\mathrm{PhLi}$ was employed for the synthesis of tert-butylated ferrocene 94 bearing phosphine and carboxylic acid in 5\% isolated yield (Figure 53). ${ }^{[82]}$ This synthetic pathway is limited concerning the nature of phosphorus substituent beyond a phenyl group, and undergone significant purification troubles due to phosphine oxidation.

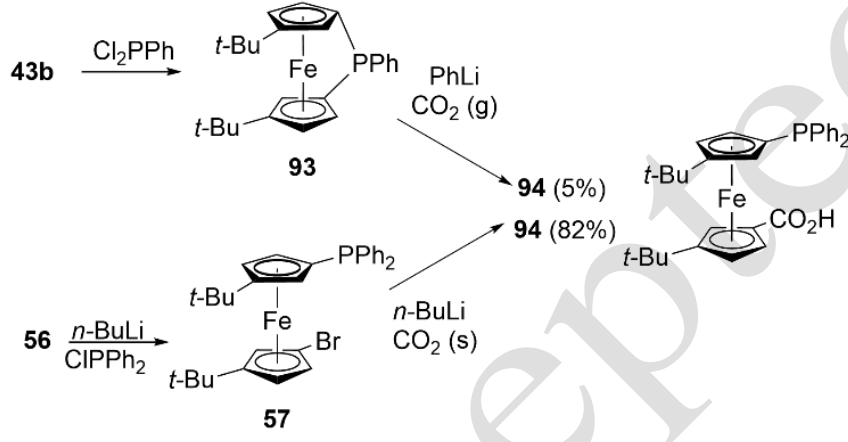

Figure 53. Synthetic pathways to phosphinoferrocene carboxylic acid $\mathbf{9 4}$.

We thus applied the post-functionalization pathway from 56 to achieve phosphino-carboxylic acid 94 and 99-101. The lithiation of bromophosphino ferrocene $\mathbf{5 7}$ followed by the reaction with solid $\mathrm{CO}_{2}$ gave 94 in a much higher $82 \%$ yield (Fig. 53). ${ }^{[82]}$ Electron-rich phosphines were protected from oxidation by adduct formation with $\mathrm{BH}_{3}$, before the lithiation/carboxylation step. We thus synthesized dicyclohexyl and di(iso-propyl) analogous 100 and 101 by lithiation and carboxylation of the protected bromophosphino ferrocenes 97 and 98 (Figure 54). Essentially, the phosphine ferrocene bromide intermediates could be isolated in their free or in P-protected form as borane adducts, which are both suitable for further synthesis. This was illustrated by the preparation of the corresponding aldehydes 102-104.
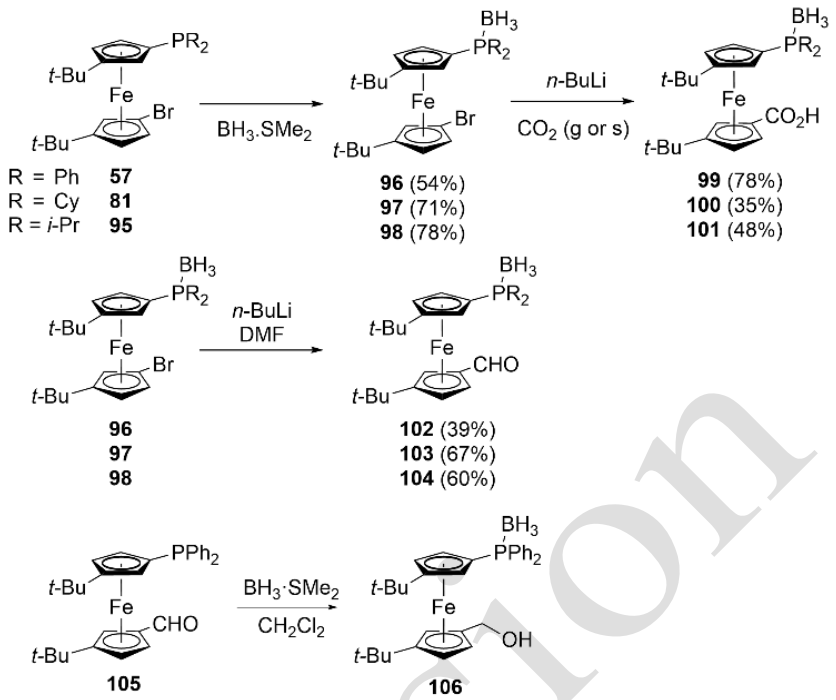

Figure 54. Synthesis of electron-rich phosphinoferrocene carboxylic acids 100-101 and analogous aldehydes 102-104.

The aldehyde function of compound 105 can be reduced in alcohol and the phosphine protected by the one-pot use of $\mathrm{BH}_{3} \cdot \mathrm{SMe}_{2}$ in excess, providing alcohol 106. In the case of acid 99, we also achieved removal of borane protecting group to form 94 by using conventional methods with 1,4-diazabicyclo[2.2.2] octane (DABCO, 2.2 equiv) in toluene $\left(80^{\circ} \mathrm{C}, 18 \mathrm{~h}\right)$ or refluxing $10 \mathrm{~h}$ in ethanol.

In relation with the successful gold-catalyzed Suzuki reaction with dinuclear gold stabilized by hybrid 1,1'-(P,N)-ferrocene ligands (see section 3.2), the coordination of phosphinocarboxylic acid 94 with gold was investigated, and easily achieved in quantitative yield (Figure 55). The mononuclear gold complex presented a linear $\mathrm{P}-\mathrm{Au}-\mathrm{Cl}$ geometry [angles found to be $178.04(5)^{\circ}$ and $176.45(5)^{\circ}$ ] for the two similar molecules present in the unit cell. Interestingly, the changed conformation of the ferrocene ligand in the gold complex resulted in close proximity between the Brönsted acidic carboxylic function and the gold center. We observed proximity between gold and oxygen atoms with $\mathrm{d}_{\mathrm{Au} \cdots \mathrm{O}=\mathrm{COH}}$ of $3.509(4)$ and $3.442(3) \AA$, and distances $\mathrm{Au} \cdots \mathrm{C}(\mathrm{O}) \mathrm{OH}$ of $3.777(5), 3.720(4) \AA)$. The proximity of oxygen atoms from the metallic center may have an influence in catalytic processes.
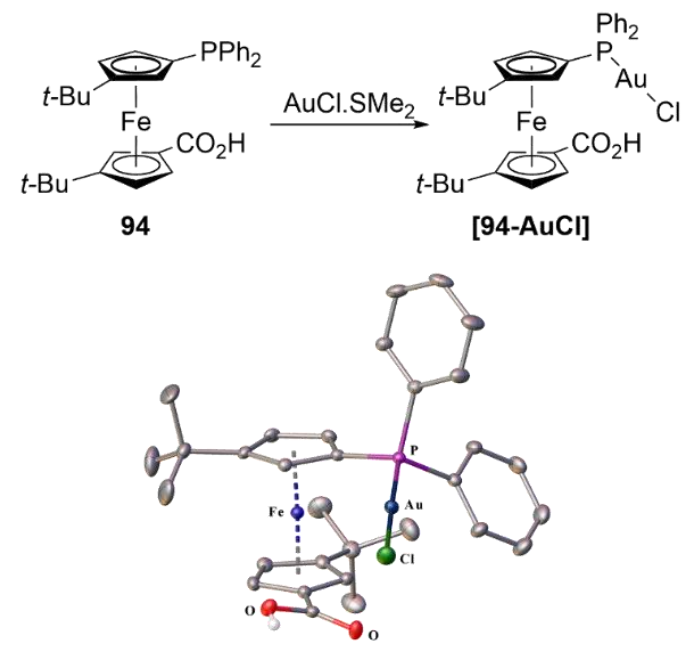
Figure 55. Coordination of 94 with gold.

In these highly functionalized hybrid compounds, besides intramolecular steric interactions, the polarity of carboxylic acids in both ligands and complexes induce significant intermolecular hydrogen bonding, which controls the supramolecular assembly of the ferrocene derivatives in the solid state. Further applications in gold and palladium catalysis are under investigation.

\section{The icing on the cake: the ferrocene hexaphosphine and its coordination modes}

Only few ferrocenyl phosphine ligands of higher rank than diphosphines are known. While ferrocene derivatives substituted with three or four groups incorporating donor atoms were early on developed in our group, we extended cyclopentadienyl functionalization to the introduction of three phosphino groups based on three successive sequences of phosphination/lithiation of cyclopentadienyl lithium. ${ }^{[83]}$ The tris-(diphenylphosphino) cyclopentadienide lithium salt $\mathbf{Z}$ was obtained from $\mathbf{F}$ in $56 \%$ yield (Figure 56). The reaction of this highly substituted cyclopentadienyl with $\mathrm{FeCl}_{2}$ led to the formation of the unique

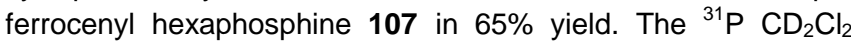
solution NMR pattern of 107 at $25^{\circ} \mathrm{C}$ displayed two broad signals at -24.5 and $-29.8 \mathrm{ppm}$. Down to $-60^{\circ} \mathrm{C}$, the fluxional behavior of the hexaphosphine is slowed down and well-defined signals in a 1:2 ratio appeared as a triplet at $-26.0 \mathrm{ppm}$ and a doublet at $31.2 \mathrm{ppm}\left(\mathrm{JPP}_{\mathrm{PP}}=37 \mathrm{~Hz}\right)$. The ${ }^{31} \mathrm{P} \mathrm{NMR}$ pattern at low temperature is consistent with the XRD structure of the hexaphosphine of $C 2 h$ molecular symmetry. The $\mathrm{Cp}$ rings of the ferrocene platform have a staggered position, leading to a pianostool arrangement for the two sets of three phosphorus atoms. The coupling constant $J_{\mathrm{PP}}=37 \mathrm{~Hz}$ between heteroannular phosphorus is a nonbonded coupling constant "through-space", arising from the overlap of the electron clouds of the lone-pairs of phosphorus pointing towards each other and consistent with the X-ray structure. Accordingly, short spatial distances between $\mathrm{P}$ atoms are observed: $\mathrm{d}_{\mathrm{P} 1 \ldots \mathrm{P} 2}=3.9121(6) \AA$, $\mathrm{d}_{\mathrm{P} 1 \ldots \mathrm{P} 3}=3.9756(6)$ $\AA$ and $\mathrm{d}_{\mathrm{P} 2 \ldots \mathrm{P} 3}=3.4083(5) \AA$.

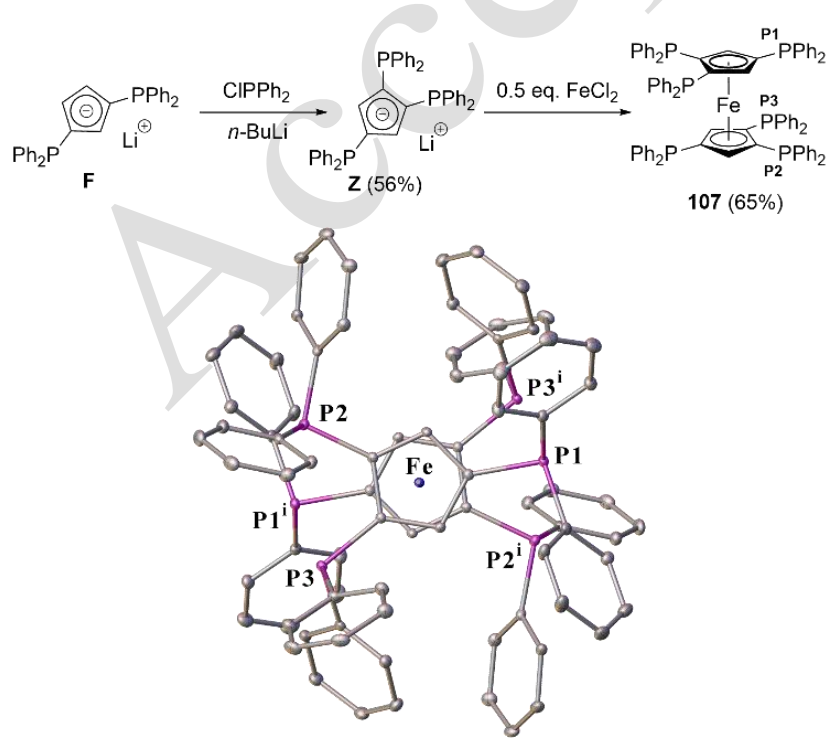

Figure 56. Synthesis and XRD structure of the hexaphosphine 107 [symmetry transformation: (i) 2-x -y 2-z].

The outstanding fluxionality of the hexaphosphine was exploited in coordination chemistry. The six phosphino groups allowed an unmatched versatility in coordination to transition metals. Coordination of 107 with molybdenum and rhodium lead to binuclear species, in which, each metal center is coordinated by three phosphines conserving the piano-stool conformation of the ligand $\left(107-\mathrm{Mo}_{2}(\mathrm{CO})_{6}\right.$ and $107-\mathrm{Rh}_{2} \mathrm{Cl}_{2}(\mathrm{CO})_{2}$, Figure 57, top).
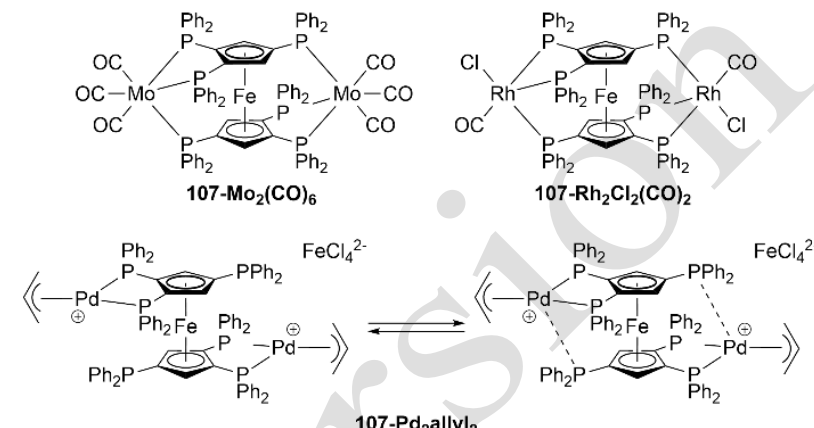

O07- $\mathrm{Rh}_{2} \mathrm{Cl}_{2}(\mathrm{CO})_{2}$
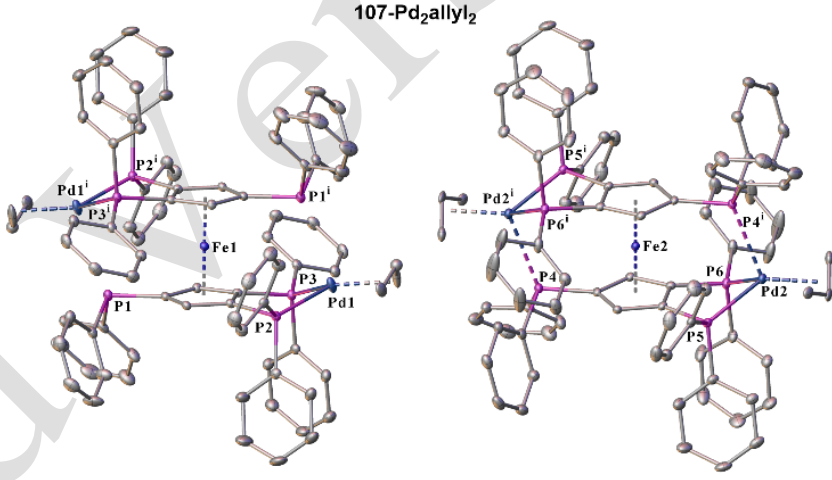

Figure 57. Dinuclear complexes of hexaphosphine 107 with transition metals [symmetry transformations: (i) $1-x, 1-y, 1-z$ (left) and $-x,-y,-z$ (right)].

Unexpectedly, the reaction of hexaphosphine with a $\mathrm{Pd}$ (II) allylic complex, in the presence of $\mathrm{FeCl}_{2}$, can lead to the formation of two cationic binuclear isomeric species (formula $\left.\left[\left\{\mathrm{Pd}\left(\mathrm{n}^{3} \text {-allyl }\right)\right\}_{2} \mathbf{1 0 7}\right]\left[\mathrm{FeCl}_{4}\right]\right)$, named [107-Pd $\left.\mathbf{P a l l y l}_{2}\right]$, and identified by XRD for which two structures are present in the unit cell (Fig. 57 , bottom). In the first isomer, while the bis-chelation of $\mathrm{Pd}(\mathrm{II})$ formed the expected square-planar structure " $\mathrm{P}_{2} \mathrm{Pd}-\mathrm{L}$ ", a labile $\mathrm{P}-\mathrm{Pd}$ bond is observed with the heteroannular phosphorus. In the complexes the P-Pd distances are similar for the chelating pairs (ranging between 2.305 and $2.349 \AA$ ). Conversely, a short $\mathrm{Pd}-\mathrm{P}$ distance is observed for the third phosphorus atom in the pentavalent $\mathrm{Pd}$ isomeric complex $(2.618 \AA)$ indicating the presence of a bonding interaction that does not exist in the other isomer ( $\mathrm{Pd} \cdots \mathrm{P}$ distance of $2.988 \AA$ ). This was not due to any distortion of hexaphosphine within the conformers since essentially similar distances and angles are found, not to special packing. Thus, the structural features of the palladium complex indicate that in hexaphosphine 107 the ferrocene backbone allows enough flexibility for the third phosphorus atom to interact in a labile way with a strongly P-chelated $\mathrm{Pd}(\mathrm{II})$ centre in a square-planar environment. This experimentally observed bonding situation reminds some calculated stabilized resting state in $\mathrm{Pd}(0)$ after reductive elimination from $\mathrm{C}-\mathrm{O}$ bond formation in catalytic etherification (section 2.2, P Fig.19). Despite the presence of this third $\mathrm{P}-\mathrm{Pd}$ bond, the strongly $\mathrm{P}$ - 
chelated $\mathrm{Pd}(\mathrm{II})$ center remained in a quasi-square-planar environment.

Hexaphosphine 107, which mainly serves as a double triphosphine with molybdenum, rhodium and palladium, operates a remarkable coordination change with platinum(II), in which the use of this heavy metal clearly highlights the flexibility capacity of the ferrocene backbone (107- $\mathrm{Pt}_{2} \mathrm{Cl}_{2}$, Figure 58).

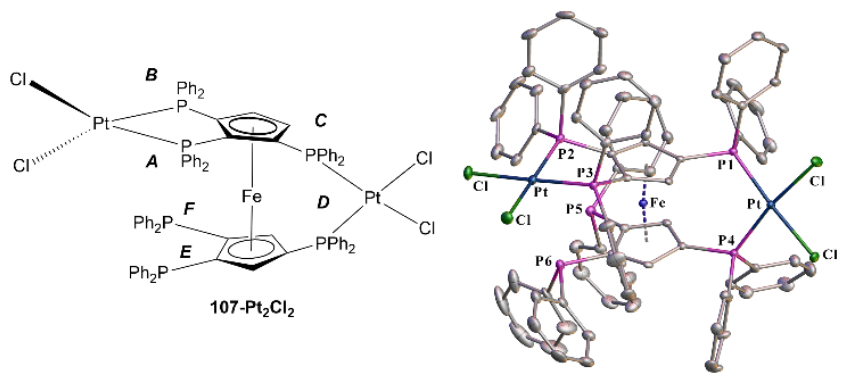

Figure 58. Dinuclear complexes of hexaphosphine 107 with transition metals.

In 107- $-\mathrm{Pt}_{2} \mathrm{Cl}_{2}$ a $\mathrm{Pt}(\mathrm{II})$ dichloride moiety is coordinated in a 1,2homoannular mode, while the second $\mathrm{Pt}$ (II) center is coordinated in a 1,1'-heteroannular mode by non-vicinal phosphines. This was made possible by a combination of rotation and tilting of the $\mathrm{Cp}$ rings. This happened despite the high steric hindrance due to the presence of six phosphino groups. The two platinum centers are in different square-planar environments. A representative difference is the wide angle found for the coordination of the heteroannular phosphorus pair at platinum, P1-Pt1-P4 = 98.99(4) ${ }^{\circ}$, compared to the narrower bite angle P2-Pt2-P3 = $85.23(4)^{\circ}$ for the coordination of the homoannular phosphorus pair. Though 1,2-homoannular and 1,1'-heteroannular coordination schemes are classical of metallocene-based ligands coordination, hexaphosphine $\mathbf{1 0 7}$ is a rare example of a metallocene derivative coordinating in both modes, ${ }^{[17]}$ with additional two phosphino groups still available for further coordination. Hexaphosphine $\mathbf{1 0 7}$ is able to adopt a variety of coordination mode representative of its outstanding flexibility despite its high functionalization at $\mathrm{Cp}$ rings. Its capacity to provide heteropolymetallic original complexes remains to be exploited.

\section{Conclusion and Outlook}

Over the period 2003-2018 the chemistry of ferrocenyl polyphosphines allowed developing catalytic applications with palladium( 0 ), in which the crucial role of polydentate interactions was elucidated by ${ }^{31} \mathrm{P}$ NMR and kinetic measurements. This reactivity was extended recently to gold(I) catalyzed crosscoupling. Perspectives in nickel chemistry are rather appealing. Intriguing fundamental knowledge in chemical physics related to nonbonded "through-space" nuclear spin-spin couplings was also gathered, and should be further addressed in the future by computational methods. The synthesis of many new cyclopentadienyl-based reagents (including Cp-boryl and amines), of original di-, tri-, tetra- and hexaphosphine, as well as their corresponding coordination complexes with group 6 to 11 transition metals has been described. Our library of phosphine ligands extended to unique tetradentate $(P, N)$-hybrids, as well as ambiphilic $(\mathrm{P}, \mathrm{B})$ - and $(\mathrm{N}, \mathrm{B})$-ferrocenes in which dialkylated structures allows for some conformational control of the ferrocenyl platform. Diverging and converging routes allowed to identify some highly diastereoselective synthetic methods. The development of other hybrids like polar species holding carboxylate would be in the future extended to sulfonates and other functions that would help cooperative catalysis in aqueous or polar media. Future work will seek to produce other densely functionalized ferrocene-based compounds with the ultimate goal of triggering reactivity and new ligand behavior also owing to the redox properties of the ferrocene moiety.

CCDC 1961440 (for [71-PdCl $\mathbf{2}$ ) and 1961441 (for [71- $\mathbf{P d}_{\mathbf{2}} \mathbf{C l}_{\mathbf{4}} \mathbf{3}$ ) contain the supplementary crystallographic data for this paper. These data can be obtained free of charge from The Cambridge Crystallographic Data Centre.

\section{Acknowledgments}

This work was supported by the ANR-PRC 2016 program (ALCATRAS, ANR-16-CE07-0001-01), the CNRS, Université de Bourgogne, the Région Bourgogne Franche Comté (Excellence program CHIMENE and ISITE-BFC program COMICS) and the fonds européen de développement regional (FEDER). The IUF is sincerely thanked for supporting $\mathrm{JCH}$. Our works benefited from the help of many talented partners from various topics in chemical sciences, including the groups of I. R. Butler (Wales), H. Doucet (Rennes), D. Lucas (Dijon), M. Saeys (Singapore), P. H Toy (Hong-Kong), D. Bourissou (Toulouse), and P. Štěpnička (Prague). Our works benefited from the help of many talented partners from various topics in chemical sciences, including the groups of I. R. Butler (Bangor), H. Doucet (Rennes), D. Lucas and C. Devillers (Dijon), M. Saeys (Singapore), P. H Toy (HongKong), D. Bourissou (Toulouse) and P. Štěpnička (Prague). The students and coworkers who participated to these works are warmly thanked (especially: A. Fihri, M. Beaupérin, S. Mom, V. V. Ivanov and R. Smaliy).

Keywords: Ferrocenylphosphines · Functionalization ·Hybrid ligands · Coordination compounds · XRD Structure

[1] K. S. Gran, T. S. A. Hor, in Ferrocenes Homog. Catal. Org. Synth. Mater Sci. (Eds.: A. Togni, T. Hayashi), VCH Verlagsgesellschaft, Weinheim, Germany, 1995.

[2] P. Štěpnička, Ferrocenes: Ligands, Materials and Biomolecules, John Wiley \& Sons, 2008.

[3] I. R. Butler, Eur. J. Inorg. Chem. 2012, 2012, 4387-4406.

[4] L.-X. Dai, X.-L. Hou, Eds. , Chiral Ferrocenes in Asymmetric Catalysis: Synthesis and Applications, Wiley-VCH, Weinheim, 2010.

[5] T. J. Colacot, Chem. Rev. 2003, 103, 3101-3118.

[6] T. Ireland, G. Grossheimann, C. Wieser-Jeunesse, P. Knochel, Angew. Chem. Int. Ed. 1999, 38, 3212-3215.

[7] We sincerely apologize for this selection of names. Please note also that numerous German and British groups and other developed ferrocene chemistry (Manners, Manoury, Erker, Siemling, Lang, Wagner, Togni, Long, Heinze, Hey-Hawkins and others).

[8] J. Boichard, J. Tirouflet, Comptes Rendus Séances Académie Sci. 1960 1394-1396.

[9] J. Tirouflet, G. Tainturier, R. Dabard, Bull. Soc. Chim. Fr. 1963, 24032405.

[10] P. Dixneuf, R. Dabard, Comptes Rendus Séances Académie Sci. Ser. C Sci. Chim. 1968, 1244-1246.

[11] D. Astruc, R. Dabard, Comptes Rendus Séances Académie Sci. Ser. C Sci. Chim. 1971, 1248-1251.

[12] B. Gautheron, R. Broussier, Bull. Soc. Chim. Fr. 1971, 3636-3642. 
[13] R. C. J. Atkinson, V. C. Gibson, N. J. Long, Chem. Soc. Rev. 2004, 33, 313-328.

[14] J.-C. Hierso, R. Amardeil, E. Bentabet, R. Broussier, B. Gautheron, P. Meunier, P. Kalck, Coord. Chem. Rev. 2003, 236, 143-206.

[15] J.-C. Hierso, R. Smaliy, R. Amardeil, P. Meunier, Chem. Soc. Rev. 2007 36, 1754-1769.

[16] I. R. Butler, L. J. Hobson, S. M. E. Macan, D. J. Williams, Polyhedron 1993, 12, 1901-1905

[17] D. A. Thomas, V. V. Ivanov, I. R. Butler, P. N. Horton, P. Meunier, J. C Hierso, Inorg. Chem. 2008, 47, 1607-1615.

[18] R. Broussier, S. Ninoreille, C. Legrand, B. Gautheron, J. Organomet. Chem. 1997, 532, 55-60.

[19] R. Broussier, S. Ninoreille, C. Bourdon, O. Blacque, C. Ninoreille, M. M. Kubicki, B. Gautheron, J. Organomet. Chem. 1998, 561, 85-96.

[20] R. Broussier, E. Bentabet, R. Amardeil, P. Richard, P. Meunier, P. Kalck, B. Gautheron, J. Organomet. Chem. 2001, 637-639, 126-133.

[21] J.-C. Hierso, A. Fihri, V. V. Ivanov, B. Hanquet, N. Pirio, B. Donnadieu B. Rebière, R. Amardeil, P. Meunier, J. Am. Chem. Soc. 2004, 126, 11077-11087.

[22] J.-C. Hierso, D. Evrard, D. Lucas, P. Richard, H. Cattey, B. Hanquet, P. Meunier, J. Organomet. Chem. 2008, 693, 574-578.

23] J.-C. Hierso, Curr. Org. Chem. 2011, 15, 3197-3213.

[24] J.-C. Hierso, D. Armspach, D. Matt, C. R. Chim. 2009, 12, 1002-1013.

25] J.-C. Hierso, Chem. Rev. 2014, 114, 4838-4867.

[26] B. E. Cowie, F. A. Tsao, D. J. H. Emslie, Angew. Chem. Int. Ed. 2015 54, 2165-2169

[27] S. Sadeh, M. P. T. Cao, J. W. Quail, J. Zhu, J. Müller, Chem. - Eur. J. 2018, 24, 8298-8301.

[28] J.-C. Hierso, A. Fihri, R. Amardeil, P. Meunier, H. Doucet, M. Santelli, B. Donnadieu, Organometallics 2003, 22, 4490-4499.

[29] E. André-Bentabet, R. Broussier, R. Amardeil, J.-C. Hierso, P. Richard D. Fasseur, B. Gautheron, P. Meunier, J. Chem. Soc. Dalton Trans. 2002, 2322-2327.

[30] M. Beaupérin, E. Fayad, R. Amardeil, H. Cattey, P. Richard, S. Brandès, P. Meunier, J.-C. Hierso, Organometallics 2008, 27, 1506-1513.

[31] V. Rampazzi, J. Roger, R. Amardeil, M.-J. Penouilh, P. Richard, P. Fleurat-Lessard, J.-C. Hierso, Inorg. Chem. 2016, 55, 10907-10921.

[32] J.-C. Hierso, M. Beaupérin, P. Meunier, Eur. J. Inorg. Chem. 2007 3767-3780.

[33] D. Evrard, D. Lucas, Y. Mugnier, P. Meunier, J.-C. Hierso Organometallics 2008, 27, 2643-2653.

[34] C. Amatore, M. Azzabi, A. Jutand, J. Organomet. Chem. 1989, 363 , C41-C45.

[35] C. Amatore, M. Azzabi, A. Jutand, J. Am. Chem. Soc. 1991, 113, 83758384.

[36] V. A. Zinovyeva, S. Mom, S. Fournier, C. H. Devillers, H. Cattey, H. Doucet, J.-C. Hierso, D. Lucas, Inorg. Chem. 2013, 52, 11923-11933.

[37] V. A. Zinovyeva, C. Luo, S. Fournier, C. H. Devillers, H. Cattey, H. Doucet, J.-C. Hierso, D. Lucas, Chem. Eur. J. 2011, 17, 9901-9906.

[38] A. Jahel, N. V. Vologdin, N. Pirio, H. Cattey, P. Richard, P. Meunier, J.C. Hierso, Dalton Trans. 2008, 4206-4208.

[39] M. Beauperin, R. Smaliy, H. Cattey, P. Meunier, J. Ou, P. H. Toy, J.-C. Hierso, Chem. Commun. 2014, 50, 9505-9508.

[40] M. Beaupérin, R. Smaliy, H. Cattey, P. Meunier, J. Ou, P. H. Toy, J.-C Hierso, ChemPlusChem 2015, 80, 119-129.

[41] M. Beaupérin, A. Job, H. Cattey, S. Royer, P. Meunier, J.-C. Hierso, Organometallics 2010, 29, 2815-2822.

[42] M. Platon, N. Wijaya, V. Rampazzi, L. Cui, Y. Rousselin, M. Saeys, J.-C Hierso, Chem. Eur. J. 2014, 20, 12584-12594.

[43] V. V. Ivanov, J. C. Hierso, R. Amardeil, P. Meunier, Organometallics 2006, 25, 989-995.

[44] R. V. Smaliy, M. Beaupérin, H. Cattey, J. Roger, H. Doucet, Y. Coppel, P. Meunier, J.-C. Hierso, Organometallics 2009, 28, 3152-3160.

[45] M. Platon, L. Cui, S. Mom, P. Richard, M. Saeys, J.-C. Hierso, Adv. Synth. Catal. 2011, 353, 3403-3414.

[46] S. Mom, M. Beaupérin, D. Roy, S. Royer, R. Amardeil, H. Cattey, H. Doucet, J. C. Hierso, Inorg. Chem. 2011, 50, 11592-11603.

[47] J.-C. Hierso, A. Fihri, R. Amardeil, P. Meunier, H. Doucet, M. Santelli, V. V. Ivanov, Org. Lett. 2004, 6, 3473-3476.

[48] J.-C. Hierso, V. V. Ivanov, R. Amardeil, P. Richard, P. Meunier, Chem. Lett. 2004, 33, 1296-1297.
[49] J.-C. Hierso, M. Beaupérin, P. Meunier, Eur. J. Inorg. Chem. 2007 $3767-3780$

[50] H. Doucet, J.-C. Hierso, Angew. Chem. Int. Ed. 2007, 46, 834-871.

[51] J. Roger, S. Mom, M. Beaupérin, S. Royer, P. Meunier, V. V. Ivanov, H. Doucet, J.-C. Hierso, ChemCatChem 2010, 2, 296-305.

[52] M. Platon, J. Roger, S. Royer, J.-C. Hierso, Catal. Sci. Technol. 2014, 4 2072-2080.

[53] S. Mom, M. Platon, H. Cattey, H. J. Spencer, P. J. Low, J.-C. Hierso, Catal. Commun. 2014, 51, 10-14.

[54] D. Roy, S. Mom, M. Beaupérin, H. Doucet, J.-C. Hierso, Angew. Chem. Int. Ed. 2010, 49, 6650-6654.

[55] D. Roy, S. Mom, D. Lucas, H. Cattey, J.-C. Hierso, H. Doucet, Chem. Eur. J. 2011, 17, 6453-6461.

[56] G. Trouve, R. Broussier, B. Gautheron, M. M. Kubicki, Acta Crystallogr Sect. C 1991, 47, 1966-1967.

[57] R. Broussier, E. Bentabet, P. Mellet, O. Blacque, P. Boyer, M. M. Kubicki, B. Gautheron, J. Organomet. Chem. 2000, 598, 365-373.

[58] S. Ninoreille, R. Broussier, R. Amardeil, M. M. Kubicki, B. Gautheron Bull. Soc. Chim. Fr. 1995, 132, 128-138.

[59] J. Roger, S. Royer, H. Cattey, A. Savateev, R. V. Smaliy, A. N. Kostyuk J.-C. Hierso, Eur. J. Inorg. Chem. 2017, 2017, 330-339.

[60] E. Lerayer, P. Renaut, S. Brandès, H. Cattey, P. Fleurat-Lessard, G. Bouhadir, D. Bourissou, J.-C. Hierso, Inorg. Chem. 2017, 56, 19661973.

[61] A. Fihri, J.-C. Hierso, A. Vion, D. H. Nguyen, M. Urrutigoïty, P. Kalck, R Amardeil, P. Meunier, Adv. Synth. Catal. 2005, 347, 1198-1202.

[62] E. Lerayer, P. Renaut, J. Roger, N. Pirio, H. Cattey, C. H. Devillers, D. Lucas, J.-C. Hierso, Chem. Commun. 2017, 53, 6017-6020.

[63] E. Lerayer, P. Renaut, J. Roger, J.-C. Hierso, Fr. Demande, 2015, FR 3014871 (A1)

[64] R. Broussier, S. Ninoreille, C. Bourdon, O. Blacque, C. Ninoreille, M. M. Kubicki, B. Gautheron, J. Organomet. Chem. 1998, 561, 85-96.

[65] R. Broussier, E. Bentabet, M. Laly, P. Richard, L. G. Kuz'mina, P. Serp N. Wheatley, P. Kalck, B. Gautheron, J. Organomet. Chem. 2000, 613, 77-85.

[66] F. Allouch, N. Dwadnia, N. V. Vologdin, Y. V. Svyaschenko, H. Cattey M.-J. Penouilh, J. Roger, D. Naoufal, R. Ben Salem, N. Pirio, J.-C. Hierso, Organometallics 2015, 34, 5015-5028.

[67] N. Dwadnia, J. Roger, N. Pirio, H. Cattey, J.-C. Hierso, Coord. Chem Rev. 2018, 355, 74-100.

[68] http://www.theses.fr/2017UBFCK050; Thesis N. Dwadnia 2017

[69] N. Dwadnia, J. Roger, N. Pirio, H. Cattey, R. Ben Salem, J.-C. Hierso, Chem. - Asian J. 2017, 12, 459-464.

[70] M. Joost, A. Zeineddine, L. Estévez, S. Mallet-Ladeira, K. Miqueu, A Amgoune, D. Bourissou, J. Am. Chem. Soc. 2014, 136, 14654-14657.

[71] D. W. Stephan, G. Erker, Angew. Chem. Int. Ed. 2015, 54, 6400-6441.

[72] G. Bouhadir, D. Bourissou, Chem. Soc. Rev. 2016, 45, 1065-1079.

[73] P. Štěpnička, Chem. Soc. Rev. 2012, 41, 4273-4305.

[74] N. Dwadnia, J. Roger, N. Pirio, H. Cattey, J.-C. Hierso, Coord. Chem Rev. 2018, 355, 74-100.

[75] E. Lerayer, P. Renaut, J. Roger, N. Pirio, H. Cattey, P. Fleurat-Lessard, M. Boudjelel, S. Massou, G. Bouhadir, D. Bourissou, J.-C. Hierso, Dalton Trans. 2019, 48, 11191-11195.

[76] M. W. P. Bebbington, S. Bontemps, G. Bouhadir, M. J. Hanton, R. P. Tooze, H. van Rensburg, D. Bourissou, New J. Chem. 2010, 34, 15561559 .

[77] M. Abubekerov, P. L. Diaconescu, Inorg. Chem. 2015, 54, 1778-1784.

[78] A. Tlili, A. Voituriez, A. Marinetti, P. Thuéry, T. Cantat, Chem. Commun. 2016, 52, 7553-7555.

[79] B. E. Cowie, D. J. H. Emslie, Chem. - Eur. J. 2014, 20, 16899-16912.

[80] B. E. Cowie, D. J. H. Emslie, Organometallics 2015, 34, 4093-4101.

[81] S. Bontemps, M. Sircoglou, G. Bouhadir, H. Puschmann, J. A. K. Howard, P. W. Dyer, K. Miqueu, D. Bourissou, Chem. - Eur. J. 2008, 14, 731-740.

[82] L. Radal, P. Vosáhlo, J. Roger, H. Cattey, R. Amardeil, I. Císařová, P. Štěpnička, N. Pirio, J.-C. Hierso, Eur. J. Inorg. Chem. 2019, 2019, 865874

[83] R. V. Smaliy, M. Beaupérin, A. Mielle, P. Richard, H. Cattey, A. N. Kostyuk, J.-C. Hierso, Eur. J. Inorg. Chem. 2012, 2012, 1347-1352. 


\section{MINIREVIEW}
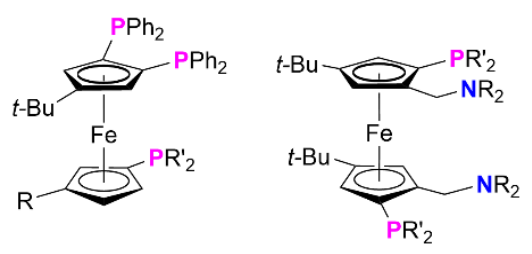

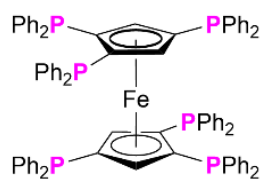

\section{Ferrocene Chemistry}

E. Lerayer, L. Radal, T. A. Nguyen, N. Dwadnia, H. Cattey, R. Amardeil, N. Pirio, J. Roger, and J.-C. Hierso*

Highly Functionalized Ferrocenes

Highly functionalized ferrocenes, which include notably (P,P,P,P)-, (P,P,N,N)-, $\left(\mathrm{P}, \mathrm{P}, \mathrm{P}^{\prime}\right)-, \quad(\mathrm{P}, \mathrm{P}, \mathrm{B})-, \quad(\mathrm{P}, \mathrm{B})-$ and $(\mathrm{N}, \mathrm{B})$-compounds were developed in which the heteroatoms coexist in a close proximity on a common ferrocene platform with a controlled conformation. 